\title{
The Geologic Retrieval and Synopsis Program (GRASP)
}

GEOLOGICAL SURVEY PROFESSIONALAPAER 966

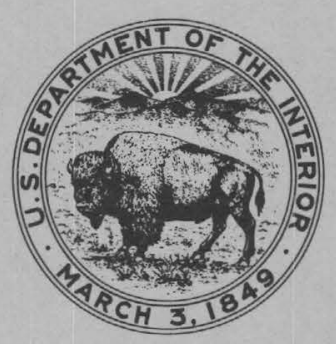





\section{The Geologic Retrieval and Synopsis Program (GRASP)}

By ROGER W. BOWEN and JOSEPH MOSES BOTBOL

GEOLOGICAL SURVEY PROFES IONALA PAER 966

A portable data-retrieval system

requiring minimal user training

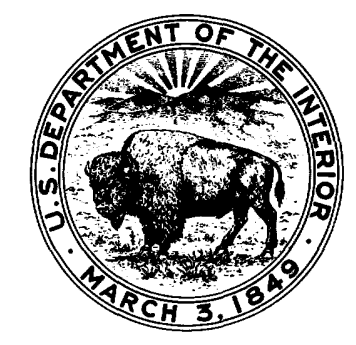

UNITED STATES GOVERNMENT PRINTING OFFICE, WASHINGTON : 1975 


\section{UNITED STATES DEPARTMENT OF THE INTERIOR}

THOMAS S. KLEPPE, Secretary

\section{GEOLOGICAL SURVEY}

V. E. McKelvey, Director

First printing 1975

Second printing 1976

Library of Congress Cataloging in Publication Data

Bowen, Roger W.

The geologic retrieval and synopsis program (GRASP)

(Geological Survey professional paper; 966)

Supt. of Docs. no.: I 19.16:966

1. Information storage and retrieval systems--Geology. I. Botbol, Joseph Moses, joint author. II. Title.

III. Series: United States. Geological Survey. Professional paper; 966.

QE48.8.B68 $029^{\prime} .9^{\prime} 55 \quad 75-619314$

For sale by Branch of Distribution, U.S. Geological Survey, 1200 South Eads Street, Arlington, VA 22202. 


\section{CONTENTS}

Abstract

Introduction

Purpose and scope

General system description -...-_-

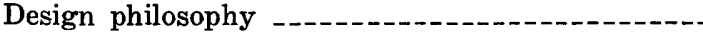

Machine portability

Data-base independence -...........

User community

Time sharing

Present utilization

COLFIL

MANFIL

RASS

Future plans

Detailed system description

Data-file structures

Mask file

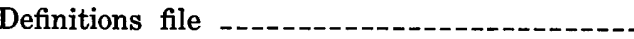

Dictionary file

Multiple-choice file

Numeric Master file

Data compression

Machine dependencies

Internal structure and functions

Processing user input

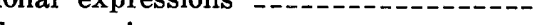

expressions

Number lists

Name lists

Arithmetic expression

Searches

Output

Data-base implementation

Use of GRASP

References cited

GRASP software specifications

Module name: DRIVER

Subroutine name: ACCESS

Subroutine name: BDEF

Subroutine name: BINIT

Subroutine name: BINTYP

Subroutine name: BLIST

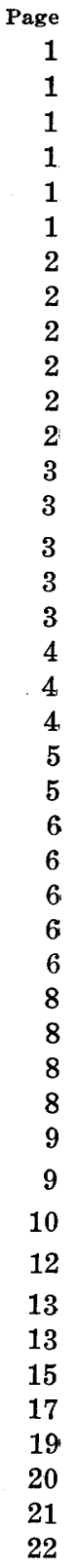

GRASP software specifications-Continued Subroutine name: COLPNT _...... 23

Function name: COMP _-_-_-_-_-_-_-_- 25

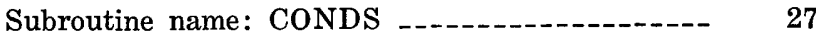

Subroutine name: CONDTN _._._........-. 28

Subroutine name: DECOMP _._-_._-_-_-_- 29

Subroutine name: DEFINE _......... 31

Subroutine name: DEFLST _._._._._. 32

Subroutine name: DUMPIT _-_-_-_-_-_-_-_- 33

Function name: EVAL _-_-_-_- 35

Subroutine name: FDRIVE _._._._._. 37

Subroutine name: FILES -_._-_._- 38

Subroutine name: FIND _-_._-_-_-_-_-_-_- 39

Subroutine name: FINDGP _._-_-_-_-_- 40

Subroutine name: FIT _-_._. 41

Subroutine name: FTNC _._.

Subroutine name: GETPUT _-_-_- 45

Subroutine name: HELP _._._._._..... 46

Function name: ICONV _._. 47

Subroutine name: IFILE _.....-_-_-_. 48

Subroutine name: INIT _..._._. 49

Subroutine name: KEYBRD _..._-

Subroutine name: LENGTH _._-_-_._- 51

Subroutine name: LIST _._. 52

Subroutine name: LOGEXP _._._-_._- 53

Subroutine name: MEAN _............- 56

Subroutine name: NAME - 58

Subroutine name: OBEY _._._._. 59

Subroutine name: OFILE _._.

Subroutine name: OPREP _._-_-_-_- 62

Subroutine name: PACK _._._._. 63

Subroutine name: PARSE -

Subroutine name: PAUSE _._._-_-_-_- 68

Function name: PNTER _._._. 69

Subroutine name: PREVAL -

Subroutine name: QUIT _-_ 72

Subroutine name: RELEXP _._______-_-_ 73

Subroutine name: RETRVE _._._-_-_-_- 76

Subroutine name: RLIST _._._- 79

Subroutine name: ROWPNT 81

Subroutine name: SCAN _-_._- 83

Subroutine name: START _._._. 84

Function name: UNCODE

Subroutine name: VLIST

\section{ILLUSTRATIONS}

FIgURE 1. Example of Mask-file and Dictionary-file arrangement

2. Example of Numeric Master file arrangement prior to compression -- 5

3. Pictorial summary of GRASP subroutine interrelationships _-..- 7 



\title{
THE GEOLOGIC RETRIEVAL AND SYNOPSIS PROGRAM (GRASP)
}

\author{
By Roger W. Bowen and Joseph Moses Botbol
}

\begin{abstract}
The Geologic Retrieval and Synopsis Program (GRASP) was designed and written to specifically accommodate interactive access to earth-science data banks. GRASP is portable, easy to use, and data-base independent.

Data banks accessed by GRASP must be partitioned and reformatted into five files which make up both data bank and pointers to parts of the bank. Machine dependencies include FORTRAN I/O unit numbers, direct-(random) access input, in-core read/write, and "prompting." GRASP isolates these dependencies to FORTRAN subroutines designed to serve these functions specifically. GRASP is manipulated by 11 user commands which select, describe, access, retrieve, summarize, and display data.
\end{abstract}

\section{INTRODUCTION}

The U.S. Geological Survey presently has the responsibility of developing and maintaining resourcedata banks. Initially, many storage and retrieval systems were critically reviewed for their data-bank characteristics, ease of use, flexibility, portability, and applicability to Survey activity. The authors concluded that no available system was wholly adequate for the needs of the Survey data banks. Generally, the observed systems were difficult to use, machine bound, or were oriented toward one type of data (for example, text oriented). The only logical alternative was to design, develop, and implement a geologic-data storage and retrieval system to be used primarily by geologists.

\section{PURPOSE AND SCOPE}

The Geologic Retrieval and Synopsis Program (GRASP) was written to provide a means of interactive access to geologic data stored in a timesharing computer.

GRASP can be implemented on any time-sharing computer system that has a FORTRAN IV compiler. Data bases accessed by GRASP must contain fixed field data in alphameric, alphanumeric, and/or numeric modes.

\section{GENERAL SYSTEM DESCRIPTION}

To obtain a broad overview of the GRASP system, consideration should first be given to the philosophy governing the design of the system, use of the present system, and future system plans. This overview provides the "framework" and the anticipated "operational environment" which are necessary for the development of any system. Both the present utilization and future system plans show the correctness of the parameters and techniques used as well as the original assumptions regarding "how," "by whom," and "where" the system will be used.

\section{DESIGN PHILOSOPHY}

Three vital questions that must be answered prior to the implementation of any system are: (1) On what computer(s) will this system be used? (2) What are the characteristics of the data to be processed? (3) Who will use the system? As is the case in many computer-system applications, these questions originally had no definite answers. A 3-month effort was necessary to establish criteria that would govern GRASP design.

\section{MACHINE PORTABILITY}

To serve as broad a spectrum of the scientific community as possible, a system should be as portable as possible. Because of differences in computer design, no system can be used on all computers without some modification. ANSI FORTRAN IV is universally accepted as a standard programming language. It may be used on the vast majority of present-day computers that have the capacity for implementing compiler-level languages in a time-sharing mode of operation. For this reason, all the processing subroutines in GRASP are written in ANSI FORTRAN IV (machine-dependent features isolated to facilitate implementation). In this way, GRASP can be installed on virtually any modern 
time-sharing computer. By designing GRASP to be portable, a much wider spectrum of the scientific community can be served by the system. Data need not be transferred from their resident banks in order to be accessed. GRASP could be used on most computers in order to access data files wherever they may reside. This machine independence eliminates the need for tedious data transformations to one system configuration, where the aggregating data eventually flood to the point of uselessness the peripheral storage of a central machine-dependent data bank. The authors believe that a common accessing system for data residing in different computers is preferable to an accessing system that can be used for data resident in only one computer.

\section{DATA-BASE INDEPENDENCE}

GRASP is designed to operate using any data base that can be represented in conventional matrix form. In matrix form, the records (that is, items to be described) are the rows, and the attributes of each record are the columns. The real structure of the data base can be thought of as the titles and arrangement of the columns of a data matrix where the rows are merely instances or occurrences described by the columns. For example, a geochemical data base would have a matrix representation in which the columns might represent chemical analyses of various elements, and each row would represent one sample. GRASP can function on any data matrix. The only requirement is that the variables (or columns) be defined ahead of time in terms of their types (that is, alpha or numeric), and, where necessary, dictionaries of legitimate alphameric entries must be provided for alphameric variables. Thus, because of the matrix orientation of GRASP, any fixed field data base can be accommodated by the system.

\section{USER COMMUNITY}

GRASP is a retrieval system having its own rules and command language for operation. In other words, to use GRASP, the user does not need to be familiar with FORTRAN or any other computer language. The GRASP command language is designed to provide users with the ability to ask questions of a data base and retain all items that answer "true" to the questions. The control language used to ask the questions (discussed in the section on "Use of GRASP" in this report) allows "retrieve only" data access to any GRASP user and does not require prior user knowledge of computer languages or system functions. Thus, GRASP can be implemented for a wide variety of users.

\section{TIME SHARING}

Inasmuch as GRASP is portable, data-base independent, and serves a wide variety of users, GRASP should be implemented in a computational mode that has the most readily available user access, namely, time sharing. In its simplest form, time sharing allows any user to communicate with the computer from a terminal near a telephone. The entire design of GRASP is based on the premise that the user community will converse directly with a computer (via a terminal) in order to access, retrieve, manipulate, summarize, and display data. This mode of computation provides the "instant" response necessary for timely decisionmaking, and also allows access by the user from the environment in which the computer response is of most value, that is, the laboratory, field, office, or conference room.

\section{PRESENT UTILIZATION}

In 1975 , the GRASP system was being used to access data from six totally different data banks: (1) oil- and gas-pool characteristics of Colorado, (2) mineral deposits of the world, (3) geochemical exploration data from the United States, (4) coal resources of the United States (prototypic data bank), (5) index of U.S. geologic map coverage (prototypic system), and (6) geothermal data bank (in Pisa, Italy). The first three of the above systems were implemented directly by the authors, and no attempt was made to redesign any of the original data-bank structures.

\section{GOLFIL}

This file contains as many as 390 characteristics for each of 800 oil and (or) gas pools in Colorado. This file served as the original model for GRASP design and ultimately will contain 60,000 records.

\section{MANFIL}

The mineral deposits of the world (MANFIL) were the second file implemented using GRASP. It is a computerized batch-processing-oriented file containing geologic, production, and reserves data from about 4,000 nonferrous metal deposits throughout the world. Each record represents one deposit, and contains as many as 250 variables. Although GRASP was designed using the oil- and gas-pool file as a model, implementation of the world-mineral-deposits file showed the flexibility of GRASP with respect to its data-base independence. 
RASS

The RASS (Rock Analysis Storage System) file is a batch-oriented geochemical data bank containing limited geologic descriptions and comprehensive geochemical analyses of all samples processed by the laboratories of the U.S. Geological Survey. This file contains a unique type of numeric data called "qualified values." Because of the upper and lower detectability limits of analytic devices, elements whose presence is known but whose content is outside the analytical range of a device are sometimes reported at a given analytical cutoff value, accompanied by a letter indicating whether the content is less than, greater than, or in interference with another element. Typical qualified entries would appear as L5000, G1000, or H100, where L signifies a content less than the attached value, $G$ signifies a content greater than the attached value, and $\mathrm{H}$ signifies analytical interference at a concentration of the attached value. Because many of the RASS data were accompanied by alpha qualifiers, GRASP was modified to accept and process this type of data in addition to the conventional numeric- and alphamericdata types.

All the above files are implemented in a retrieve mode only, and graphics have not yet been added. Input to the files is done by people who are responsible for data entry and does not fall in the domain of the user.

\section{FUTURE PLANS}

Currently, the development of GRASP is primarily oriented toward implementation of techniques for interactive graphics storage and retrieval. Three problem areas are presently being researched: automatic recognition of features on scanned input documents, annotation methods, and resolution of "intersecting feature" problems. Present research efforts are directed toward feature recognition and subsequent computational extraction of simple boundary vectors from scanned digital maps and photographs. In addition to recognition of features, methods are also being developed for annotation of both graphics-data entry and presentation of graphics data on output.

One of the major anticipated technical and philosophical problems is concerned with the graphical resolution of intersecting features. Techniques are being developed that should resolve these problems for any particular data set.

All the GRASP graphics output is being designed primarily for interactive graphics cathode ray tube
(CRT) representation. This is in keeping with GRASP's original "totally interactive" design philosophy.

\section{DETAILED SYSTEM DESCRIPTION}

GRASP is designed as a highly modular, hierarchically structured set of subroutines (see section "GRASP Software Specifications"). Each subroutine performs a fixed task. The higher level subroutines are primarily concerned with the flow of control required to execute a user command. The lower level subroutines are primarily concerned with extremely independent and specific tasks (such as "get a record," "access a dictionary," and "accept user input," and so on). All information related to a specific data base is obtained from various files associated with that data base. Structuring the system in this way leads to a high degree of functional isolation. These design characteristics simplify the development, documentation, maintenance, growth, and inevitable change inherent in a system that supports a variety of data bases on a wide spectrum of computer main frames. The section on GRASP software specifications is intended for use by those familiar with FORTRAN language.

\section{DATA-FILE STRUCTURES}

Upon initial execution, the GRASP system reads an "index" file which contains the names of data bases available for access. Each record of the index file corresponds to a data base and contains the names of the files associated with that data base and a 40-character description of the data base.

Each data base is composed of five files which contain the actual data, information on the structure of records, names which will be used to refer to particular items within records, descriptive information on the names themselves, and a grouping into categories of information. These files are called Mask, Definitions, Dictionary, Multiple-choice, and $\mathrm{Nu}$ meric Master files.

\section{MASK FILE}

The Mask file contains the item names, item types (integer, real, character string, multiple choice, and qualified real), and pointers to the first entry in the Dictionary file for each character-type item. This file is read once and rewound when a data base is selected via the FILE command. An example of Mask file arrangement is shown in figure 1. 
Conceptual noncomputerized dictionaries for three character type variables:

Variable No. 1 Variable No. 2 Variable No. 3

$\begin{array}{llll}\text { Continent } & \text { Country } & & \text { Province (State) } \\ \text { North America } & \text { USA } & & \text { California } \\ \text { South America } & \text { Canada } & & \text { Virginia }\end{array}$

Europe Mexico British Columbia

Argentina Quebec

Brazil Cordova

Chile

Germany
In the computer, the Dictionary File is arranged as follows:

Dictionary File

Item No. Pointer to next item

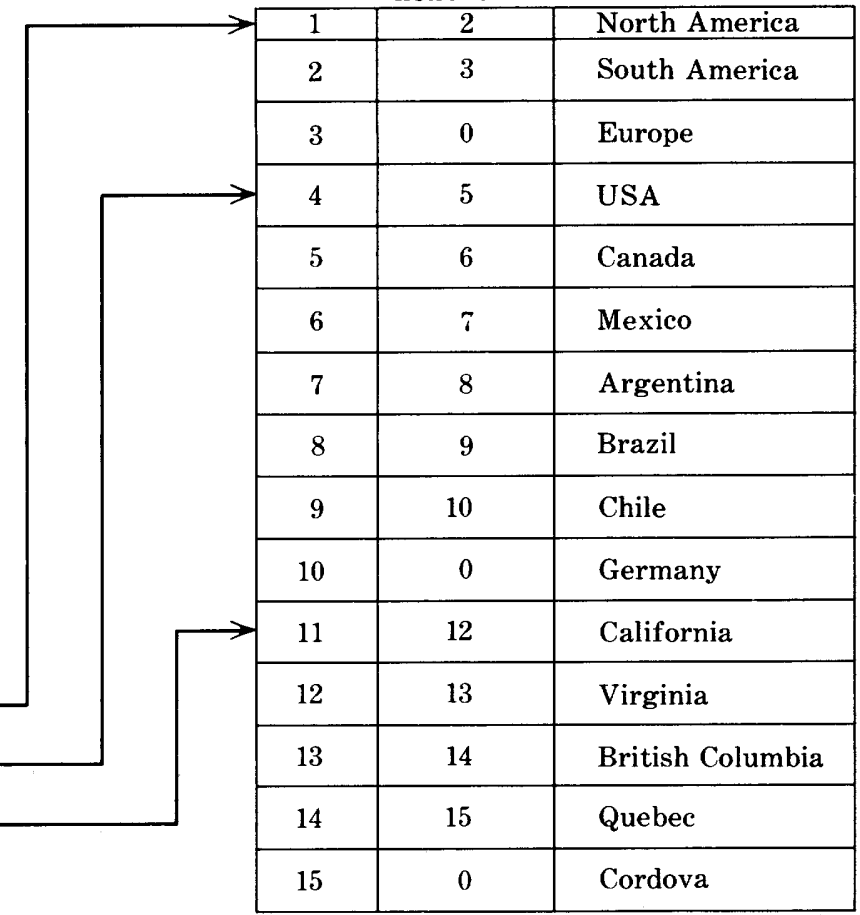

In the computer, the MASK File is arranged as follows:

Mask File

\begin{tabular}{llc} 
Variable Name & Variable Type & $\begin{array}{c}\text { Starting Position in } \\
\text { Dictionary File }\end{array}$ \\
\hline Continent & Character & 1 \\
\hline Country & Character & 4 \\
\hline Province (State) & Character & 11 \\
\hline Production & Numeric, real & $*$
\end{tabular}

*Note: This variable is numeric, and does not require a pointer to the Dictionary File
(" 0 " indicates end of list for particular variable)

Figure 1.-Example of Mask-file and Dictionary-file arrangement.

\section{DEFINITIONS FILE}

The Definitions file contains the following information:

1. The number of categories in the file.

2. The maximum number of (computer) words in a category name.

3. The category names.

4. For each category the following information is recorded:

(a) category number.

(b) number of lines used to describe this category.

(c) maximum length (in computer words) of a description in this category.

(d) number of variables appearing in this category. In some cases this will be different from item $b$ (the number of lines for description).

(e) indices of the variables appearing in this category. (f) the variable names, types, and descriptions for this category.

\section{DICTIONARY FILE}

The Dictionary file contains all character-string values which are assumed by character-type items. Each record contains a pointer to the record containing the next value, followed by the current value. The last value assumed by a character-type item is indicated by a pointer value of zero (the record containing the first character-string value for a character-type item is pointed to by a value in the Mask file). The Dictionary file is designed as a random-access file whose values form a linked list. Figure 1 shows an example of the Dictionary-file arrangement.

\section{MULTIPLE-CHOICE FILE}

The Multiple-choice file contains the acronyms and acronym meanings for the values assumed by mul- 
tiple-choice items. Each record of this file is composed of an item number indicating the multiplechoice item, the number of possible values this item assumes, the maximum length of an acronym value description, and a list of acronyms (which are double words) and their descriptions.

\section{NUMERIG MASTER FILE}

The Numeric Master file is composed of the records for a data base in a compressed form. Values for integer-type items are stored as integers. Values for floating-point- (or real-) type items are stored as real numbers. Values for character-type items are stored as integer pointers to the entry number in the Dictionary file. Values for multiple-choice-type items are stored as integers containing a binary encoding that represents the value set. (For example, if the second and fifth bit of the word are "on," the value assumed is the second and fifth acronym value.) Each record of the compressed Master file is variable length in form and corresponds to an expanded 400-word record. Expansion of the compressed record is performed by subroutine GETPUT. Figure 2 shows an example of the Numeric Master file prior to compression.
DATA COMPRESSION

The compression technique used is a form of blank suppression. The words of the compressed record are one of the following four types:

A. Integer value.

B. Real value.

C. Integer blank count.

D. Integer word count.

The first word of all records is of type D (above) and is used to give the length of the record. Subsequent words may be types A, B, and C. For types A and $\mathrm{C}$, the last two bits give the type of the next word. The value of the word is obtained by dividing by 4 . The type of the next word is obtained via the remainder modulo 4 , where the numbers $1-3$ correspond to types $\mathrm{A}, \mathrm{B}$, and $\mathrm{C}$. Type-A words are used for numeric integers, pointers to entries in character dictionaries, and binary encodings of multiple-choice-type items. Type-C words are used to count the number of consecutive blanks to be inserted in the expanded record. Type-B words are used for floating-point numeric values. The type of the next word is contained in the last 2 bits of the whole (integer) part of the words. For example, consider a data word having a value of 49.723 . The

Given the following two successive noncomputerized records to be entered into the Numeric Storage File:

\begin{tabular}{|c|c|c|}
\hline & Record 1 & Record 2 \\
\hline Continent .. & North America & South America \\
\hline Country ............. & United States & Argentina \\
\hline Production ..... & 39281.6 & 49298.7 \\
\hline Identification No... & 38 & 39 \\
\hline Province (or State) & Virginia & Cordova \\
\hline
\end{tabular}

Prior to compression, the computerized Numeric Storage File is arranged as follows:

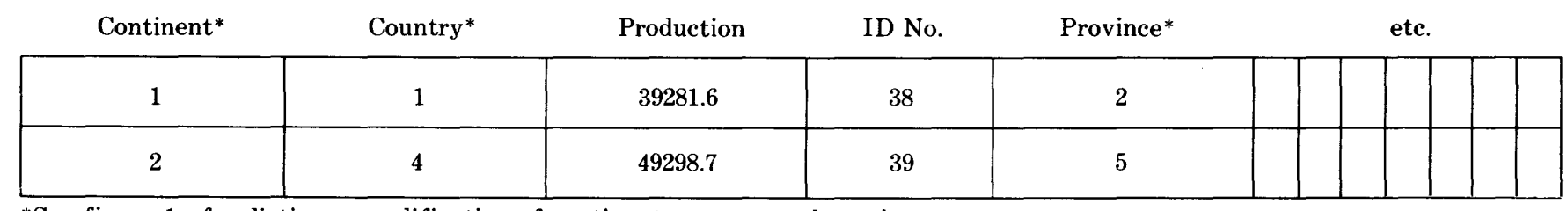

*See figure 1-for dictionary codification of continent, country, and province

FIGURE 2.-Example of Numeric-Master-file arrangement prior to compression. 
floating-point value would be $12.723 \quad(12=49 / 4)$, and the type of the next word would be $49-(4 \times$ $12)=1$ or $\mathrm{A}$.

\section{MACHINE DEPENDENGIES}

Although most of the GRASP-system code is written in ANSI FORTRAN IV, certain isolated functions must be tailored to the particular FORTRAN compiler on any given machine. These functions deal with the dynamic association of data set names and FORTRAN I/O unit numbers, direct(random-) access input, the method of accommodating "prompting," and internal (in-core) transfer (writes) using format control.

For the dynamic association of data-set names and FORTRAN unit numbers, the routines IFILE, OFILE and DEFINE are used. Details of these routines can be found in the section "GRASP Software Specifications."

Direct-access input is used to access the Dictionary file (in subroutine ACCESS). The FORTRAN unit number, an integer expression giving the record number, and an input list are supplied in the READ statement. This form of direct-access input is compatible with most FORTRAN compilers which support direct-access input. Systems not having directaccess capabilities can be accommodated by modifying the logic of this subroutine. This modification involves positioning of a sequential file to the appropriate record prior to execution of the READ statement.

For systems which do not accept the "prompt" option in the READ statement, user "prompting" can be accomplished by using WRITE statements immediately preceding (in time) user input. The "prompt" message is contained in a FORMAT statement, along with a character which inhibits the generation of the normal carriage-return/line-feed usually associated with output directed to a timeshare terminal. If a particular system does not have this capability, the "prompting" message will appear on a separate line immediately preceding the user input.

The internal transfer of data under format control is accomplished via the ENCODE statement. The ENCODE statement is used in subroutine COLPNT to construct a line of output. The only other use of ENCODE is in subroutine PACK which is used to convert characters from unpacked to packed form. Most non-IBM FORTRANS support this statement in one form or another. In the case of IBM FORTRAN, a routine must be provided that allows internal data transfer under format control.

\section{INTERNAL STRUGTURE AND FUNCTIONS}

GRASP is designed to accept a "command" (or directive) from the user. Once the command has been recognized, the appropriate subroutine is executed. This subroutine will, in most cases, call other subroutines in order to accomplish its intended task. In some cases subroutine calls are nested to a depth of six. Figure 3 gives a pictorial summary of the calling hierarchy for subroutines which are in GRASP. This figure will be useful in implementing or modifying the GRASP system.

\section{PROCESSING USER INPUT}

All user input to GRASP is passed to the system in unpacked character form. At the highest level are single words used to execute a GRASP "command." In this case, the characters are packed, and the result is compared to the list of available commands. After a command has been issued, supplementary user input is usually required. This supplementary input must then be "parsed" (that is, converted) into a form more meaningful to the GRASP system. This parsed form is entirely numeric in nature. The numbers themselves may represent values, integer encodings, or pointers. Supplementary input falls into five independent areas: conditional expressions, logical expressions, number lists, name lists, and arithmetic expressions.

\section{CONDITIONAL EXPRESSIONS}

A conditional expression is an attribute name, followed by a relation, followed by a value. The attribute name is identified using the binary-search technique. The relation is identified by a sequential table lookup. The value is converted to correspond in type with the attribute name referenced. This may result in a pointer to a character entry in the Dictionary file, a binary encoding of an acronym value in a record of the Multiple-choice file, or simply a numeric value. Each conditional expression entered is associated with a letter (A-Z).

\section{LOGICAL EXPRESSIONS}

Logical expressions are composed of letters referring to conditional expressions, the grouping symbols used to control the order of evaluation, and the logical operators .AND. $(*)$, .OR. $(+)$, .NOT. (-). For ease of evaluation logical expressions are converted to reverse-Polish form. This is a parenthesisfree form which permits rapid evaluation using a push-down stack technique. For a detailed description of the conversion to and evaluation of reverse- 


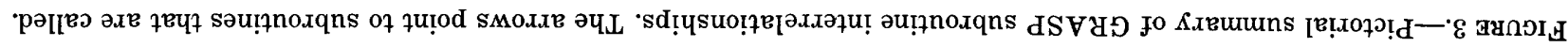

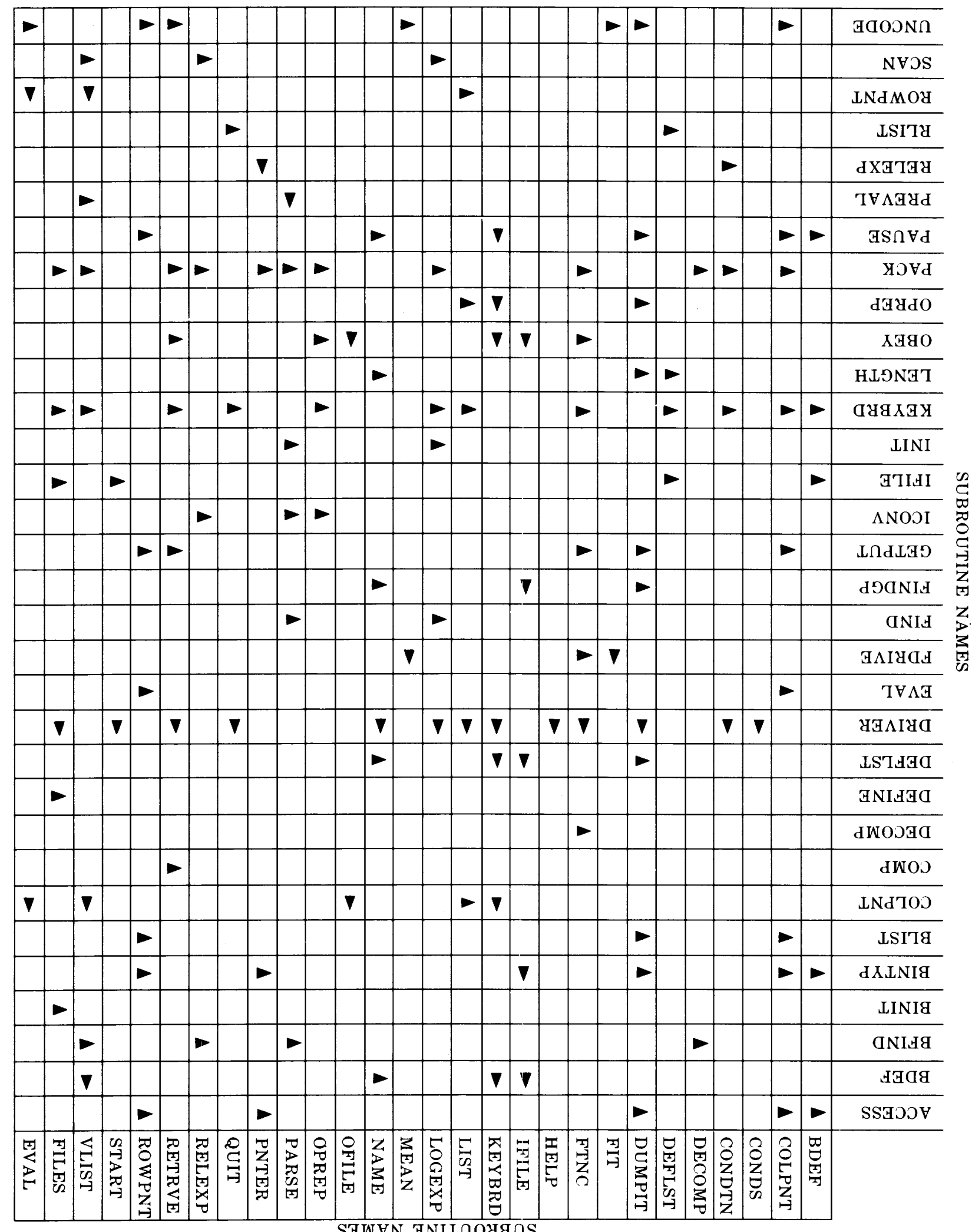

SGWVN GNIJOOGAS 
Polish form expressions, the reader is referred to Lee (1967, p. 162-180).

\section{NUMBER LISTS}

Number lists are composed of one or more integer numbers or number ranges (for example, 1 , $2-7,10)$. Each pair of elements in a number list must be separated by a comma. Individual elements are generated from the unpacked character form by constructing each number, one digit at a time, using a sequential lookup on each character. Number ranges are generated by filling in the interior numbers from the pair of extremes.

\section{NAME LISTS}

Name lists are composed of one or more names. When the name list contains a single element such as a file name, the packed form is obtained and associated with the appropriate FORTRAN unit number. If the name list is one or more attribute names, each pair of which is separated by a comma, each element is packed and looked up using the binarysearch technique.

\section{ARITHMETIG EXPRESSIONS}

Arithmetic expressions may be entered in the place of single attribute names as supplementary input to the LIST command. These arithmetic expressions may be composed of constants, the grouping symbols ( ), attribute names, the arithmetic operators $+, *, /,-$, and the functions square (SQR), square root (SQRT), log base 10 (LOG) and power of $10(\mathrm{EXP})$. The arithmetic expression is converted on input to reverse-Polish form. Evaluation is done on output. If any of the attributes in the expression has no value for a given record, the expression is not evaluated. All conversion to reverse-Polish form is done using transition-matrix parsing. Bauer and Samelson (1960) give a discussion of this technique.

\section{SEARCHES}

The two general types of GRASP searches are external file and internal table. External-file searches are made on the Dictionary file, Multiple-choice file, and Numeric Master file.

The Dictionary file is searched in two ways. The first way is as an indexed sequential file. When a condition relating an attribute name to a characterstring value is entered, the record number of the first entry of the dictionary for that attribute is obtained from the "unnamed" common area. That record is read (directly), giving the entry value and a pointer to the record containing the next entry. The entry value is compared with the characterstring value, and, if not equal, the record containing the next entry is read. This process continues until an entry is found that matches the character-string value, or until all entries of the dictionary have been read. The latter condition is detected by a nextrecord-pointer of zero. The second way of searching the Dictionary file is as a direct- (random-) access file. To display the value of a character-type attribute, its pointer is obtained from the current record of the selected Numeric Master file ${ }^{1}$ and its value is obtained by a direct-access read on the Dictionary file.

Multiple-choice acronym values are obtained when a condition is entered involving a multiple-choicetype attribute and when the value (s) of a multiplechoice-type attribute is to be displayed. Each record of the Multiple-choice file contains all the acronym values for a particular multiple-choice attribute. In all cases, the Multiple-choice file is read in direct(random-) access mode using a pointer from the "unnamed" common area. After the correct record has been obtained, the attribute values are available in a tabular (array) form.

The Numeric Master file is searched in a purely sequential fashion. This search involves the application of a "question" to each record of the file where the "answer" can only be "yes" or "no." If the answer is "yes," the record is written on an output file. The question is posed by previously entering conditions and relating them by a logical expression.

Internal table searches are made on attribute names and single characters. All lookups on attribute names are done using the "binary search" technique on a sorted list. The list of names are read and sorted by execution of the FILE command. The interval that possibly contains the desired name is repeatedly halved until it is of length one. At that point, the position of the name is known, or the name is not in the list.

Single characters are looked up sequentially when the list of possibilities is short, as in the case of digits in a number. A "hash code" technique is applied for longer lists such as alphabetic letters. This technique involves the initial storage of possibilities in a position dictated by a function applied to the value itself. This is done in a table whose size is greater than the number of possibilities. If

1 The selected Numeric Master file most probably will be some retrieved subset of the true Numeric Master file. 
the position is already occupied, an additional function is applied to the value until an unoccupied position is found. Once the possibilities have been stored in this manner, the lookup of an arbitrary character is accomplished by applying the same procedure. If an empty position is detected during lookup, the character is not in the list. Bell and Kaman (1970) give a more detailed description of the technique.

\section{OUTPUT}

A data-retrieval system designed for interactive use should provide the user with information regarding use of the system, the structure and content of a particular data base, and the capability of displaying selective attribute values for records of some partition of a data base. These capabilities have been incorporated in GRASP and are individually discussed in the following paragraphs.

Information regarding use of the GRASP system is provided in two ways. First, all user response is preceded by system-generated "prompts" which indicate the type of response desired. Secondly, a command (HELP) has been implemented that gives the user a brief description of each command recognized by the system.

Information regarding the structure and content of a particular data base is obtainable via the NAMES and FUNCTION commands. The NAMES command allows the user to determine attribute names (acronyms) and corresponding data types. A brief description is provided for each attribute name printed. After the selected attribute names have been printed, the user may examine the set of possible values assumed by character-and multiple-choice-type attributes. For numeric-type attributes, the user may obtain arithmetic means and ranges by selecting the MEAN function after issuing the FUNCTION command.

A partition of a data base is created when a retrieval has been made using the CONDITIONS, LOGIC, and SEARCH commands. The displaying of selective attribute values for records of this partition is accomplished by using the LIST or DUMP commands. The DUMP command permits the user to print all values present for attributes in a selected set of categories. The values are printed one to a line with the corresponding attribute name. The LIST command permits the selection of specific attributes or arithmetic expressions containing attribute names for printing. The printing is selectably formatted into columns or rows. For columnar output, the user may create a separate data set which could be used by other programs at a later time.

\section{DATA-BASE IMPLEMENTATION}

In the previous section on file description, it was noted that the various files were integral to and necessary for GRASP to function. There are approximately as many methods of data collection as there are data bases, and it is not the intention of the writers to dictate data-base structures or methods of data collection. However, the following suggestions will facilitate the construction of the files necessary for GRASP implementation.

The structure of any GRASP data base must be such that it can be manifest in a tabular fashion. The table representing a data base is composed of columns that are attributes and rows that are items described by these attributes. For purposes of this report, the word "record" will be used in reference to rows. Before any files can be constructed, a comprehensive list of names of attributes (or column headings) must be compiled. Keep in mind that this arrangement of attributes will describe every record in the data base, and that although provision is made for all attributes, no record need contain data on every attribute. For each attribute that assumes a character-string value, a dictionary is compiled whose entries are the values assumed by that attribute. These dictionaries are used to create the Dictionary file. Once the Dictionary file is constructed, the record number (that is, pointer) of the first entry (that is, value) for each charactertype attribute is known. By using this information and the previously compiled list of names of attributes, the Mask file can be created. Next, all attributes should be grouped into categories of related information. This grouping provides the information necessary for the construction of the Definitions file. For multiple-choice-type attributes one simply needs to assign and to delineate value acronyms for each attribute in a record. Each group of value acronyms forms a set, and the collection of sets forms the Multiple-choice file.

Finally, the Numeric Master file is constructed, one record at a time. The individual record is constructed by assigning values for each attribute in the order of its occurrence in the Mask file. For integer or real attributes, the value is inserted directly. For character-type attributes, the entry number of the value in the appropriate dictionary is inserted. 
For multiple-choice-type attributes, the binary encoded word that describes its value is inserted. The record is then compressed as described in the section "Data File Structures."

\section{USE OF GRASP}

From the viewpoint of a user, GRASP is a mechanism for obtaining information from a data bank in a very simplistic and rigid manner. The "language" which is used to "direct" GRASP is composed of 11 "commands." These commands can logically be divided into four groups.

GROUP 1 (FILES, NAMES) is used to:

A. Select or change the data base of interest.

B. Obtain information regarding the nomenclature and content of the selected data base.

GROUP 2 (LIST, DUMP, FUNCTION) is used to:

A. Examine a selected set of records that is called a file.

B. Perform selected computations of numeric attributes in a file.

GROUP 3 (CONDITIONS, LOGIC, SEARCH) is used to perform a retrieval (SEARCH) on the data bank based on given criteria (CONDITIONS) which are combined via a logical expression (LOGIC), a shorthand method of indicating which records of the data bank are to be retrieved.

GROUP 4 (HELP, REVIEW, QUIT) is used to:

A. Obtain brief information about the commands that GRASP will accept.

B. Obtain information regarding the history and status of the current session with GRASP.

C. Terminate the current session with GRASP.

All commands except HELP and REVIEW will ask for some type of response. Each response entered must end by striking the "cr" (RETURN) key. If a typing error or incorrect response is given, the system asks for another response. If at any point the system seems to be idle it is a good practice to strike the cr key. Certain commands (SEARCH, LIST, DUMP, FUNCTION) require an input file name. Entering a blank name in response to prompts generated by these commands (that is, cr only) results in the selection of the current Numeric Master file (as specified in the most recent FILE command). The LIST and DUMP commands also ask for the number of lines per page. This causes the system to pause after each printing of this number of lines, awaiting a response from the user. The user may then make a hard copy and (or) clear the screen if using a CRT terminal. Also, the user may terminate the printing altogether. At each pause, the user should enter a nonblank character followed by a cr if it is desired to abort the rest of the printout; otherwise, only a cr will continue printing. The method of calling the GRASP system into execution will vary, depending on what computer is used. At the beginning of execution, the GRASP system will print out the names and descriptions of the data bases available. The data-base name corresponds to the name of the Numeric Master file. Assume, for purposes of explanation, that a data consisting of oil and gas pools in the State of Colorado is available and named COLFIL. Following is a discussion of each command:

FILES.-This command is used to select a data base and may be issued at any time during a session. The individual-attribute names for any one data base will not be recognized by GRASP until this command has been issued. The user must enter a data-base name when the system asks for it.

NAMES.-This command is used to list the acronyms which will be used to identify individual attributes within a record (that is, pool) and their meaning. First, 17 categories are printed. Then the system asks the user to enter a list of numbers corresponding to the categories of interest. The list should be composed of individual numbers or number ranges (such as 2-5), each of which must be separated by a comma. The list must be terminated by the cr key: for example, 1, 2-5, $9 \mathrm{cr}$ and 1-4, 10, $11 \mathrm{cr}$. The system then lists each acronym and its meaning for all the categories of interest. After each category is complete, the system pauses. At this point the user must enter cr to continue, or enter any letter (or digit) followed by $\mathrm{cr}$ to stop. After all categories have been completed, the system asks if the user would like to see the possible values of any character-type or multiple-choice-type items. The user must then enter $\mathrm{Y}$ or $\mathrm{N}$ followed by cr to indicate his decision. If the user enters $\mathrm{N}$, the system will ask the user to enter his next command. If the user enters $\mathrm{Y}$, the system asks for the names (acronyms) of the attributes of interest. The names are prompted and are given one per line followed by a cr. After each name is given, the system skips to the next line and prints a numeral. To end the list (a maximum of 10 names may appear), enter cr (with no name). The system then starts printing the attribute names and possible values, pausing after each name is complete. A pause also occurs after 30 lines of print. At each pause, enter cr to continue or any letter (or digit) 
followed by cr to stop. After this process is completed, the system then asks if the user would like to see any more possible values. Again, enter $\mathrm{Y}$ for yes or $\mathrm{N}$ for no.

LIST.-This command is used to output selected attribute values (or expressions) from a selected file. Output may be to an interactive terminal or to a specified data set which could be processed at some later time by other programs. The system first asks the user for the input-file name and the number of lines per page. The user is next asked to enter $C$ for column printing or $\mathrm{R}$ for row printing. If column output is selected, the user is asked if he wants output to be to a disk data set in character form. If so, the system will ask for a data-set name. Column output prints the selected acronyms as headings and their respective values below. Each column is composed of 8 character positions in a field of 10 . One line of column output corresponds to one record. Row output consists of lines, each of which contain an acronym and its corresponding value. If the value for a selected attribute is missing, the attribute name is not printed. Records are separated by a line of asterisks. Before output proceeds, the system asks for the names of attributes or expressions which are desired. This is done by prompting with index numbers.

Expressions may optionally be preceded by some name. Five intrinsic functions are available: square root (SQRT), square (SQR), log base 10 (LOG), power of ten (TEN), and absolute value (ABS). Expressions may involve these intrinsic functions, attribute names, numeric constants, the arithmetic operators $(+,-, *, /)$, and the grouping symbols ( ). The following is an example of a list to be output:

\section{POOL \\ 2. FIELD \\ 3. DEPTH \\ 4. LOG (DEPTH) \\ 5. WELLAV $=$ CRUAN69/(NUMPOOL- TOTPROD) \\ 6.}

In the above example, GRASP has prompted with the index numbers $1-6$. Note that the list is terminated by a blank entry.

DUMP.-This command is very similar to the LIST command having row printing specified. Instead of asking for a list of names, the system asks for a list of category numbers. It then prints (in row fashion) the attribute name and value for each attribute present in the selected categories of the specified file.

FUNCTION.-This command performs functions on a file. Currently, the only functions available are the arithmetic mean (MEAN) and a linear leastsquare fit (FIT) of two attributes. The system asks for the name of the input file. Next, the user is asked for the name of the function and names of the arguments. The argument names are the acronyms for attributes within a record; as many as five may be given. For instance, if MEAN DEPTH, TOTPROD, CRUCM70 cr were entered, the range, mean, root mean square, sum, and sum of squares for DEPTH, TOTPROD, and CRUCM70 would be computed and printed. If FIT DEPTH, TOTPROD cr were entered, the system would respond with the slope, intercept, and correlation coefficient. Values for all attributes in a record must be present for that record to be included in a computation.

CONDITIONS.-This command is used to enter a set of retrieval criteria. Each criterion must be given in the form acronym relation value, where acronym is an attribute name (such as COUNTY, CRUCM69, POOL), where relation is $\mathrm{EQ}, \mathrm{NE}, \mathrm{GT}$, $\mathrm{LT}, \mathrm{LE}, \mathrm{GE}$, or $\mathrm{BE}$, and where value is a number or a series of letters (such as ADAMS, 19342, MISSISSIPPIAN). The above relations have the following meanings :

$\mathrm{EQ}$ - equal to.

$\mathrm{NE}$-not equal to.

GT-greater than.

LT-less than.

LE-less than or equal to.

GE-greater than or equal to.

$\mathrm{BE}$-between (numerically, inclusive).

The system precedes each condition with a letter prompt (up to 26 may be entered), which will be used in the logic expression that combines the conditions. Entering cr by itself terminates the list of conditions. Following is an example of a set of conditions :
A. COUNTY
EQ
BACA
B. DEPTH
$\mathrm{BE}$
C. TOTPROD
GE
D. LITHOL
NE
E. COUNTY
EQ
F. POOL
$\mathrm{NE}$ 5000,6000
10
DOLOMITE
ADAMS
G.

In the above example, the system provided the letters $\mathrm{A}$ through $\mathrm{G}$ as prompts.

LOGIC.-This command is used to enter a logical or connective expression which combines the pre- 
viously entered conditions to form the retrieval criterion. The logical expression may be composed of the logical connectives (operators), the letters corresponding to the criteria entered via the CONDITIONS command, and the grouping symbols ( ). The logical connectives are AND, inclusive OR, and NOT (written .AND., .OR., .NOT.). Note that they are each bracketed by periods. Provision has also been made to use * (for AND), + (for OR), - (for NOT). Assume that the example conditions given in the preceding CONDITIONS command section had been entered. If the user wanted to retrieve the pools in Baca County that had a depth of 5,000-6,000 feet, the logic expression would be A .AND. B cr. If all the pools in Adams and Baca Counties except those of Mississippian age having dolomite lithology were desired, the logic expression would be (A .OR. E) .AND. (D .AND. F) cr. Note that the last pair of parentheses is not really needed. The ANDs will be applied before the ORs. NOTs are applied before ANDs and ORs. Hence, the first set (A. OR. E) is necessary so that the $\mathrm{E}$ is connected to $\mathrm{A}$ instead of to D. If one wanted to retrieve all pools with at least 10 producing wells having a depth greater than 6,000 feet or less than 5,000 feet, the logic expression would be .NOT. B .AND. $\mathrm{C}$ cr. If one wanted to retrieve all pools having less than 10 producing wells in the same range as above, one could use .NOT. (B .OR. C) cr for a logic expression. This expression, in words, says "if the pool has a depth of 5,000-6,000 feet, or if it has 10 or more producing wells, I don't want it."

$S E A R C H$.-After the system has been given the conditions and connecting logic that compose the question to be asked of some file, an actual search of the data bank can be made. This is done with the SEARCH command. The system will ask for the name of the file to be searched (input file) and the name to call the file of records found (output file). After the search has been made, the system types the number of records searched and the number of records found. The capability of entering both input and output file names allows the user to perform "nested" searches. This means searches of files that were the result of previous searches. Frequently this is the most economical way of performing multiple or complex retrievals. For instance, suppose one wanted information on several sets of pools, all of which were in one county. One would first create an output file that contained all the pools in that county and then use that file as the input file for subsequent searches.

HELP.-This command is used to print a list of the possible commands and a brief description of their functions.

REVIEW.-This command provides a review of the conditions and logic which are currently in effect. The names of input and output files for the last 10 retrievals are also printed. This command is used to refresh one's memory on what was done recently during the current session.

QUIT.-This command is used to exit from the GRASP system. A list of the files created during this session is printed, and the user is permitted to save them for future use. Abnormal session interrupts and terminations will cause GRASP to cease functioning. However, all files created during the active session are either saved or not saved, according to the abnormal termination rules of the particular computing system. On abnormal termination, GRASP neither saves nor deletes files.

\section{REFERENCES CITED}

Bauer, F. L., and Samelson, K., 1960, Sequential formula translation: Assoc. Computing Machinery Commun., v. 2, no. 2, p. 76-83.

Bell, J. R., and Kaman, C. H., 1970, The linear quotient hash code: Assoc. Computing Machinery Commun., v. 13, no. 11 , p. $675-677$.

Lee, J. A. N., 1967, The anatomy of a compiler: New York, Reinhold Publishing Corp., 275 p. 


\section{GRASP SOFTWARE SPECIFICATIONS}

\section{MODULE NAME: DRIVER}

Purpose: DRIVER is used primarily as a switching/calling mechanism. User commands are accepted and decoded. Control is then passed to the routine designed to process the given command. This process continues until the user "quits."

Subroutines called: START, KEYBRD, CONDTN, LOGEXP, RETRVE, FTNC, FILES, CONDS, HELP, DUMPIT, NAME, LIST, QUIT, PACK.

Common data referenced: None

Called by: None

Error checking and reporting: The command entered by the user is checked against the list of legal commands. If a command is not recognized, it is echoed back to the user terminal with a message suggesting use of the HELP command.

Program logic:

1. Initialization is performed by zeroing counters and calling START.

2. An unpacked character string is accepted from the user via subroutine KEYBRD.

3. A four-character command is formed by packing the above string into COMMAND.

4. COMMAND is then compared with the list (WORDS) of acceptable command words (NAMES). When a match is found, control is transferred to the appropriate subroutine via a computed GO TO.

5. Steps 2 through 4 are repeated until an end-of-file (EOF) condition is sensed on the terminal or until the QUIT command is executed.

G A S P SOURCE PROARAM

INTEGER WORDS(11), COMAND, NAMEPT (26), RCCDE (26), I VAL (26), POL ISH(30) 0000001

1 , IMAGE (5), IFILES (20), OFILES $(20)$ 0000002

DATA WOROS $/$ 'COND', 'LOGI','SSEAR', 'LIST', 'FILE', 'QUIT', 'NAME', 'HELP'0000003

1, 'REVI', 'DUMP', 'FUNC', IBLNK/, ',

0000004

NFILES $=0$

LPS $=0$

0000005

CALL START

0000006

0000007

110 TYPE 270

COMAND $=I B L N K$

CALL KEYBRD $(\varepsilon 260,1 M A G E, 4)$

0000008

0000009

CALL PACK(IMAGE, COMAND, 4,4)

0000010

DO $120 \quad I=1,11$

0000011

IF (COMAND.EQ.WORDS(I)) GO TO 130

0000012

120 CONTINUE

TYPE 290, COMAND

GO TO 110

0000013

0000014

0000015

0000016

130 GO TO $(140,150,160,24 C, 190,260,230,210,180,220,170)$, I

0000017

140 CALL CONDTN (E110, NAMEPT, RCODE, I VAL, NRE XP)

0000018

GO TO 110

0000019

150 CALL LOGEXP $(\& 110$, POLISH,LPS, NREXP;

GO TO 110

160 CALL RETRVE $(\& 150, \varepsilon 110$, IFILES, OF ILES, NFILES, POL ISH, LPS, NAMEPT, 0000020

0000021

0000022

1 RCODE, I VAL, NREXPI

GO TO 110

$17 C$ CALL FTNC $(\& 110)$

GO TO 110

$190 \mathrm{CALL}$ FILES $(\& 110)$

GO TO 110

180 CALL CONDS(NREXP,LPS)

IF (NFILES.GT.0) GO TO 200

0000023

0000024

0000025

0000026

0000027

0000028

0000029

TYPE 300

GO TO 110

200 TYPE 310 , (IFILES(I), OFILES (I), I =1, NFILES)

0000030

0000031

0000032

GO TO 110

0000033

0000034

$21 C$ CALL HELP(WORDS)

GO TO 110

0000035

0000036

220 CALL DUMPIT

0000037

GO TO 110

0000038 
230 CALL NAME $(\& 110)$

0000039

GO TO 110

$24 C$ CALL LIST(E110)

GO TO 110

260 CALL QUITIOFILES, NFILES) STOP

270 FORMAT (// ENTER COMMAND: "\$)

0000040

0000041

0000042

0000043

0000044

0000045

290 FORMAT ( $1 X, A 5, '$ ILLEGAL COMMANO. ENTER HELP IF YOU WISH TO SEE', 0000346 1. THE legal COMMANDS." /

$30 C$ FORMAT (" NO FILES HAVE BEEN USED AT THIS TIME.")

310 FORMAT 1 INPUT: OUTPUT: $1 /(2 X, A 5,2 X, A 5 /))$ END 


\section{SUBROUTINE NAME: ACCESS}

Purpose: ACCESS looks up character-string values in dictionary files. In order to minimize disk accesses, five previous values are saved for as many as 100 distinct character-type items.

Calling sequence: CALL ACCESS(NUMD,IVAL,TANK, NWORDS,ISWTCH)

Arguments :

NUMD-Item number of the character-type variable whose values are to be accessed.

IVAL-Direct-access key under which value is stored.

TANK-Contains the character value accessed.

NWORDS-The number of words in TANK.

ISWTCH-Switch to control which of the following four functions are desired:

1. Initialization for dictionary lookup.

2. Lookup a random item.

3. Return the direct-access key of the first item in this dictionary.
4. Return the indicated (by IVAL) entry and the KEY for the next entry (that is, reset IVAL).

Subroutines called: None

Common data referenced: IDPT in /DACOMM/

Called by: BDEF, COLPNT, DUMPIT, PNTER, ROWPNT

Error checking and reporting: None

Program Logic: The logic is divided into four sections relating to values of. ISWTCH.

1. If $\mathrm{ISWTCH}=1$, initialize saved pointer arrays (USED, LASTDX) and set character variable counter NCVAR to zero.

2. If ISWTCH=2, see if the value has been stored in BUFFER. If so, return it; otherwise access it on FORTRAN unit 21 and save its value (TANK), index (IVAL) and the item number (NUMD).

3. If ISWTCH $=3$, return the direct-access key for the first entry of the dictionary pointed to by NUMD.

4. If ISWTCH $=4$, access the entry pointed to by IVAL and reset IVAL to the key for the next entry in this dictionary.

G R A P SOURCE PROGRA M

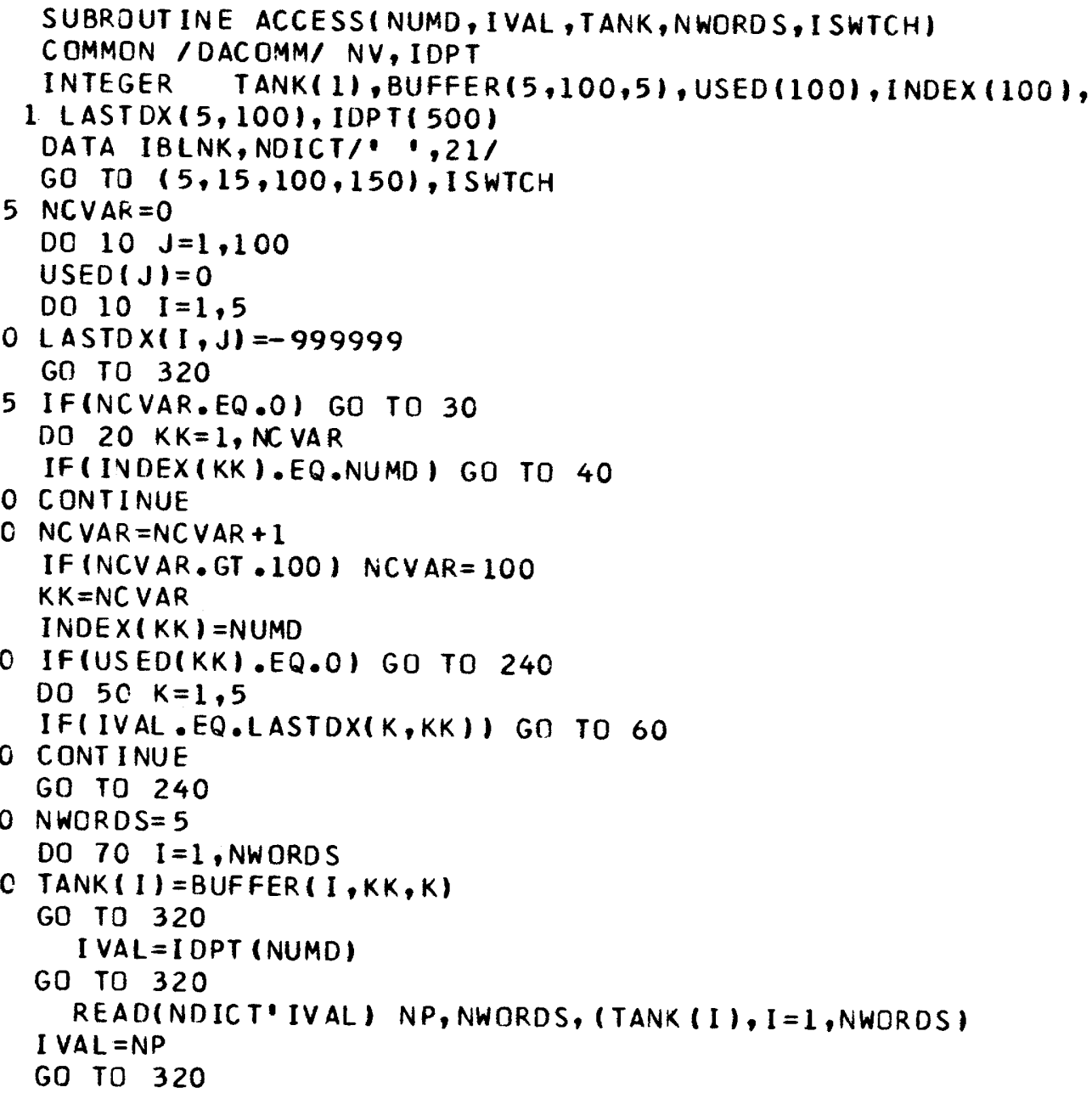

0000051

0000052

0000053

0000054

0000055

0000056

0000057

0000058

0000059

0000060

0000061

0000062

0000063

0000064

0000065

0000066

0000067

0000068

0000069

0000070

0000071

0000072

0000073

0000074

0000075

0000076

0000077

0000078

0000079

0000080

0000081

0000082

0000083

0000084 


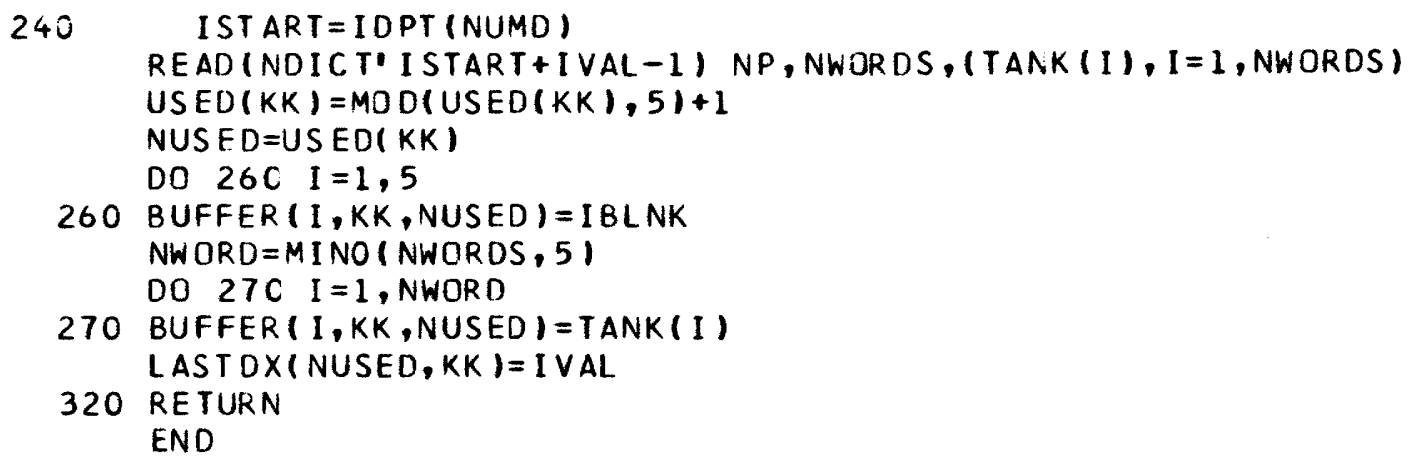

0000085

0000086 0000087 0000088 0000089 0000090 0000091 0000092 0000093 0000094 0000095 0000096 


\section{SUBROUTINE NAME: BDEF}

Purpose: BDEF provides access to the character and multiplechoice dictionaries.

Calling sequence: CALL BDEF (\&n)

Argument:

$\mathrm{n}$-Statement number (in caller) to which a branch is made if an EOF is sensed by KEYBRD.

Subroutines called: KEYBRD, VLIST, ACCESS, PAUSE, BINTYP, IFILE

Common data referenced:

FNAMES, WHICH in / FILNAM/

ITYPE in blank common

Called by: NAME

Error checking and reporting: The user response to a "yes/ no" question is checked. If illegal, a message is typed, and the user is prompted for another response. If an item is selected that is not a multiple-choice or character-type item, a message is typed, and the user is requested to reenter a list of item names.
Program logic: The user is prompted to determine if a list of multiple-choice or character-type values is desired. If the response (obtained from KEYBRD) is " $N$ ", a branch is made to the end of the routine. If the response is "Y," a list of item names is obtained by a call to VLIST. If an EOF is sensed, the nonstandard return (from VLIST) exits via the nonstandard return of BDEF. The data type is determined for each name (TAGS) returned by VLIST. If the type is not multiple choice or character, that message is typed, and the next element of TAGS is considered. If the type is multiple choice, a call to BINTYP is used to obtain the permissible values for printing. If the type is character, calls to ACCESS are made to obtain the possible values. When the second argument of ACCESS is returned as zero, all possible values have been referenced. A programmed pause is generated after each 30 lines of print and after each item in TAGS is processed. Just prior to return (standard or nonstandard), unit 22 (the binary or multiple-choice file) is rewound, and the unit number is reassociated with the current file name via a call to IFILE.

$$
\text { GRASPSOURA E PROGRAM }
$$

\author{
SUBROUTINE BDEF(*) \\ COMMON NAMES, ITYPE, IPTS, IPAD \\ COMMON /FIL NAM/ FNAMES, WHICH, PAD \\ DOUBLE PRECISION LABEL (25), NAMES (500), TAGS (20) \\ INTEGER IPTS $(500)$, FNAMES( 21$)$, WHICH, PAD (4) \\ INTEGER BINL(20), YES, NO, REPLY, BITEM(15,25), ITYPE(500), TANK( 25$)$ \\ EQUIVALENCE (BITEM $(1,1)$, TANK(1)) \\ DATA YES, NO, NBIN/ Y $,, N \cdot, 221$ \\ 10 TYPE 120 \\ 20 TYPE 130 \\ CALL KEYBRD (E110, REPLY, 1$)$ \\ IF (REPLY.EQ.NO) GO TO 100 \\ IF (REPLY.EQ.YES) GO TO 30 \\ TYPE 150 \\ GO TO 20 \\ 30 CALL VLISTIEI10,TAGS, B INL, NUM) \\ DO $90 \mathrm{~N}=1$, NUM \\ INDEX $=B$ I NLI (N) \\ IF (ITYPE(INDEX) -3$) \quad 60,40,70$ \\ 40 TYPE 190 , TAGS(N) \\ CALL ACCESS (INDEX, $K, T A N K, N O M, 3$ ) \\ DO $50 \mathrm{~J}=1,10000$ \\ CALL ACCESS(INDEX, K, TANK, M, 4) \\ TYPF 160, (TANK $(I), I=1, M)$ \\ IF $(K . E Q .0)$ GO TO 90 \\ IF $(M O O(J, 30), N E .0)$ GO TO 50 \\ CALL PAUSE(E100) \\ 50 CONTINUE \\ 60 TYPE 170, TAGS(N) \\ GO TO 90 \\ 70 IF (ITYPE (INDEX).NE.4) GO TO 60 \\ CALL BINTYP (INDEX, LABEL, BITEM, K, M) \\ TYPE 190, TAGS(N) \\ $D O 80 \mathrm{~J}=1, M$ \\ 80 TYPE 180, LABEL $(J),(B I T E M(I, J), I=1, K)$ \\ 0000097 \\ 0000098 \\ 0000099 \\ 0000100 \\ 0000101 \\ 0000102 \\ 0000103 \\ 0000104 \\ 0000105 \\ 0000106 \\ 0000107 \\ 0000108 \\ 0000109 \\ 0000110 \\ 0000111 \\ 0000112 \\ 0000113 \\ 0000114 \\ 0000115 \\ 0000116 \\ 0000117 \\ 0000118 \\ 0000119 \\ 0000120 \\ 0000121 \\ 0000122 \\ C000123 \\ 0000124 \\ 0000125 \\ 0000126 \\ 0000127 \\ 0000128 \\ 0000129 \\ 0000130 \\ 0000131
}


90 CALL PAUSE $(\varepsilon 100)$

0000132 GO TO 10

100 REW IND NB IN

CALL IFILE(NBIN, FNAMES $(16+W H I C H))$

0000133

0000134

RETURN

110 REW IND NB IN

CALL IFILE(NBIN, FNAMES $(16+W H I C H)$

0000135

0000136

RETURN 1

0000137

0000138

0000139

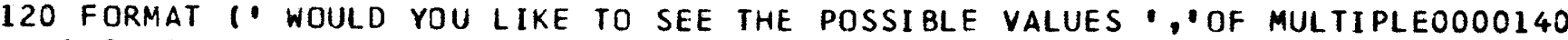

1 CHOICE' $/$ OR CHARACTER TYPE ITEMS?')

0000141

130 FORMAT (" (ENTER Y FOR YES, N FOR NO): ',\$) 0000142

150 FORMAT (" YOUR REPLY WAS NOT UNDERSTOOD.") 0000143

160 FORMAT $(10 X, 12 A 5)$

170 FORMAT $(1 X, A 8, '$ 'IS NOT A MULTIPLE CHOICE OR CHARACTER TYPE ITEM.' $) 0000145$

180 FORMAT $(11 X, A 7,-1,15 A 4)$

190 FORMAT $\left(1 X, A 8,0^{\prime}=\bullet\right)$

END 0000146 0000147 0000148 


\section{SUBROUTINE NAME: BFIND}

Purpose: BFIND is used to look up a double-word-item name in a list of double-word-item names having a given sorted order.

Calling sequence: CALL BFIND(\&n,KEY,IPOST,KEYS, INDEX,K)

Arguments:

$\mathrm{n}$-Statement number (in caller) to which a branch is made if the name KEY is not in the list of names KEYS.

KEY-The double-word item to be looked up.

IPOST-The position in KEYS of the item KEY.
KEYS-The list of double-word names that will be used to look up KEY.

INDEX - Gives the indices of the sorted form of KEYS.

$\mathrm{K}$-The number of elements in KEYS.

Subroutines called: None

Common data referenced: None

Called by: DECOMP, PARSE, RELEXP, VLIST

Error checking and reporting: None

Program logic: The standard binary-search technique is used, which repeatedly halves the interval of search on a sorted list. If the interval of search goes negative, the element is not in the list and the nonstandard return is taken.

\section{GRASP SOURAE PROGRAM}

SUBROUT INE BFIND(*,KEY, IPOST, KEYS, INDEX, K)

0000149

DOUBLE PREC ISION KEY, KEYS(1)

0000150

DIMENSION INDEX $(1)$

$\mathrm{LI}=1$

$L 2=K$

70 IF (L2.LT.L1) RETURN 1

$J=(L L+L 2) / 2$

$I=I N D E X(J)$

IF (DABS (KEY).GT.DABS(KEYS(I))) GO TO 90

IF (DABS(KEY).LT.DABS(KEYS(I)) GC TO 80

GO TO 100

$80 \mathrm{~L} 2=\mathrm{J}-1$

GO TO 70

0000151

0000152

0000153

0000154

0000155

0000156

0000157

0000158

0000159

0000160

$90\lfloor l=J+1$

GO TO 70

0000161

0000162

100 I POST $=I$

0000163

RETURN

0000164

END 


\section{SUBROUTINE NAME: BINIT}

Purpose: BINIT is used to sort a list of double-precision words (NAMES, in this instance) into ascending order and return an array of indices giving the sorted order of the elements in terms of the unsorted order.

Calling sequence: CALL BINIT (KEYS,INDEX,M)

Arguments :

KEYS-The list of double-precision words to be sorted.

INDEX-An array of indicies giving the unsorted order of KEYS.

$\mathrm{M}$ - The number of words in the KEYS and INDEX arrays. Subroutines called: None

Common data referenced: None

Called by: FILES

Error checking and reporting: None

Program logic: An in-place sort is performed using the standard "Shell" technique. The original order of KEYS is overwritten, and the sorted order is returned in INDEX.

DO $10 \quad J=1, M$

$10 \operatorname{INDE} X(J)=J$

$M O=M$

20 IF (MO.LE.1) GO TO 60

$J=4$

IF (MO.GT.15) $\mathrm{J}=8$

$M O=2 *(M O / J)+1$

$K \mathrm{O}=M-M O$

$\mathrm{JO}=1$

0000170

0000171

0000172

0000173

0000174

0000175

0000176

$30 \quad I=J O$

$40 \mathrm{~J}=\mathrm{I}+\mathrm{MO}$

IF (DABS(KEYS(I)).LE.DABS(KEYS(J))) GO TO 50

$\operatorname{KEYS}(I)=K \operatorname{KEYS}(J)$

$\operatorname{KEYS}(J)=K$ TEMP

I TEMP = I NDEX (I)

INDEX (I $)=\operatorname{INDEX}(\mathrm{J})$

INDEX $(J)=$ IT EMP

0000185

0000186

$I=I-M O$

0000187

IF $(I-1) \quad 50,40,40$

0000188

$50 \mathrm{JO}=\mathrm{J} 0+1$

IF $(J O-K O) \quad 30,30,20$

0000189

0000190

0000191

60 RETURN

0000192

END

0000193 
SUBROUTINE NAME: BINTYP

Purpose: BINTYP reads the values (LABEL, BITEM) which can be assumed by the multiple-choice-type item whose number is NUMD.

Calling sequence: CALL BINTYP,(NUMD,LABEL,BITEM, LNG,NUM)

Arguments :

NUMD-Integer specifying a multiple-choice-type item.

LABEL-Set of values (double word) that may be assumed by this item.

BITEM-Set of descriptions corresponding to elements of LABEL.
LNG-Maximum length of a description.

NUM-The number of descriptions.

Subroutines called: IFILE

Common data referenced: FNAMES, WHICH in /FILNAM/

Called by: BDEF, COLPNT, DUMPIT, PNTER, ROWPNT

Error checking and reporting: None

Program logic: Records of the multiple-choice (binary) file are read sequentially until the correct record is obtained. If the file was positioned past the desired record at call time, an EOF is sensed, the file is rewound, and the current multiple-choice file name is reassociated with unit 22 .

\section{GRASPSOURCEAROGRAM}

SUBROUT INE BINTYP(NUMD, LABEL, BITEM, LNG, NUM)

0000194

COMMON/FILNAM/ FNAMES, WHICH, PAD

0000195

DOUBLE PRECISION LABEL (1)

INTEGER FNAMES (21), WHICH,PAD( 4), BI TEM $(15,25)$

0000196

DATA NBIN/22/

300 READ(NBIN, END $=310)$ NAME, NUM, LNG,

A (LABEL $(J),(B I T E M(I, J), I=1, L N G), J=1, N U M)$

0000197

0000198

0000199

0000200

IF(NUMD-NAME) $\quad 310,320,300$

310 REW IND NB IN

0000201

CALL IFILE(NBIN,FNAMES $(16+W H I C H))$

0000202

GO TO 300

0000203

0000204

320 RETURN

0000205

END 
SUBROUTINE NAME: BLIST

Purpose: BLIST returns a list of numbers giving the bit positions of the "ones" in a binary word.

Calling sequence: CALL BLIST (LIST,NUML,ICODE)

Arguments :

LIST-Array of integers giving the bit positions in ICODE which are "ones," counting right to left.

NUML-The number of items in LIST.

ICODE-The binary word to be examined by BLIST.
Subroutines called: None

Common data referenced: None

Called by: COLPNT, DUMPIT, ROWPNT

Error checking and reporting: None

Program logic: ICODE is moved to IDUM. IDUM is successively divided by 2 , and the least significant bit is accessed by the MOD function. If the least significant bit is "one," the position counter is added to LIST.

\section{GRASP SOURCE PROARA M}

SUBROUT INE BLIST(LIST, NUML, ICODE)

0000207

INTEGER LIST(1)

NUML $=0$

$I D U M=I C O D E$

DO $10 \quad I=1,25$

IF (I DUM.EQ.0) GO TO 20

IF (MOD(IDUM,2).EQ.0) GO TO 10

NUML $=$ NUML +1

L IST $($ NUML $)=I$

10 I DUM $=$ IDUM $/ 2$

0000208

0000209

0000210

0000211

0000212

0000213

0000214

0000215

20 RETURN

0000215

END 


\section{SUBROUTINE NAME: COLPNT}

Purpose: COLPNT outputs the values of as many as 20 selected items or expressions. Output is columnar and is directed to the terminal or to a disk data set.

Calling sequence: CALL COLPNT (\&n,NPAGE)

Arguments :

n-Statement (in calling routine) to which a branch is made if the nonstandard return is taken from VLIST (KEYBRD senses EOF).

NPAGE-Number of lines between pauses per page of terminal output.

Subroutines called: KEYBRD, OFILE, VLIST, ACCESS, GETPUT, PAUSE, EVAL, UNCODE, BINTYP, BLIST, PACK

Common data referenced:

POLISH, ICODE, LPS in/EXPRNS/

ITYPE in blank common
Called by: LIST

Error checking and reporting: None

Program logic:

1. The user is asked if he would like the output to go to disk. $\mathrm{His}$ reply is returned by KEYBRD. If affirmative a logical flag is set, and he is prompted for a data-set name. This name is then associated with unit 24 via a call to OFILE.

2. A call to VLIST returns the item names (or expression pointers) that are selected.

3. A call to ACCESS is made to initialize the lookup of character dictionary values.

4. Each record of the selected file is then obtained via GETPUT, and a line (or record) of output is constructed. For numeric data, a format is constructed to maximize the number of significant digits displayed, and the constructed line is printed.

\section{G R A S P SOURA}

SUBROUT INE COLPNT (*,NPAGE)

0000219

COMMON NAMES, ITYPE, IPTS, IDIM

0000220

COMMON /EXPRNS/ POLISH, ICODE, LPS

DIMENS ION ITYPE (500), BITEM $(15,25)$, ITEMS(20), IREC (500), IPTS(500),

IREC(500), NAMES(500), TANK(25), LABEL(25), LIST (25), POLISHI

$215,8), \operatorname{ICODE}(15,8), \operatorname{LPS}(8), \operatorname{IQUAL}(6)$

DOUBLE PRECISION DBLNK, AREA, LINE( 20$)$, NAMES, LABEL, VNAMES( 20$),$

1 FMT (3), FMTS( 8$)$

INTEGER BLANK, TANK, YES

LOGICAL BLNK, TTY

EQUIVALENCE (REC, IREC), (IVAL, VAL), (TANK, LIST), (BLANK, IQUAL)

DATA FMT,FMTS/, 1, , , A1) , 'F8.6 , 'F8.5 ,

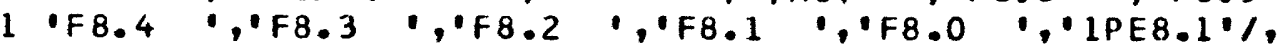

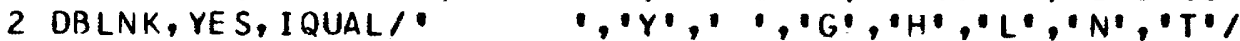

TYPE 100

CALL KEYBRD $(\& 290, I, 1)$

0000221

0000222

0000223

0000224

0000225

0000226

0000227

0000228

0000229

0000230

0000231

0000232

0000233

TTY $=I \cdot N E$. YES

0000234

IF(TTY) GO TO 115

NPAGE $=10000000$

TYPE 105

CALL KEYBRD $(\varepsilon 290$, ITEMS, 5)

0000235

0000236

0000237

0000238

$I=B L A N K$

CALL PACK (ITEMS, I, 5,5)

0000239

0000240

CALL OFILE(24, I)

0000241

KOUNT $=0$

115

CALL VLIST ( \&290, VNAMES, ITEMS, NUM)

0000242

0000243

0000244

IF (NUM.EQ. O) GO TO 280

IF(TTY) TYPE 300, (VNAMES( I), I =1, NUM)

0000245

CALL ACCESS (II, IVAL, TANK,LK, I)

120 CALL GETPUT $(\varepsilon 270$, IREC, 1$)$

0000246

0000247

$K$ OUNT $=$ KOUNT +1

IF (KOUNT.LE.NPAGE) GO TO 130

0000248

0000249

KOUNT $=0$

CALL PAUSE( \&270)

0000250

TYPE 300, (VNAMES ( I), I = 1, NUM)

0000251

0000252

0000253 


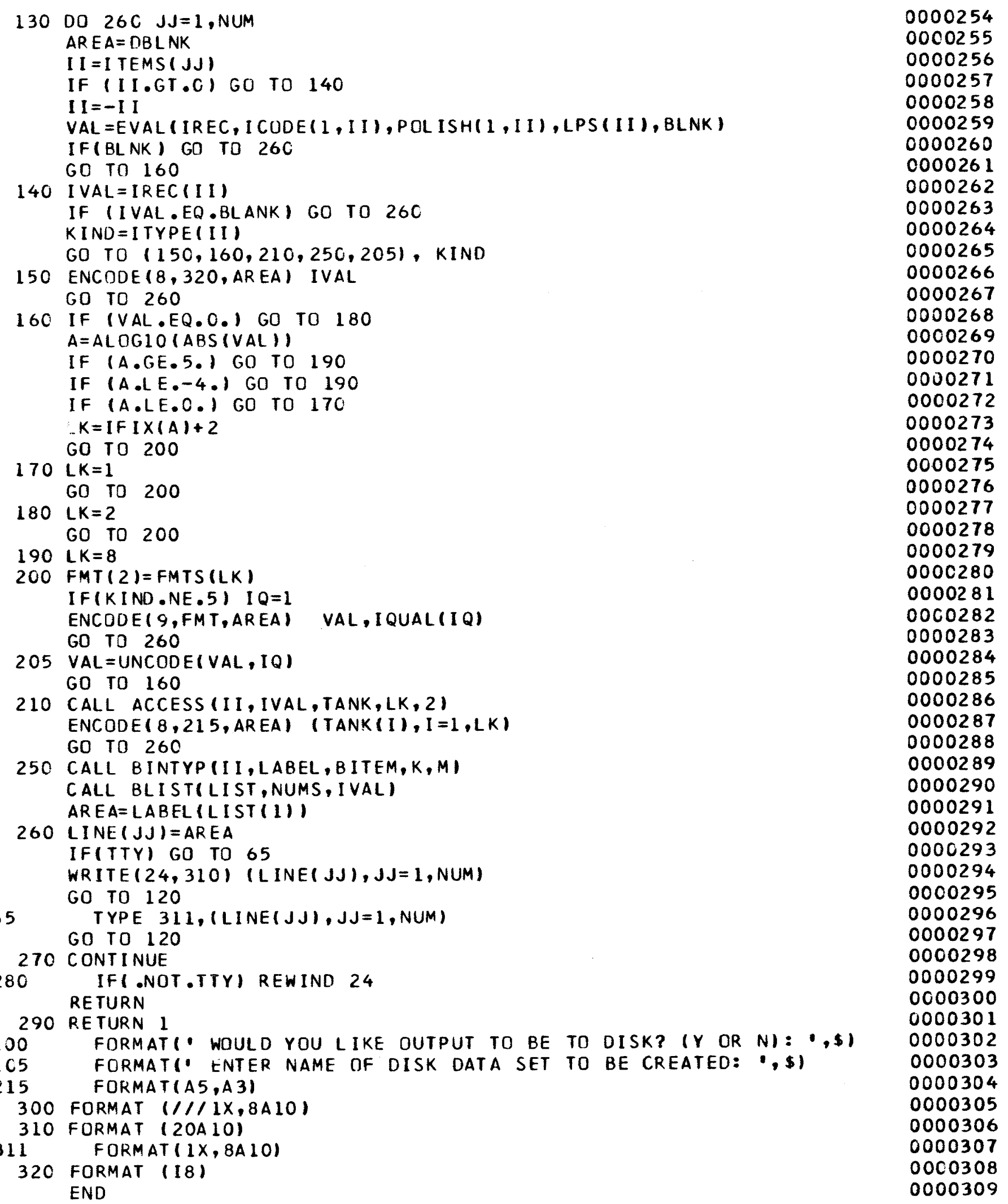


FUNCTION NAME: COMP

Purpose: COMP evaluates a relational expression. The relational operators may be (in FORTRAN notation) EQ, LT, GT, LE, GE, NE, or BE (denoting between). The evaluation is performed on integer, real, or binary-(that is, bit) type data.

Calling sequence: HIT $=$ COMP (IVAR,IVAL,VAR,VAL, ICODE,ISWTCH), where HIT is of type LOGICAL.

Arguments :

IVAR, IVAL-Integer-type arguments to be compared if ISWTCH is 1 .

VAR, VAL-Real-type arguments to be compared if ISWTCH is 2.

ICODE-Encoding of comparison to be made. Assumes values 1 through 7 , respectively, indicating the relations EQ, LT, GT, LE, GE, NE, BE.

ISWTCH-Indicates the type of arguments for the comparison (integer, real, or binary).
Subroutines called: None

Common data referenced: IVALS in / BTWN/

Called by: RETRVE

Error checking and reporting: If ISWTCH is 3 (that is, binary-type arguments), ICODE is tested for 1 or 6 (EQ or NE). If the test fails, a message is typed and COMP returns FALSE as a value.

Program logic:

1. The logical variable NONBLK is set to indicate nonblank operands.

2. If ISWTCH is less than 3 , the two operands are compared according to ICODE. If ICODE is 7 (indicating the between operator), the operands are obtained from IVALS in /BTWN/ by use of IVAL as a pointer to the appropriate set.

3. If ISWTCH is 3 , a bit (binary) comparison is made by examining the IVAL'th bit in IVAR.

$$
\text { GRASP SOURCE PROGRAM }
$$

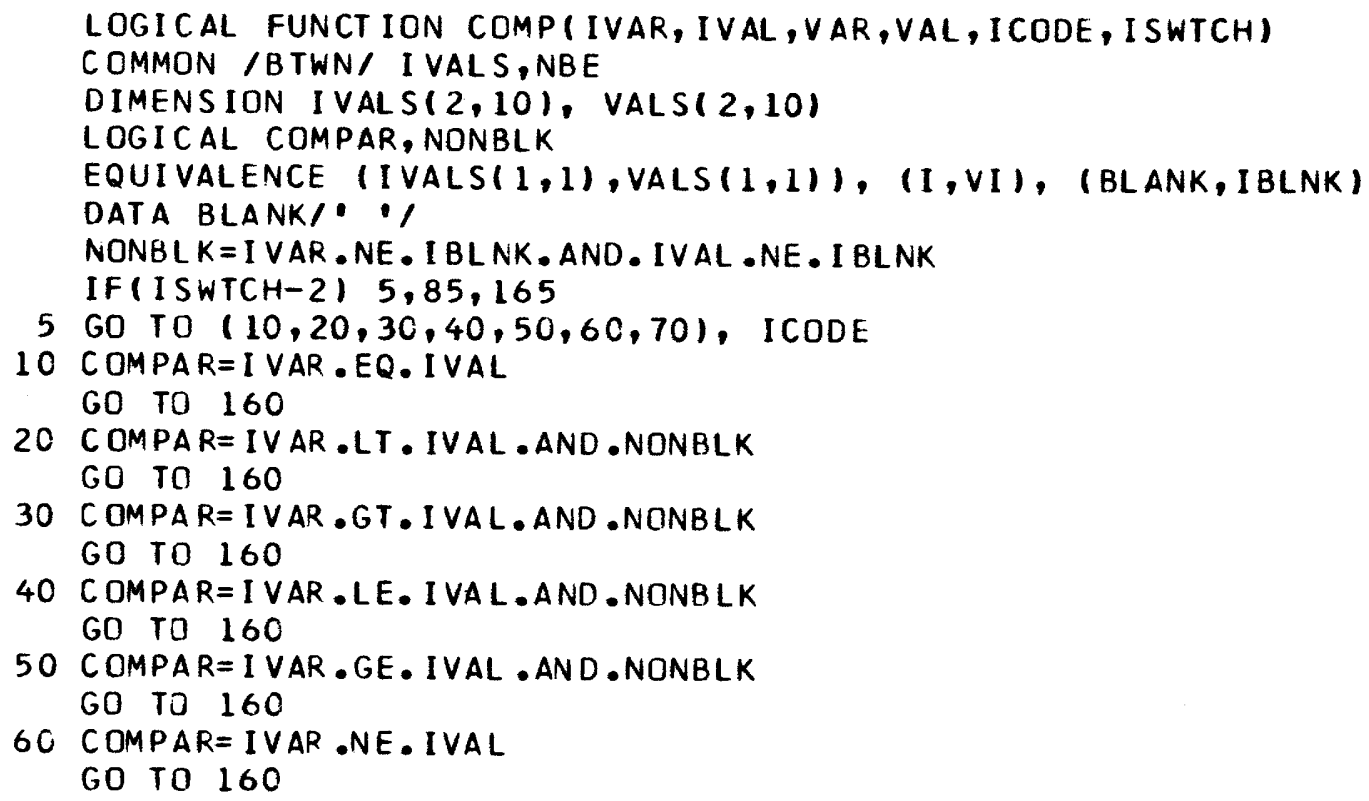

70 COMPAR = I VAR. GE. IVALS (1, IVAL). AND. IVAR. LE. IVALS (2, IVAL) .AND.NONBLK OOOOO331

0000310

0000311

0000312

0000313

0000314

0000315

0000316

0000317

0000318

0000319

0000320

0000321

0000322

0000323

0000324

0000325

0000326

0000327

0000328

0000329

0330332

0000333

0000334

0000335

0000336

0000337

0000338

0000339

0000340

0000341

0000342

0000343

0000344

0000345

0000346 


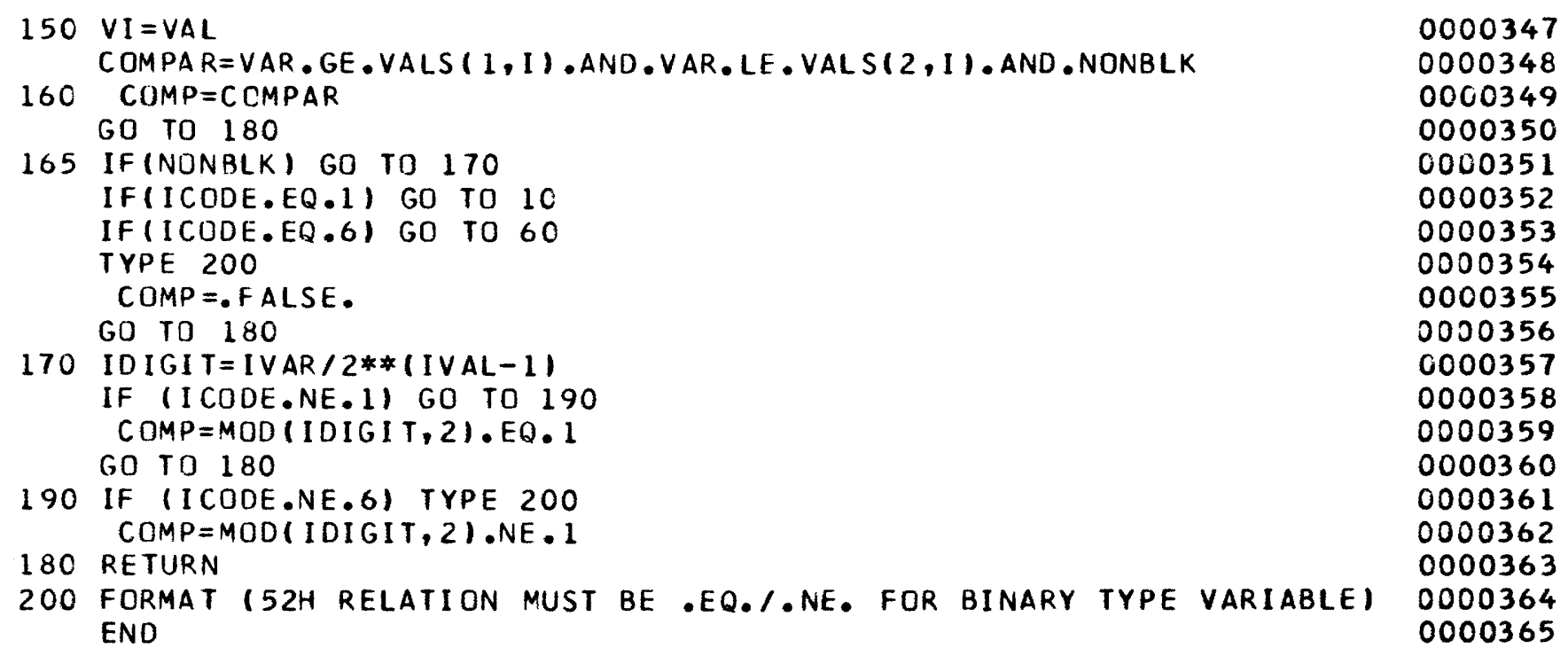

0000347

0000348

0000349

0000350

0000351

0000352

0000353

0000354

0000355

0000356

0000357

0000358

0000359

0000360

0000361

0000362

0000363

0000364

0000365 
SUBROUTINE NAME: CONDS

Purpose: CONDS types out the last set of conditions and logic entered.

Calling sequence: CALL CONDS (NCONDS,LPS)

Arguments:

NCONDS-The number of conditions currently entered.

LPS-The length of the current logical expression.

Common data referenced: EXPR, LOGIC in /INPUT/
Called by: DRIVER

Error checking and reporting: None

Program logic:

1. If any conditions have been entered (that is, NCOND $>0$ ), they are typed out.

2. If a logic expression has been entered (that is, LPS $>0$ ), it is typed out.

$$
\text { G R S P SOURCE PROGRAM }
$$

SUBROUT INE CONDS (NCOND, LPS)

0000366

COMMON /INPUT/ EXPR,LOGIC

0000367

DIMENSION LABELS(26)

DOUBLE PREC ISION EXPR $(4,26), \operatorname{LOGIC}(8)$

0000368

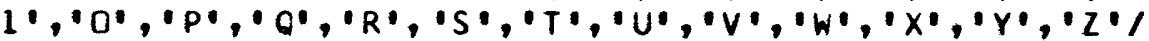

0000369

TYPE 40

IF (NCOND.EQ.0) GO TO 20

0000371

DO $10 \mathrm{~J}=1$, NCOND

$10 \operatorname{TYPE} 50, \operatorname{LABELS}(\mathrm{J}),(\operatorname{EXPR}(I, J), I=1,4)$

GO TO 30

0000372

0000373

0000374

TYPE 60

30 IF (LPS.NE.0) TYPE 70, LOGIC

0000375

RETURN

40 FORMAT $(/ /)$

50 FORMAT $(4 X, A 1, \cdot \cdot, 4 A 10)$

60 FORMAT (" NO CONDITIONS HAVE BEEN ENTERED YET.")

70 FORMAT (" LOGIC STATEMENT IS: ',8A10)

END 


\section{SUBROUTINE NAME: CONDTN}

Purpose: This subroutine is used to control the entry of "conditions" (see RELEXP). Conditions are entered via KEYBRD, decoded via RELEXP, and saved (in character form) in the common area named INPUT.

Calling sequence: CALL CONDTN (\&n,VARS,CODES,VALS, NCOND)

Arguments:

$\mathrm{n}$-Statement number (in caller) to which a branch will be made on a nonstandard return.

VARS-Array of pointers to items referenced in the set of entered conditions.

CODES-Array of integers giving the individual relational operators in the entered conditions.

VALS-Array of values associated with the conditions entered.

NCOND-Counter giving the number of conditions entered.

Subroutines called: KEYBRD, RELEXP, PACK

Common data referenced:
NBE in / BTWN/

EXPR in /INPUT/

Called by: DRIVER

Error checking and reporting: An error flag returned by RELEXP is tested. If set, a request to retype the condition is issued.

Program logic:

1. A letter $(\mathrm{A}-\mathrm{Z})$ is printed as a prompt.

2. The user responise (a condition) is obtained via KEYBRD and passed to RELEXP.

3. If no errors have been detected by RELEXP, the user response is packed into AREA and then moved (first 40 characters) into the INPUT common block.

4. Steps 1-3 are repeated and incrementally counted until an all-blank response is entered. When this occurs, execution resumes at statement 40 , which sets the number of conditions entered. Control returns to the caller.

5. The nonstandard return is taken if an EOF is sensed from the terminal.

\section{GRASPSOURAE PROGRAM}

SUBROUT INE CONDTN(*, VARS, CODES, VALS, NCONDI

0000385

COMMON /BTWN/ IVALS, NBE

COMMON /INPUT/ EXPR, LOGIC

DOUBLE PRECISION EXPR $(4,26)$, AREA(4), LOGIC (8)

0000386

0000387

INTEGER IMAGE $(80), \operatorname{VARS}(1), \operatorname{VALS}(1), \operatorname{CODES}(1)$, IVALS $(2,10)$, PROMPT $(26) 0000389$

LOGICAL ERR

0000390

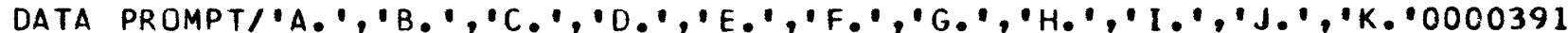

1,'L.', 'M.', 'N.', O.', 'P.', Q.', 'R.', S.', 'T.', U.', 'V.', 'W.', X.',00C0392

L'Y.', Z, I

0000393

$\mathrm{NBE}=0$

$J=1$

10 TYPE 50, PROMPT (J)

0000394

0000395

CALL KEYBRD( 845, IMAGE, 80)

CALL RELEXP $(\varepsilon 40, \operatorname{IMAGE}, \operatorname{VARS}(J), \operatorname{CODES}(J), \operatorname{VALS}(J), E R R)$

0000396

IF (ERR) GO TO 30

0000397

CALL PACK (IMAGE, AREA, 40,40)

DO $20 \quad I=1,4$

$20 \operatorname{EXPR}(I, J)=\operatorname{AREA}(I)$

$J=J+1$

GO TO 10

30 TYPE 60

GO TO 10

0000398

0000399

0000400

0000401

0000402

0000403

0000404

0000405

0000406

40 NCOND $=\mathrm{J}-1$

0000407

RETURN

45 RETURN 1

50 FORMAT $(1 X, A 3, \$)$

60 FORMAT ("RE-TYPE CONDITION')

0000408

0000409

0000410

END 


\section{SUBROUTINE NAME: DECOMP}

Purpose: DECOMP extracts a list of item names and a corresponding list of item numbers from an unpacked character string.

Callng sequence: CALL DECOMP(\&l,\&m,IMAGE,NLIST, LIST,N)

Arguments :

l-Statement (in caller) which will be branched to if an invalid item name is detected.

$m$-Statement (in caller) which will be branched to if the input string contains no item names.

IMAGE-Unpacked input-character string.

NLIST-List of item names (offset by one from LIST).

LIST-A function name followed by a list of item numbers.

$\mathrm{N}$-Total number of itoms in LIST.

Subroutines called: BFIND, PACK

Common data referenced: NAMES, IPTS, IDIM in blank common

Called by: FTNC

Error checking and reporting: BFIND takes the nonstandard return if a name is not found. This causes an error message to be typed and a new input to be requested. If a comma is detected before the list of item names begins, a message is typed and new input is requested.

Program logic: The input-string IMAGE is scanned, a character at a time, via a transition matrix. The list of names is created and the list of item numbers is obtained via calls to BFIND. The following transition matrix is used:

IMAT (4, 3)

$\begin{array}{lcccc} & \text { blank } & \text { comma } & \text { nonblank } & \text { purpose } \\ 1 & \mathrm{f}(0) / 1 & \text { error } & \mathrm{f}(1) / 2 & \text { start function name } \\ 2 & \mathrm{f}(2) / 3 & \text { error } & \mathrm{f}(0) / 2 & \text { find end of function name } \\ 3 & \mathrm{f}(0) / 3 & \mathrm{f}(0) / 3 & \mathrm{f}(3) / 4 & \text { start item name } \\ 4 & \mathrm{f}(2) / 3 & \mathrm{f}(2) / 3 & \mathrm{f}(0) / 4 & \text { find end of item name }\end{array}$

where the $f(i)$ are:

$f(0)$-No operation.

$f(1)$-Mark first character.

- $f(2)$-Mark last character. Pack and find index of item name (that is, find item number).

f(3) -Increment list item counter and mark first character of new list item.

The entire input stream is scanned, and control is returned to caller. Refer to program logic section of LOGEXP for a more complete discussion of transition-matrix parsing.

SUBROUT INE DECOMP(*,*, IMAGE, NLI ST, LIST,N)

0000413

COMMON NAMES, ITYPE, IPTS, IDIM

DIMENSION I TYPE (500), IMAGE (1), LIST (1), IPTS(500), IMAT $(4,3)$

0000414

DOUBLE PRECISION NAMES(500), NAME, DBLNK, NLIST( 5$)$

0000415

EQUIVALENCE (INAME, NAME)

DATA DBLNK, IBLNK,ICOMMA / ' ', ',',

0000416

0000417

OATA IMAT/ $1,23,3,23,2 * 40,3,23,12,2,34,4 /$

0000418

$N=1$

I ROW $=1$

DO $90 \quad I=1,80$

IF (IMAGE (I).EQ.I COMMA) GO TO 10

IF (IMAGE(I).NE.IBLNK) GO TO 20

I VAL = IMAT (I ROW, I)

GO TO 30

10 IVAL $=$ IMAT (IROW, 2)

GO TO 30

20 I VAL $=$ IMAT $(I R O W, 3)$

30 I ROW $=$ MOD (IVAL, 10)

$J O B=I V A L / 10+1$

GO TO $(90,50,70,40,120), \mathrm{JOB}$

0000419

0000420

0000421

0000422

0000423

0000424

0000425

0000426

0000427

0000428

0000429

0000430

0000431

0000432

$40 \quad N=N+1$

$50 \quad$ IC $=\mathrm{I}$

GO TO 90

$70 \quad \mathrm{LC}=\mathrm{I}-1$

NAME $=$ DBLNK

CALL PACK(IMAGE(IC), NAME, LC-IC+ 1,8$)$

0000433

0000434

0000435

0000436

0000437

0000438

IF (N.GT.1) GO TO 80

LI ST $(1)=$ I NAME

GO TO 90

80 CALL BFIND( $\& 100$, NAME, LIST (N), NAMES, IPTS, IDIMI

0000439

0000440

0000441

0000442

NLI ST $(N-1)=N A M E$ 
90 CONTINUE IF (N.EQ.1) RETURN 2

0000444 RETURN

1CO TYPE 140, NAME

110 RETURN 1

120 TYPE 150, I MAGE(1) GO TO 110

140 FORMAT ( $1 X, A 8$, 'IS AN INVALID NAME. RE-ENTER LINE.')

150 FORMAT 1 PUNCTUATION ERROR CAUSED BY ',Al, $\because$ RE-ENTER LINE." END

0000445

0000446 0000447 0000448 0000449 0000450 0000451 0000452 0000453 


\section{SUBROUTINE NAME: DEFINE}

Purpose: DEFINE is used to define the structure and name of a direct-access disk-data set having fixed-length records. Individual records may then be directly accessed by specifying the record number.

Calling sequence: CALL DEFINE (U,S,V,F,PJ,PG)

Arguments:

U-The FORTRAN unit number expressed as an integer.

$\mathrm{S}-\mathrm{The}$ size of the records within the file, expressed as an integer. For formatted records, $\mathrm{S}$ gives the number of characters per record. For unformatted records, $S$ gives the number of words per record.

$\mathrm{V}$-The associated integer variable. The record number which would be accessed next if $\mathrm{I} / \mathrm{O}$ were to continue sequentially is returned as an integer in the associated variable after each random read or write.
F-The name of the file which will be accessed when an I/ $O$ statement references $U$ (the above unit number).

PJ-The project number in octal of the disk area in which the file resides.

$\mathrm{PG}$ - The programmer number in octal of the disk area in which the file resides.

Subroutines called: None

Common data referenced: None

Called by: FILES

Error checking and reporting: None

Program logic: This is a DEC 1070, TOPS-10 system resident routine. It provides the capabilities referred to in the Purpose section above. If the GRASP system is to be implemented on some other main frame, a comparable routine must be written or acquired. No listing is shown here. 


\section{SUBROUTINE NAME: DEFLST}

Purpose: DEFLST outputs the category names to the user and allows him to indicate which categories are of interest.

Calling sequence: CALL DEFLST (\&m,\&n,CAT,NUMC,MC, LIST)

Arguments :

$\mathrm{m}$-Statement (in calling routine) that will be branched to

if no category numbers are given when asked for.

$\mathrm{n}$-Statement (in calling routine) that will be branched to if an EOF is sensed in KEYBRD.

CAT-Contains the category names as read from unit 20 (the "definitions file").

NUMC-Number of categories selected by the user.

MC-Maximum length in words of a category name.

LIST-The category numbers selected.

Subroutines called: IFILE, KEYBRD, LENGTH, RLIST

Common data referenced: FNAMES, WHICH in /FILNAM/

Called by: NAME, DUMPIT
Error checking and reporting: All user response is checked for validity. If errors are detected, the response is requested again.

Program logic:

1. A call to IFILE associates the "definitions" file name with FORTRAN unit 20, and the category names are read from this file.

2. The user is asked if he is interested in all categories. His response is checked against " $\mathrm{Y}$ " or "N." If invalid, an error message is typed, and he is asked to respond again.

3. If the user's response was "Y," LIST is set to all the category numbers and control is returned to the calling routine.

4. If the response was " $N$," the user is asked to enter a list of category numbers of interest.

5. His response, contained in IMAGE, is passed to RLIST to generate the values of LIST.

SUBROUTINE DEFLST(*, *CAT, NUMC, MC, LIST)

0000454

COMMON /FIL NAM/ FNAMES, WHICH, PAD

INTEGER CAT $(8,1)$, LIST(1), IMAGE(30), FNAMES (21), WHICH, PAD (4)

0000455

DATA IYES, NO/'Y', ' $N \cdot /$

CALL IFILE( 20, FNAMES $(8+W H I C H))$

READ (20) NCAT, MC, $((C A T(I, J), I=1, M C), J=1, N C A T)$

25 TYPE 30

CALL KEYBRD $(\varepsilon 100,1,1)$

0000456

0000457

0000458

0000459

IF (I.EQ. IYESI GO TO 40

0000460

0000461

IF(I.EQ.NO) GO TO 5

TYPE 35

GO TO 25

0000462

0000463

0000464

0000465

40 NUMC $=$ NCAT

DO $45 \quad I=1$, NUMC

0000466

0000467

$45 \operatorname{LIST}(I)=I$

GO TO 85

0000468

0000469

5 TYPE 110

DO $10 \mathrm{~J}=1, \mathrm{NCAT}$

0000470

CALL LENGTH (CAT $(1, J), M C, M C L)$

0000471

0000472

10 TYPE 120, J,(CATI I,J), I=1,MCL)

TYPE 130

20 CALL KEYBRD( $\& 100$, IMAGE, 30$)$

CALL RL IST \& \&20, IMAGE, LI ST, NUMC, NCAT )

0000473

0000474

0000475

0000476

IF (NUMC.EQ.0) GO TO 90

85 RETURN

0000477

0000478

90 RETURN 1

100 RETURN 2

30 FORMATI SHALL ALL CATEGORIES BE CONSIDERED? (YES OR NO): $1, \$$ )

0000479

0000480

35 FORMATI' YOUR REPLY WAS NOT UNDERSTOCD.')

0000481

0000482

110 FORMAT (" EACH RECORD HAS BEEN DIVIDED INTO THE FOLLOWING ' 9 GENEROOC0483 IAL CATEGORIES:'/8X,'CAT. \# CAT. NAME'/8X,'-

120 FORMAT $(10 X, 12,4 X, 9 A 5)$ 0000485

130 FORMAT ("ENTER A LIST OF ASCENDING NUMBERS MATCHING ' 'YOUR CATEg0000486 IORIES OF INTEREST $/$ (IE. 1,3,5 OR 2-5) ) END 


\section{SUBROUTINE NAME: DUMPIT}

Purpose: DUMPIT outputs to the terminal those values for all items present in a set of user-selected categories. The values are obtained from a user-selected file.

Calling sequence: CALL DUMPIT

Arguments: None

Subroutines called: OPREP, DEFLST, FINDGP, ACCESS, GETPUT, PAUSE, LENGTH, UNCODE, BINTYP, BLIST

Common data referenced:

NFILE in /IOUNIT/

NAMES, ITYPE in blank common

Called by: DRIVER

Error checking and reporting: None

Program logic:

1. Page size (NPAGE), input file name, and file unit are set up by a call to OPREP.

2. A call to DEFLST is made to determine categories to be dumped.

3. Calls to FINDGP are made to determine pointers (KLIST) for those items in the selected categories. As DEFLST and FINDGP used FORTRAN unit 20, the "definitions" file for the current data base, the unit is rewound.
4. A call to ACCESS is made to initialize character dictionary lookups.

5. Each record in the input file is obtained by GETPUT, the selected items are tested for nonblank characters, and their value is output.

6. The output algorithm is basically as follows:

(a) Determine item type and switch to appropriate code section via a computed GOTO.

(b) If type is integer, print under an I format.

(c) If type is real, print under a $\mathrm{G}$ format.

(d) If type is character, obtain string value by a call to ACCESS and print under an A format.

(e) If type is multiple choice, obtain possible values by a call to BINTYP, and select the actual subset via a call to BLIST. Print this subset under an A format.

(f) If type is qualified real, obtain value and qualifier via a call to UNCODE. Print under a $G$ and $A$ format.

(g) After each line is printed, increment and test KOUNT against page size. If KOUNT is greater than page size, call PAUSE for a programmed pause and reinitialize KOUNT to zero.

(h) After each record has been processed, print a line of asterisks as a record separator.

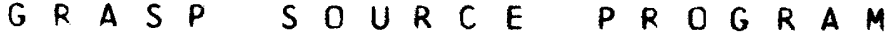

\section{SUBROUT INE DUMPIT}

COMMON NAMES, ITYPE, IPTS, IPAD

0000489

COMMON /I OUNIT/ NFILE, IOF

DIMENSION I TYPE (500), BITEM 15,25$),$ IREC (500), I QUAL (6),

000490

1

REC (500), TANK(25), LABEL(25), LIST(25)

DOUBLE PRECISION LABEL, NAMESI, NAMES 1500$)$

INTEGER TANK,CAT $(8,17), K L I S T(17)$, SELECT(500), IPTS(500)

LOGICAL PNT HOG, NEWCAT, HIT

EQUIVALENCE (REC, IREC), (IVAL, VAL), (TANK,LIST), (IBLNK, I QUAL)

DATA IQUAL/' , 'G', 'H', 'L', 'N', 'T'/

KOUNT $=0$

CALL OPREP $(\varepsilon 200, \varepsilon 205, N P A G E)$

CALL DEFLST $(\varepsilon 200, \varepsilon 200, C A T, N U M C, M C, K L I S T)$

NTOT $=0$

DO $20 \mathrm{~K}=1$, NUMC

CALL FINDGP $(\varepsilon 200, K L I S T(K), I, J, N G, I R E C)$

READ (20)

DO $10 \quad I=1, N G$

NTOT $=$ NTOT +1

0000491

0000492

0000493

0000494

0000495

0000496

0000497

0000498

0000499

0000500

0000501

0000502

0000503

0000504

0000505

0000506

0000507

10 SELECT(NTOT) $=2 *$ IREC(I)

SELECT $(N T O T-N G+1)=S E L E C T(N T O T-N G+1)+1$

0000508

0000509

20 CONT INUE

REWIND 20

CALL ACCESSIII, IVAL, TANK, J, I)

0000510

0000511

0000512

0000513

HIT $=$. FALSE.

$K N T=0$

DO $190 \mathrm{JJ}=1$, NTOT

0000514

0000515

0000516

I I = SELECT $(\mathrm{J} \mathrm{J}) / 2$

0000517

NEWCAT=SELECT(J J).NE . 2*II

0000518

IF (NEWCAT) KNT $=K N T+1$

0000519

PNTHDG = PNTHDG . OR . NEWCAT 
NAMES I = NAMES(I I )

0000521

IVAL = IREC (I I)

IF (IVAL.EQ.IBLNK) GO TO 190

0000522

HIT = .TRUE.

KOUNT $=$ KOUNT +1

IF (KOUNT.LE.NPAGE) GO TO 50

0000523

0000524

0000525

$K O U N T=0$

CALL PAUSE ( 8200$)$

$50 K I N D=I T Y P E(I I)$

IF(.NOT.PNTHDG) GO TO 55

$K L=K L I S T(K N T)$

CALL LENGTH (CAT $(1, K L), M C, M C L)$

TYPE 210, (CAT (I, KL), I =1, MCL)

PNTHDG $=$. FAL SE.

55 GO TO $(60,70,80,170,160), K I N D$

0000526

0000527

0000528

0000529

0000530

0000531

0000532

0000533

0000534

0000535

60 TYPE 230, NAMESI, IVAL

GO TO 190

70 TYPE 240, NAMESI, VAL

GO TO 190

80 CALL ACCESS (II, IVAL, TANK, J, 2$)$

TYPE 250, NAMESI, ( TANK ( I ), I $=1, J)$

GO TO 190

160 VAL $=U N C O D E(V A L, I Q)$

TYPE 240, NAMES I, VAL, IQUAL (IQ)

GO TO 190

170 CALL BINTYP (I I LABEL, B ITEM, K, M)

$K$ OUNT $=$ KOUNT +1

TYPE 250, NAMESI

CALL BLISTILIST, NUMS, IVAL)

DO $180 \quad I=1$, NUMS

$\mathrm{J}=\mathrm{L}$ I ST(I)

180 TYPE 260, LABEL $(J),(B I T E M(L, J), L=1, K)$

190 CONTINUE

IF (HIT) TYPE 220

GO TO 40

200 REWIND NFILE

REWIND 20

205 RETURN

210 FORMAT (' CATEGORY: ',8A5)

220 FORMAT $(1 X, 318 H * * * * * * *))$

$23 C$ FORMAT $(2 X, A 8,1 X, I 9)$

240 FORMAT $(2 X, A 8,1 X, 1 P G 12,5, A 1)$

250 FORMAT $(2 X, A 8,1 X, 12 A 5 / 11 X, 12 A 5)$

260 FORMAT $(5 X, A 8,15 A 4)$

END

0000536

0000537

0000538

0000539

0000540

0000541

0000542

0000543

0000544

0000545

0000546

0000547

0000548

0000549

0000550

0000551

0000552

0000553

0000554

0000555

0000556

0000557

0000558

0000559

0000560

0000561

0000562

0000563

0000564

0000565 


\section{FUNCTION NAME: EVAL}

Purpose: By using a particular set of values as operands, EVAL evaluates a previously parsed Reverse-Polish-form arithmetic expression.

Calling sequence: VAL $=$ EVAL (VALUES,TYPE,POLISH, I,BLNK)

Arguments:

VALUES-Set of operand values.

TYPE, POLISH-Arrays containing the encoded ReversePolish form of the expression to be evaluated. The encoding is as follows: Let ITY be the I'th element of TYPE. If ITY $=0$, the I'th element of POLISH is a numeric constant. If ITY $>0$, ITY is an index to the array VALUES. If ITY $<0$, ITY corresponds to an arithmetic operator or function.

I-Gives the length of the arrays TYPE and POLISH.

BLNK-Logical variable set to TRUE if any operand with a blank value is sensed.

Subroutines called: UNCODE

Common data referenced: ITYPE in blank common
Called by: COLPNT, ROWPNT

Error checking and reporting:

1. Division by zero attempted.

2. Log of a nonpositive value attempted.

3. Square root of a negative value attempted.

Program logic: A push-down stack technique is used to evaluate the Reverse-Polish string contained in TYPE and POLISH. TYPE is scanned, an element at a time, pushing operand values down on the stack until an operator is sensed. Either the top or topmost two stack elements are then used as operands resulting in a new topmost-stack element which is the resulting value of the operator. Unary operators/functions (absolute value, ABS; square root, SQRT; logarithm, LOG; square, SQR; ten exponent, TEN : minus, -) operate on the top stack element. Binary operators $(+,-, *, /)$ operate on the topmost-two stack elements. After all elements of TYPE have been processed, the stack should have one value in it. This value, the result, is returned. If a blank operand value is detected, the flag BLNK is turned on and zero is returned.

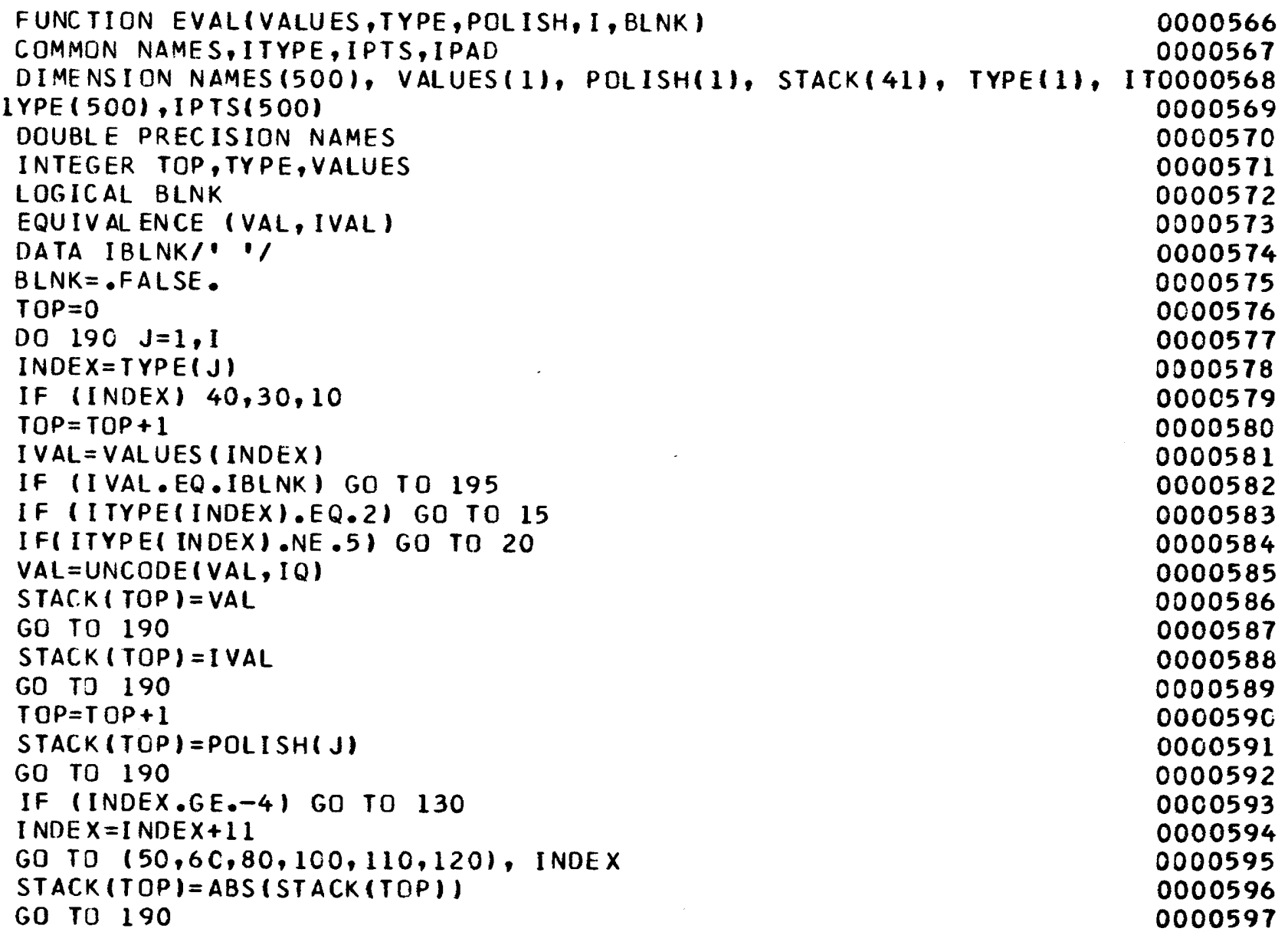


$60 \mathrm{TV}=\mathrm{STACK}(\mathrm{TOP})$

IF (TV.GE.O.) GO TO 70

TYPE 230

GO TO 200

70 STACK $(T O P)=S Q R T(T V)$

GO TO 190

$80 T V=S T A C K(T O P)$

IF (TV.GT.0.) GO TO 90

TYPE 220

GO TO 200

90 STACK $(T O P)=A L O G 1 O(T V)$

GO TO 190

100 STACK $(T O P)=S T A C K(T O P) * * 2$

GO TO 190

$110 \operatorname{STACK}(T O P)=10 . * * \operatorname{STACK}(T O P)$

GO TO 190

$120 \operatorname{STACK}($ TOP $)=-$ STACK $($ TOP $)$

GO TO 190

130 INDEX $=$ INDEX +5

$V T=S T A C K(T O P)$

$T O P=T O P-1$

GO TO $(150,140,180,170)$, INDEX

140 STACK $(T O P)=S T A C K(T O P) * V T$

GO TO 190

150 IF (VT.NE.0.0) GO TO 160

TYPE 240

GO TO 200

160 STACK (TOP) = STACK $($ TOP $) / V T$

GO TO 190

$170 \operatorname{STACK}(T O P)=\operatorname{STACK}(T O P)+V T$

GO TO 190

180 STACK $($ TOP $)=S T A C K(T O P)-V T$

190 CONT INUE

IF (TOP .NE. 1 ) GO TO 200

$E V A L=S T A C K(1)$

GO TO 210

195 BLNK = .TRUE.

200 EVAL $=0.0$

210 RETURN

220 format ("attempted to take log of a zero or neg. Value.")

230 FORMAT 1" ATTEMPTED TO TAKE SQRT OF A NEGATIVE VALUE.')

240 FORMAT 1 ' DIVIDE BY ZERO ATTEMPTED.')

END 
SUBROUTINE NAME: FDRIVE

Purpose: FDRIVE provides for the single-pass computation of all implemented mathematical or statistical functions. Using this routine to make all calls to the subroutines corresponding to implemented functions simplifies the addition of new functions.

Calling sequence: CALL FDRIVE (ISWTCH)

Arguments:

ISWTCH-Integer code passed to called subroutines indi- cating phase 1,2 , or 3 . The phases are initialization, body, and postprocessing.

Subroutines called: MEAN, FIT

Common data referenced: None

Called by: FTNC

Error checking and reporting: None

Program logic: This routine merely makes calls to the functions selected by the user via computed GOTO.

SUBRUUT INE FDR IVE(ISWTCH)

COMMON /FTNCOM/ TAGS, IREC, ARGS, NARGS, IFTN, NFTN

0000641

DOUBLE PRECISION TAGS $(5,5)$

INTEGER ARGS $(6,5), \operatorname{NARGS}(5), \operatorname{IFTN}(5), \operatorname{IREC}(500)$

0000642

DO $30 \mathrm{~J}=1$, NFTN

0000643

$I=I F T N(J)$

GO TO $(10,20,30,30,30,30)$, I

10 CALL MEAN (J, I SWTCH)

GO TO 30

20 CALL FIT (J, ISWTCH)

30 CONT INUE

0000644

0000645

0000646

0000647

0000648

0000549

RETURN

0000650

0000651

END 


\section{SUBROUTINE NAME: FILES}

Purpose: FILES prompts for and accepts a data-base name. After the name has been provided and verified, the Mask file of data-base characteristics associated with that name is read. Some preliminary processing is done on these characteristics.

Calling sequence: CALL FILES (\&n)

Argument:

$\mathrm{n}$-Statement (in caller) to which a branch is made if the nonistandard return from KEYBRD is taken (namely, an EOF is sensed).

Subroutines called: KEYBRD, IFILE, BINIT, DEFINE, PACK

Common data referenced:

NAMES, ITYPE, IPTS, IDIM in blank common.

MASTER, MASK, DFILE, BFILE, NUMF, NUMI, IDIMS in /FILNAM/.

I, IDPT in /DACOMM/.

Called by: DRIVER
Error checking and reporting: The data-base name entered by the user is compared with the list (MASTER) of those available. If the data-base name is not recognized, an error message is typed.

Program Logic:

1. A data-base name is prompted for and accepted via KEY$B R D$, and is then packed into FILEID and compared with the list (MASTER) of available names. If not found, an error message and the list of available names is typed followed by a prompt for another name.

2. Once the data base has been established, its corresponding Mask file is read to fill the blank common area.

3. The item names from MASK are sorted via a call to BINIT and the array of pointers (IPTS) to the sorted NAMES is returned from BINIT.

4. NAMES is restored to its unsorted form and DEFINE is called to associate the name of the direct-access character dictionary with unit 21. IFILE is then called to associate the name of the multiple-choice file with unit 22 .

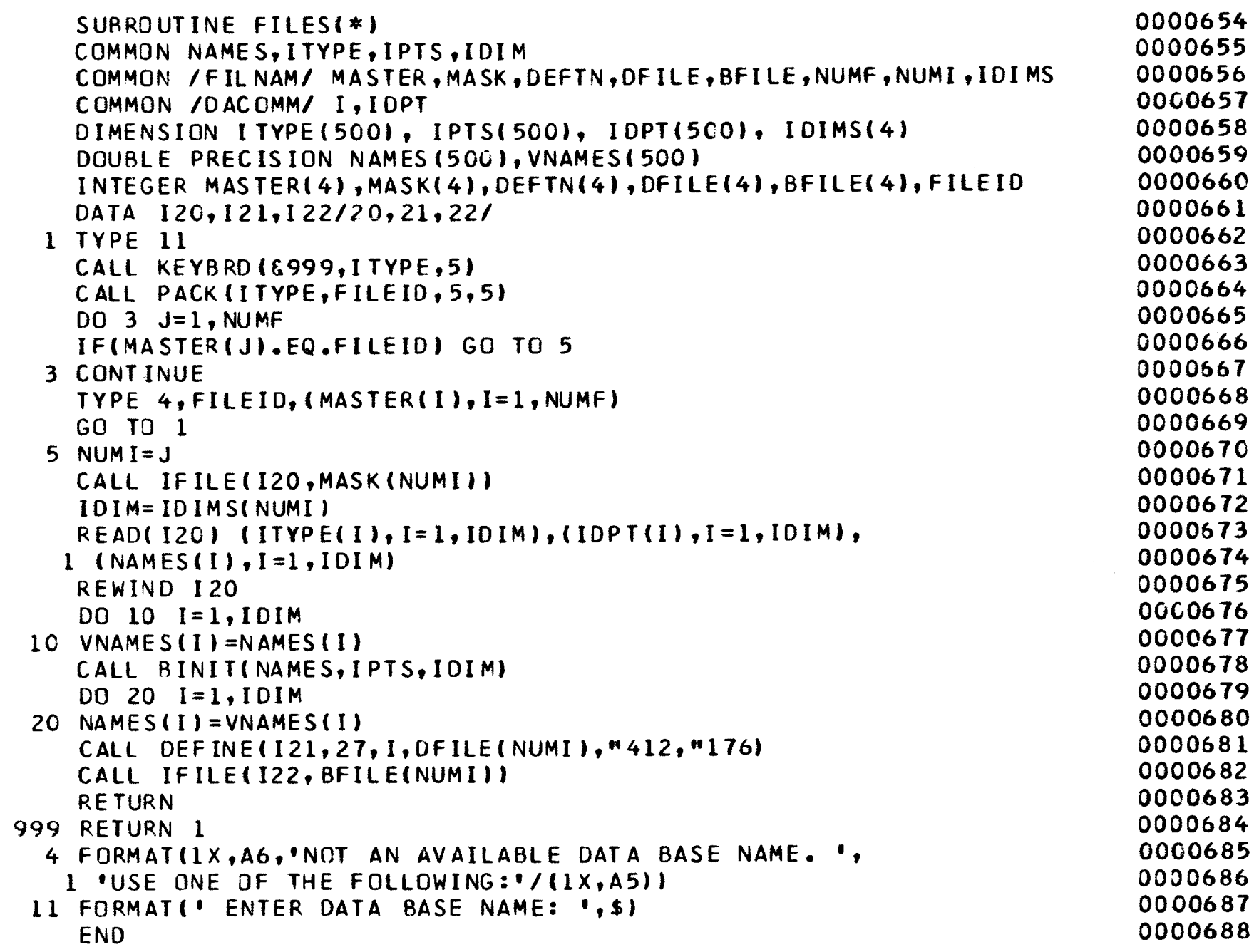




\section{SUBROUTINE NAME: FIND}

Purpose: FIND is used to look up a word in a "hash coded" table and return a code associated with its position. The "Linear quotient" technique, as described by Bell and Kaman (1970), is used.

Calling sequence: CALL FIND (\&n,ISYMBL,KODE,CHARS, CODES,M)

Arguments :

$\mathrm{n}$-Statement (in caller) to which a branch is taken if ISYMBL is not in CHARS.

ISYMBL-Word to be looked up.

KODE-Integer from the position in CODES corresponding to the position of ISYMBL in CHARS.

CHARS-"Hash coded" table of words to be looked up.
CODES-Table corresponding to CHARS giving the original position of the word to be looked up.

M-Table size (a prime number) for CHARS and CODES. Subroutines called: None

Common data referenced: None

Called by: LOGEXP, PARSE

Error checking and reporting: If ISYMBL is not in CHARS, the nonstandard return is taken.

Program logic: An initial location $I$ and displacement $\mathbf{J}$ is determined from the internal machine representation of the word stored in ISYMBL. Initial and successive probes to CHARS are made until an empty location is probed. If ISYMBL is not in CHARS, the nonstandard return is taken. If ISYMBL is found in CHARS, the corresponding element of CODES is returned in KODE.

\section{G R A S P S OURAE PR O G RA M}

SUBROUT INE FIND(*, ISYMBL, KODE, CHARS, CODES,MI

0000689

INTEGER CHARS $(1), \operatorname{COOES}(1)$, FILLER

0000690

DATA FILLER/ V VOID /

$L=I A B S$ (ISYMBL)

0000691

$J=L / M$

0000692

$I=L-M * J$

0000693

IF $(M O D(J, M), E Q . O) \quad J=1$

0000694

0000695

5C ICHAR $=$ CHARS $(I+1)$

IF (ICHAR •EQ. ISYMBL) GO TO 60

0000696

IF (ICHAR .EQ.FILLER) RETURN I

$I=M O D(I+J, M)$

0000698

GO TO 50

0000699

$60 \mathrm{KDDE}=\operatorname{CODES}(1+1)$

0000700

RETURN

0000701

END 


\section{SUBROUTINE NAME: FINDGP}

Purpose: FINDGP positions the file associated with FORTRAN unit 20 to a particular record paid associated with a category. Data concerning that category are returned to the caller.

Calling sequence: CALL FINDGP(\&n,KNUM,NUM,MAXL, NG,GROUP)

Arguments :

$\mathrm{n}$-Statement number (in caller) to which control is passed if an EOF is sensed on unit 20.

KNUM-The category number to which the file will be be positioned.

NUM-The number of descriptions in this category.

MAXL-The maximum length (in words) for a description. NG-Number of items referred to in this category.

GROUP-List of item pointers associated with this category.
Subroutines called: IFILE

Common data referenced: FNAMES, WHICH in/FILNAM/

Called by: NAME, DUMPIT

Error checking and reporting: None

Program logic:

1. The next record on unit 20 is read, giving a category number KK and values for the last four arguments.

2. $\mathrm{KK}$ is tested against $\mathrm{KNUM}$.

(a) If $\mathrm{KK}<\mathrm{KNUM}$, record pairs are skipped up to the one of interest.

(b) If $\mathrm{KK}=\mathrm{KNUM}$, return.

(c) If $\mathrm{KK}>\mathrm{KNUM}$, rewind unit 20 and reassociate it with the correct name via a call to IFILE having FNAMES and WHICH as arguments. Next, reposition the file to the number pair of interest.

\section{G R S P SOURCE PROGRAM}

SUBROUT INE FINDGP(*, KNUM, NUM, MAXL,NG, GROUP)

0000704

COMMON/FILNAM/ FNAMES, WHICH,PAD

0000705

INTEGER GROUP (1), FNAMES (21), WHICH,PAD (4)

0000706

DATA NDEF / $20 /$

30 READ (NDEF, END=90) KK,NUM, MAXL,NG, (GROUP(I), I=1,NG)

0000707

IF $(K K-K N U M) \quad 40,80,70$

0000708

$J=K N U M-K K-1$

50 READ (NDEF)

IF $(\mathrm{J} . \mathrm{LT} .1)$ GO TO 30

0000709

0000710

DO $60 \quad I=1, J$

0500711

READ (NDEF)

0000712

0000713

60 READ (NDEF)

0000714

GO TO 30

0000715

0000716

70 REWIND NDEF

0000717

CALL IFILE(NDEF, FNAMES $(8+W H I C H))$

0000718

$J=K N U M$

0000719

GO TO 50

0000720

80 RE TURN

90 RETURN 1

0000721

END 


\section{SUBROUTINE NAME: FIT}

Purpose: FIT is used to provide a least-square linear fit between two items within a selected file.

Calling sequence: CALL FIT(J,ISWTCH)

Arguments :

$\mathrm{J}$-Pointer used to retrieve argument values from the common area /FTNCOM/.

ISWTCH-Switch indicating which of three parts (initialization, body, postprocessing) of the code is to be executed.

Subroutines called: UNCODE

Common data referenced:

ITYPE in blank common

TAGS, IREC, ARGS, NARGS, in /FTNCOM/

Called by: FDRIVE

Error checking and reporting: If two arguments are not given, an appropriate error message is typed and return is immediate. If the computation would yield an infinite slope, that message is typed.

Program logic: The value of ISWTCH determines which of three sections of the code is executed. If ISWTCH $=1$, the number of arguments is checked, and various sums are set to zero. If ISWTCH $=2$, the error flag is tested. If not set, the appropriate values of the arguments are tested for nonblank. If nonblank, they are added to the appropriate sums. If ISWTCH $=3$, the slope, intercept, and correlation coeffcient are calculated (if possible), using the sums previously determined. They are then printed out using the appropriate item names. All summations and least-square determinations are done using double-precision arithmetic to minimize the round-off effects introduced by performing the computation using only one pass on the data.

Assuming the function FIT X,Y had been issued, the calculations are performed using the following formula:

$$
\begin{aligned}
& D=N \cdot \Sigma X^{2}-\Sigma X \cdot \Sigma X \\
& B_{1}=(N \cdot \Sigma X Y-\Sigma X \cdot \Sigma Y) / D \\
& B_{0}=\left(\Sigma Y-B_{1} \cdot \Sigma X\right) / N \\
& C=D \cdot B_{1} / V D \cdot\left(N \cdot \Sigma Y^{2}-\Sigma Y \cdot \Sigma Y\right)
\end{aligned}
$$

where:

$B_{\mathrm{o}}=$ intercept,

$B_{1}=$ slope,

$C=$ correlation coefficient, and

$N=$ number of nonblank $\mathrm{X}, \mathrm{Y}$ points.

\section{G R A P SOURAE PROGRA M}

SUBROUT INE FIT(J,ISWTCH)

COMMON NAMES, ITYPE, I PTS, IPAD

COMMON /FTNCOM/ TAGS, IREC, ARGS, NARGS, IFTN,NFTN

DOUBLE PREC IS ION NAMES $(500)$, TAGS $(5,5)$, SUMX, SUMY, SUMXY,

1 SUMXS, SUMY S,D,FN,VI,V2

INTEGER IPTS(500)

INTEGER ARGS $(6,5)$, NARGS(5), IFTN(5), ITYPE(500), IREC (500)

LOGICAL ERR

EQU IVAL ENCE (IVAL 1, VAL 1), (IVAL2, VAL2)

DATA IBLNK/ '/

IF(ISWTCH-2) $2,4,6$

$2 E R R=N A R G S(\mathrm{~J}) \cdot N E \cdot 2$

IF (ERR) GO TO 20

$N=0$

SUMX $=0.000$

SUMY $=0.000$

SUM XY $=0.0 D O$

SUMXS $=0.000$

SUM $Y S=0.000$

GO TO 30

4 IF (ERR) GO TO 30

IVAL $1=I \operatorname{REC}(\operatorname{ARGS}(2, \mathrm{~J}))$

IF (IVALI.EQ.IBLNK) GO TO 30

I $V A L 2=I \operatorname{REC}(\operatorname{ARGS}(3, \mathrm{~J}))$

IF (IVAL2.EQ.IBLNK) GO TO 30

$V 1=I V A L I$

$\checkmark 2=I V A L 2$

IF (I TYPE (ARGS $(2, J)), E Q .2) \quad V I=V A L I$

IF (ITYPE (ARGS $(3, \mathrm{~J}) . E Q .2) \vee 2=V A L 2$

I F (I TYPE (ARGS $(2, J)), E Q .5)$ VI=UNCODE (VALI, I Q)

IF (ITYPE $(A R G S(3, J)) . E Q .5) \quad V 2=\operatorname{UNCODE}(\operatorname{VAL} 2, I Q)$

0000724

0000725

0000726

0000727

0000728

0000729

0000730

0000731

0000732

0000733

0000734

0000735

0000736

0000737

0000738

0000739

0000740

0000741

0000742

0000743

0000744

0000745

0000746

0000747

0000748

0000749

0000750

0000751

0000752

0000753

$N=N+1$

0000754

SUM $X=\operatorname{SUM} X+V 1$

0000756 
SUMXS $=$ SUMXS $+V 1 * V 1$

0000757

SUMXY $=S U M X Y+V I * V 2$

0000758

SUMY $=S U M Y+V 2$

0000759

SUMY S = SUMYS +V $2 * V 2$

0000760

GO TO 30

0000761

6 IF (ERR) GO TO 30

0000762

$F N=N$

$D=F N *$ SUMXS- SUMX* SUMX

0000763

If $(D . E Q \cdot 0.0 D O)$ GD TO 10

0000764

$B 1=(F N * S U M X Y-S U M X *$ SUMY $) / D$

0000765

$B O=(\operatorname{SUM} Y-B) * S U M X) / F N$

0000766

(SUMY) I

TYPE 40, N, TAGS $(1, \mathrm{~J}), \operatorname{TAGS}(2, \mathrm{~J}), \mathrm{B1}, \mathrm{BO}, \mathrm{CC}$

0000767

GO TO 30

10 TYPE $50, \mathrm{~N}$

0000769

0000770

0000771

GO TO 30

0000772

20 TYPE 60

0000773

30 RE TURN

0000774

40 FORMAT 0000775

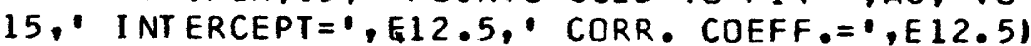

50 FORMAT 1 UNABLE TO CALCULATE FIT WITH', I5.' POINTS')

60 FORMAT ("THE FIT FUNCTION MUST HAVE 2 ARGUMENTS") 0000777 END 
SUBROUTINE NAME: FTNC

Purpose: This routine acts as a driver for the processing of the FUNCTION command. It accepts (via KEYBRD) the function names and arguments, sets up system-required input-file information, and is then used to supply input records to the routines that actually calculate the requested functions.

Calling sequence: CALL FTNC $(\& n)$

Argument:

$\mathrm{n}$-Statement (in caller) to which a branch is made if the nonstandard return (EOF) from KEYBRD is taken.

Subroutines called: KEYBRD, OBEY, DECOMP, FDRIVE, GETPUT, PACK

Common data referenced:

FNAMES, WHICH in /FILNAM/

TAGS, IREC, ARGS, NARGS, IFTN, NFTN in /FTNCOM/ NFILE in /IOUNIT/

Called by: DRIVER

Error checking and reporting: Function names entered by the user are checked against a list of those available. If an invalid function name is entered, that message is typed.

Program logic:

1. A prompted input-file name is obtained via KEYBRD, packed via a call to PACK, and associated with the FORTRAN input unit number via OBEY.

2. A list of the implemented function names is typed along with a request to enter the names of desired functions and their corresponding arguments.

3. As each function name is entered (via KEYBRD), it and its argument names are identified via DECOMP.

4. After the names have been entered and identified, a call to FDRIVE using an argument of 1 is issued to perform initialization.

5. Each record of the selected file is obtained via GETPUT and processed via a call to FDRIVE using an argument of 2 .

6. Finally, a call to FDRIVE using an argument of 3 is made to accomplish any wrap-up processing associated with the selected function, and the input file is rewound.

$$
\text { GRASP SOURCE PROGRAM }
$$

SUBROUTINE FTNC(*)

COMMON /FILNAM/ FNAMES, WHICH, PAD

COMMON /FTNCOM/ TAGS, IREC, ARGS, NARGS, IFTN, NFTN

0000781

COMMON /IOUNIT/ NFILE, IPAD

DOUBLE PRECISION TAGS $(5,5)$

INTEGER DFAULT, FILE, DBLNK, FNAMES (21), WHICH, PAD(4), IFTN(5),

0000782

0000783

IEQUATE (4), FTNS( 5$)$, ARGS $(6,5)$, I MAGE (80), NARGS (5), IREC (500),

0000784

0000785

0000786

2 PROMPT( 5$)$

LOGICAL ANY, GOOD

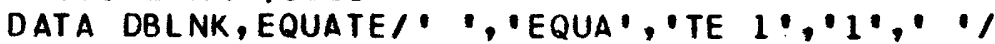

DATA IMPLTD,FTNS/ 2, MUEAN $^{\circ}, \mathrm{FIT}^{\prime}, 3 *^{\circ}, \%$

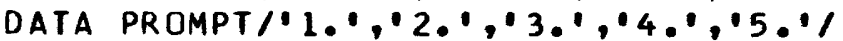

EQU IV AL ENCE (EQUATE( 4 ), FILE)

TYPE 100

DFAUL T=FNAMES $(W H I C H)$

CALL KEYBRD ( \&90, IMAGE, 5 )

CALL PACK(IMAGE,FILE, 5,5$)$

0000787

0000788

0000789

0000790

0000791

0000792

0000793

0000794

0000795

0000796

0000797

IF (FILE.EQ.DBLNK) FILE=DFAULT

CALL OBEY (\&85,EQUATE, 4)

TYPE 120, (FTNS (I), I =1, IMPLTD)

0000798

0000799

TYPE 130

0000800

0000801

10 NFTN $=1$

20 TYPE 150, PROMPTINFTN)

0000802

CALL KEYBRD ( 890, IMAGE, 80)

CALL DECOMP $(\varepsilon 20, \varepsilon 30, \operatorname{IMAGE,TAGS}(1, N F T N), \operatorname{ARGS}(1, N F T N), N A R G)$

0000803

0000804

NARGS $(N F T N)=N A R G-1$

NFTN $=$ NFTN+1

IF INFTN-IMPLTD-1) $20,30,30$

30 NFTN $=$ NFTN -1

IF (NFTN.EQ.0) RETURN

0000805

0000806

0000807

0000808

0000809

$A N Y=$. FALSE .

DO $60 \mathrm{I}=1, \mathrm{NFTN}$

GOOD $=$. TRUE.

0000810

0000811

INAME $=A R G S(1, I)$

0000812

0000813

DO $40 \mathrm{~J}=1$, IMPLTD

0000814

IF (INAME.EQ.FTNS(J)) GO TO 50 
40 CONTINUE

0000817

TYPE 160, INAME

$J=6$

$G O O D=. F A L S E$.

0000818

0000819

0000820

$50 \quad \operatorname{IFTN}(I)=J$

60 ANY $=A N Y . O R, G 00 D$

IF (.NOT.ANY) GO TO 10

0000821

CALL FDRIVE (1)

70 CALL GETPUT ( 880, IREC, 1$)$

0000822

0000823

0000824

CALL FDRIVE(2)

GO TO 70

80 CALL FDRI VE (3)

REW IND NFILE

0000825

0000826

0000827

0000828

8590 RETURN

100 FORMAT $("$ ENTER NAME OF FILE: $\because \$ 1$

120 FORMAT (" FUNCTIONS AVAILABLE AT THIS TIME ARE: $/ 1 X, 5 A 8$ )

0000829

0000830

0000831

0000832

130 FORMAT ('ENTER FUNCTION NAMES AND CORRESPONDING ARGUMENTS. ") 0000834

150 FORMAT $(1 X, A 3, \$)$

0000834 160 FORMAT (IX,A5,' IS NOT AN AVAILABLE FUNCTION AND HAS ', 'BEEN IGNORO000836
IED.') 


\section{SUBROUTINE NAME: GETPUT}

Purpose: GETPUT is used to read and unpack a record from the current input file, or to write the last-packed record obtained from the current input file on the current output file.

Calling sequence: CALL GETPUT(\&n,IREC,ISWTCH)

Arguments :

n-Statement (in caller) to which a branch is made if an EOF is sensed on the current input file.

IREC-Contains the expanded record from the current input file.

ISWTCH-Switch indicating whether record is to be read or written.

Subroutines called: None

Common data referenced: IN, IOUT in /IOUNIT/

Called by: COLPNT, DUMPIT, FTNC, RETRVE, ROWPNT

Error checking and reporting: None

Program logic:

1. If $\mathrm{ISWTCH}=1$, the next input record is read into TANK on the unit referenced by IN in /IOUNIT/. If an EOF is sensed, the nonstandard return is taken. If ISWTCH $>1$, the last-read input record is output on the unit referenced by IOUT in /IOUNIT/.

2. The first word of TANK is assumed to be of type INTEGER and corresponds to the first word of IREC. The last 2 bits contain the type of the next word in TANK. TYPE values are:

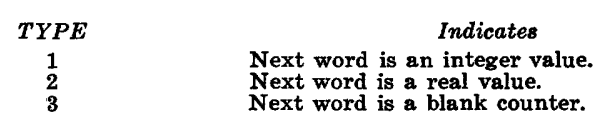

The value part of types 1 and 3 is in the leading bits (that is, 2-bit truncation).

3. If the word is of type REAL, it may be visualized as being composed of an integer and a fraction. The type for the next word is in the last 2 bits of the integer part and the associated real value is obtained by adding the fractional part to the leading bits of the integer part.

REAL TANK(150)

EQUIVALENCE (FRACT, IVAL), (ITANK(1), TANK (1))

0000842

DATA BLANK/' $/$

0000843

IF(ISWTCH-2) $5,70,70$

5 READ (IN, END $=110)$ NUM, $(\operatorname{TANK}(I), I=1, N U M)$

0000844

TYPE $=1$

0000845

0000846

I $P T=1$

DO $50 \quad I=1$, NUM

0000847

IF (TYPE.LT.O) TYPE $=-T Y P E$

0000848

0000849

IF (TYPE- 2 ) $10,20,30$

10 IV AL $=I T$ ANK $(I) / 4$

TYPE $=$ IT ANK (I)-4*IVAL

0000850

0000851

0000852

GO TO 25

0000853

0000854

20 TYPE $=$ TANK (I )

FRAC T $=$ TANK $(I)-T Y P E$

$J=T Y P E / 4$

0000855

0000856

TYPE $=$ TYPE-4*J

0000857

FRACT $=J+F R A C T$

0000858

0000859

25 IREC (IPT) =I VAL

0000860

I $P T=I P T+1$

0000861

GO TO 50

0000862

$30 \mathrm{~J}=\mathrm{I}$ T ANK $(\mathrm{I}) / 4$

0000863

$T Y P E=I T A N K(I)-4 * J$

0000864

DO $40 K=1, J$

0000865

IREC( I $P$ T I $=B$ LANK

40 IPT $=$ I $P T+1$

50 CONTINUE

60 RETURN

70 WRITE (IOUT) NUM, (TANK (I), I =1, NUM) GO TO 60 


\section{SUBROUTINE NAME: HELP}

Purpose: HELP types the names and descriptions of GRASP commands available to the user.

Calling sequence: CALL HELP(WORDS)

Argument:

WORDS-An array containing the command names that may be issued by the user.
Subroutines called: None

Common data referenced: None

Called by: DRIVER

Error checking and reporting: None

Program logic: The text associated with each of the commands is initialized in DATA statements. Each command name (in WORDS) is typed with its corresponding description in TEXT.

GRAS P SOURCE PROGRA M

SUBROUT INE HELP (WORDS)

0000874

INTEGER WORDS (1)

DOUBLE PRECISION TEXT(11,11),MSG1(11),MSG2(11),MSG3(11),

0000875

1 MSG4(11),MSG5(11),MSG6(11),MSG7(11),MSG8(11),MSG9(11),

0000876

2 MSG $10(11), M S G 11(11)$

EQUIVALENCE (MSG1(1),TEXT(1,1), (MSG2(1), TEXT $(1,2))$,

1 (MSG3(1), TEXT $(1,3)),(\operatorname{MSG} 4(1), \operatorname{TEXT}(1,4)),(\operatorname{MSG} 5(1), \operatorname{TEXT}(1,5))$,

0000878

0000879

2 (MSG 6(1), TEXT( 1,6$)),(M S G 7(1), \operatorname{TEXT}(1,7)),(\operatorname{MSG} 8(1), T$ EXT $(1,8))$,

0000880

3 (MSG9(1), TEXT $(1,9)),(M S G 10(1), \operatorname{TEXT}(1,10)),(\operatorname{MSG} 11(1), \operatorname{TEXT}(1,11)$

DATA MSGL/'- INITIA', 'TES THE', 'REQUEST', 'FOR RETR','IEVAL CR',

0000881

0000882

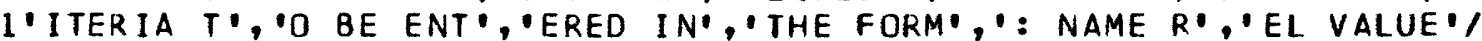

0000883

DATA MSG2/.- INITIA', 'TES THE', 'REQUEST', 'FOR a LO', 'GICAL EX',

1'PRESSION', TO BE E', 'NTERED', USING LO', 'GICAL OP', 'ERATORS.'/

DATA MSG3/.- INITIA', 'TES THE', SEARCH $0^{\prime},{ }^{\circ} F$ A FILE', BASED U',

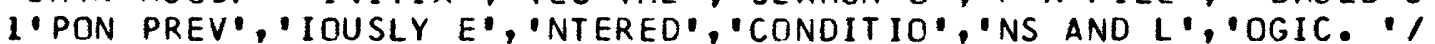

DATA MSG 4/.- ALLOWS', THE USE', 'R TO LIS', 'T SELECT', "ED VALUE',

I'S (VARIA', 'BLE NAME', 'S WILL', 'BE ASKED', FOR) IN', A FILE.'/

DATA MSG5/. - ALLOWS', THE USE', 'R TO SEL', 'ECT OR C', "HANGE TH",

1 'E DATA B', 'ASE TO B', 'E USED.',3*' 1

0000884

0000885

0000886

0000887

0000888

0000889

0000890

DATA MSG6/. - TERMIN', 'ATES THE', SYSTEM.', ENTERIN', 'G IN R',

0000892

1 'ESPONSE', TO A PRO', 'MPT WILL', 'ALSO STO','P THE SY', STEM. '/

DATA MSGT/'- USED T', O PRINT', ITEM NAM', 'ES, THEI', 'R TYPES',

1. AND DEFI', 'NITIONS', IN a ', SELECTED", SET OF','GROUPS." 0000893

DATA MSG8/.- USED T', O OBTAIN', THE ABO', 'VE COMMA , ND DEFIN',

1. ITIONS. . 5*

'THE FILE','S WHICH', 'HAVE BEE', 'N USED A', 000089

I'S WELL A','S THE CD', 'NDITIONS', AND LOGI', 'C ENTERE', D. $1 \% 0000900$

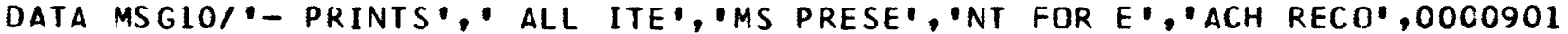

1'RD IN A','SELECTED','FILE.','WAITS AF','TER EACH','N LINES'/ 0000902

DATA MSGI1/'- PROVID', 'ES FCR T', 'HE COMPU', 'TATION $0^{\prime}, ' F$ FUNCTI',000O903

1'ONS ON I','TEMS IN', 'A DATA','SET (OR','FILE).',

TYPE 10, (WORDS (J), (TEXT $(I, J), I=1,11), J=1,11$ )

RETURN

0000905

0000906

10 FORMAT ('OTHE COMMANDS WHICH MAY BE ISSUED ' 'AND THEIR MEANING) OOOO907

IARE LISTED BELOW:'/(', A4,8A8/7X,3A8) )

0000908

END

0000909 


\section{FUNCTION NAME: ICONV}

Purpose: ICONV is used to convert a number from unpackedcharacter form to numeric fixed-point form.

Calling sequence: IVAL $=$ ICONV (TANK,LNGTH,EXP, ERR)

Arguments :

TANK-Contains the number to be converted in unpackedcharacter form.

LNGTH-The number of elements in TANK.

EXP-The power of 10 to which the value returned must be raised to obtain the floating point value represented.

ERR-An error flag which is turned on if an error is detected.

Subroutines called: None
Common data referenced: None

Called by: OPREP, PARSE, RELEXP

Error checking and reporting: Each character is checked. If an invalid character is detected, an error message is typed, and the error flag is turned on.

Program logic: If all characters are blank, blank is returned as a value. Leading blanks and imbedded commas are ignored, and a blank acts as a string deliminator. If a decimal point is sensed, the position counter EXP is initialized to 1 and incremented for each subsequent digit. As each digit is detected in a left-to-right fashion, the value is shifted left one digit, and the detected digit is added to the least significant part of the value. If all (LNGTH) characters have been scanned or if a trailing blank is detected, the scan is terminated and control is returned to the caller.

\section{GRASP SOURCE PROGRAM}

INTEGER FUNCTIONICONV (TANK, LNGTH, EXP, ERR)

INTEGER TANKI 1$)$, DIGITS $(10)$, BLANK, COMMA, POINT,EXP,VALUE

0000910

LOGICAL ERR

DATA BLANK, COMMA,POINT/4H ,4H, ,4H, /, DIGITS/4HO, ,4HI

$14 \mathrm{H} 2,4 \mathrm{H3}$

$E R R=. F A L S E$.

, $4 \mathrm{H} 6$

1, DIGITS/4HO
$.4 \mathrm{HB} \quad, 4 \mathrm{Hg}$

$E X P=0$

IF ILNGTH.GT.0I GO TO 10

I $C O N V=B L A N K$

GO TO 90

10 VALUE $=0$

DO $20 \mathrm{~K}=1$, LNGTH

IF (TANK(K).NE.BLANK) GO TO 30

20 CONT INUE

GO TO 80

$3 C$ DO $70 \mathrm{~J}=\mathrm{K}, \mathrm{LNGTH}$

NEXT $=$ TANK (J)

IF (NEXT.EQ.COMMA) GO TO 70

IF (NEXT.EQ.BLANK) GO TO 80

IF (NEXT.NE.POINT) GO TO 40

$E \times P=1$

GO TO 70

4C IF $(E X P . G T .0)$ EXP $=E X P+1$

DO $50 \mathrm{~L}=1,10$

IF (NEXT.EQ.DIGITS(L)) GO TO 60

0000911

0000912

0000913

0000914

0000915

0000916

0000917

0000918

0000919

0000920

0000921

0000922

0000923

0000924

0000925

0000926

0000927

0000928

0000929

0000930

000093.1

0000932

0000933

0000934

50 CONTINUE

TYPE $100, \operatorname{VALUE,EXP,(TANK}(L), L=1, L N G T H)$

0000935

0000936

$E R R=$.TRUE .

GO TO 90

60 VALUE $=10 * V A L U E+L-1$

0000937

0000938

0000939

0000940

0000941

80 EXP=MINO $(0,1-E X P)$

0000942

I CONV $=$ VALUE

90 RETURN

100 FORMAT (15H BAD CHARACTER, $111,15,3 \times, 64 A 1)$

0000943

0000944

END 


\section{SUBROUTINE NAME: IFILE}

Purpose: This subroutine is used to associate dynamically the name of an existing data set with a FORTRAN input unit number (that is, logical device number). When this subroutine is called, the file is opened and read; statements referencing the unit number given in the argument list are directed to the named file. The file may be closed by use of a rewind statement.

Calling sequence: CALL IFILE (I,NAME)

Arguments :

I-An integer variable or constant specifying a logical device number.
NAME-Either a literal (hollerith) constant or a variable containing a file name consisting of five or fewer characters.

Subroutines called: None

Common data referenced: None

Called by: BINTYP, DEFLST, FINDGP, OBEY, START, FILES

Error checking and reporting: None

Program logic: This is a DEC 1070 , TOPS -10 system resident routine. It provides the capabilities referred to in the Purpose section above. If the GRASP system is to be implemented on some other main frame, a comparable routine must be written or acquired. No listing is shown here. 


\section{SUBROUTINE NAME: INIT}

Purpose: INIT initializes a set of words and codes for future table lookup. The initialization assumes that the "linear quotient hash code" technique will be used for table lookup. See Bell and Kaman (1970) for a complete description of the technique.

Calling sequence: CALL INIT(CHARS,CODES,M,SYMBOL, $\mathrm{N})$

Arguments :

CHARS-Table which is to contain the symbols in "hashcoded" order.

CODES-Table giving the index of the symbol as it was stored in CHARS.

M-Table size for CHARS and CODES. Note this must be a prime number.
SYMBOL-Table of words to "hash" into CHARS.

$\mathrm{N}$-Number of words in SYMBOL.

Subroutines called: None

Common data referenced: None

Called by: LOGEXP, PARSE

Error checking and reporting: None

Program logic:

1. CHARS is filled with "VOID," the flag for an empty location.

2. Each element of SYMBOL is then inserted into CHARS at the "hashed" address. "Collisions" are handled via the linear-quotient method.

3. As each element of SYMBOL is "hashed" into CHARS, its position is stored in CODES.

4. The initial probe address and collision displacement are determined from the contents of each element of SYMBOL.

SUBROUT INE INIT (CHARS, CODES, M, SYMBOL, N)

INTEGER FILLER, CHARS $(1), \operatorname{CODES}(1), S Y M B O L(1)$

DATA FILLER/ 'VOID'/

DO $10 \quad I=1, M$

10 CHARS (I ) =FILLER

DO 40 I CODE $=1, N$

IC HAR = SYMBOL ( ICODE)

$L=I A B S($ ICHAR )

$J=L / M$

$I=L-M * J$

IF $(M O D(J, M) . E Q .0) J=1$

20 IF (CHARS $(1+1)$. EQ.FILLER) GO TO 30

$I=\operatorname{MOD}(I+J, M)$

GO TO 20

30 CHARS $(I+1)=I$ CHAR

$40 \operatorname{CODES}(I+1)=1$ CODE

RETURN

END

0000946

0000947

0000948

0000949

0000950

0000951

0000952

0000953

0000954

0000955

0000956

0000957

0000958

0000959

0000960

0000961

0000962

0000963 
SUBROUTINE NAME: KEYBRD

Purpose: KEYBRD accepts all user input in unpacked character form and returns it to the caller.

Calling sequence: CALL KEYBRD (\&m,IMAGE,N)

Arguments :

$\mathrm{m}$-Statement number (in caller) to which a branch is made if an EOF is found.

IMAGE-Contains the user input in unpacked character form.
$\mathrm{N}-\mathrm{Number}$ of characters to be read.

Subroutines called: None

Common data referenced: None

Called by: BDEF, COLPNT, CONDTN, DEFLST, FTNC, LIST, LOGEXP, OPREP, QUIT, RETRVE, VLIST, FILES, DRIVER, OBEY, PAUSE

Error checking and reporting: None

Program logic: KEYBRD accepts input from the user (unit 5) and takes nonstandard return if EOF occurs.

\section{$\begin{array}{lllllllllllllllll}G & R & S & P & S & O & U & R & C & E & P & R & 0 & G & R & A & M\end{array}$}

SUBROUT INE KEYBRD(*, IMAGE,N)

0000964

DATA IXI' $/$

DIMENSION IMAGE( 1 )

0000965

$\operatorname{READ}(5,20, E N D=10)$ (IMAGE (I), I $=1, N)$

0000966

IF(IMAGEI I).EQ.IX) GO TO 10

0000967

RETURN

0000968

10 RE TURN 1

0000969

20 FORMAT $(80 A 1)$

0000970

END 
SUBROUTINE NAME: LENGTH

Purpose: LENGTH determines the number of leading nonblank words in a character string.

Calling sequence: CALL LENGTH (VECT,N,L)

Arguments :

VECT-Array containing the character string to be examined.
$\mathrm{N}$-The number of words to check.

L-The number of nonblank leading words.

Subroutines called: None

Common data referenced: None

Called by: DEFLST, DUMPIT, NAME

Error checking and reporting: None

Program logic: The first full-word blank is searched for; its position is returned in $\mathrm{L}$.

GRASP SOURAE PROGRA M

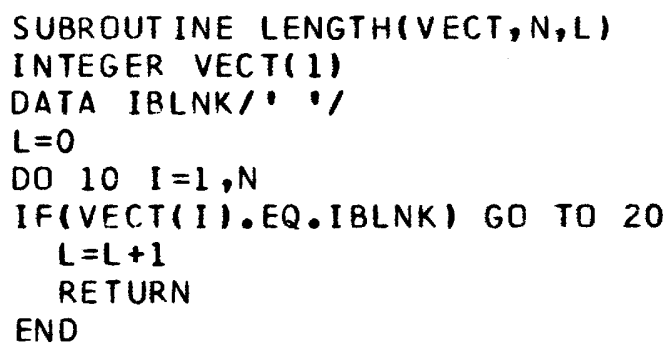




\section{SUBROUTINE NAME: LIST}

Purpose: LIST is used as a driver for the listing of items from a selected file. LIST performs initialization common to both row and column forms of printout, and rewinds the input file after returning from the routine which created the printout.

Calling sequence: CALL LIST (\&n)

Argument:

$\mathrm{n}$-Statement (in caller) that is branched to if an EOF is sensed in any of the called routines.

Subroutines called: OPREP, KEYBRD, ROWPNT, COLPNT

Common data referenced: None
Called by: DRIVER

Error checking and reporting: The user response returned by KEYBRD is checked for validity. If in error, a message is typed, and the user is prompted again.

Program logic:

1. The input file name and page size are set by a call to OPREP.

2. The user is prompted for " $C$ " (column) or " $R$ " (row) to establish the desired output form.

3. Either ROWPNT or COLPNT is called depending on the user's response to step 2 above.

4. The input file is rewound prior to the return to DRIVER.

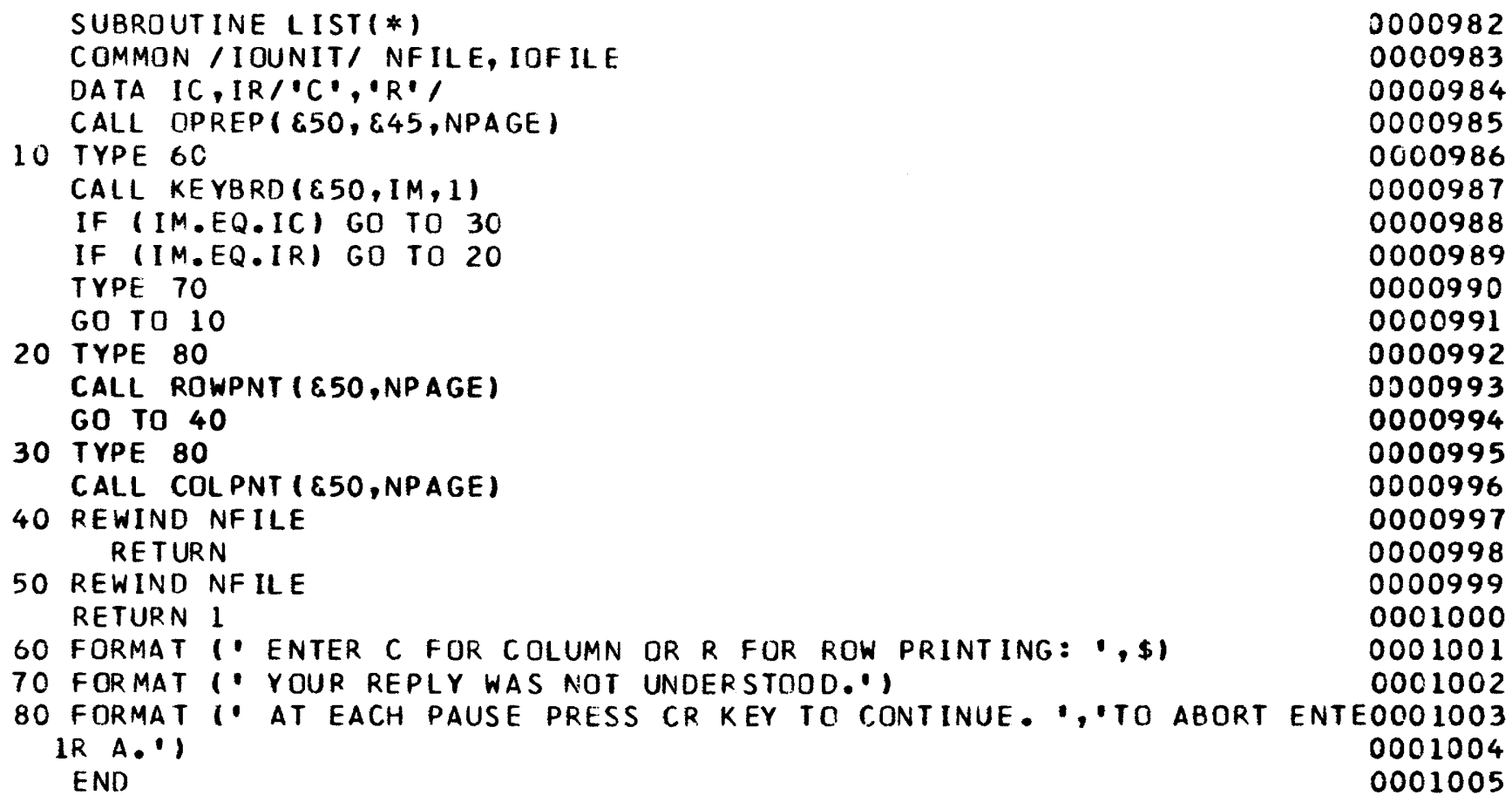




\section{SUBROUTINE NAME: LOGEXP}

Purpose: This routine accepts a logical expression as user input via a call to KEYBRD and returns the encoded Reverse-Polish form of the expressions. The logical expression may be composed of single-letter (A-Z) operands which refer to previously entered conditions, the logical operators "and," "or," "not," and the grouping symbols (,). Each of the logical operators may be denoted in two ways, as follows: .AND. or *, .OR. or + , .NOT. or -

Calling sequence: CALL LOGEXP (\&n,POLISH,LPS,NCOND) Arguments :

$\mathrm{n}$-Statement number (in calling routine) to which a branch will be made if an EOF is sensed by KEYBRD.

POLISH-Contains the encoded Reverse-Polish form of a logical expression. Let $n$ denote the value of some element of POLISH. Then $1 \leq n \leq 26$ implies reference to the nth condition entered. If $29 \leq n \leq 31$, the logical opperators OR, AND, NOT correspond to these three values. No other values will be assumed by elements of POLISH. LPS-Gives the number of elements in POLISH.

NCOND-Gives the number of conditions which have been entered by a previous call to CONDTN.

Subroutines called: INIT, KEYBRD, SCAN, FIND, PACK

Common data referenced: LOGIC in /INPUT/

Called by: DRIVER

Error checking and reporting: The logic expression entered is checked for syntactic correctness. Following are eight error messages which may be typed:

1. LOGICAL OPERATOR NOT PRECEDED BY A ) OR A LETTER (A-Z).

2. UNBALANCED PARENTHESIS.

3. LETTER (A-Z) NOT SEPARATED BY AN OPERATOR.

4. UNEXPECTED LEFT PARENTHESIS OR .NOT. OPERATOR (-).

5. INVALID CHARACTER IN EXPRESSION.

6. UNDETERMINED SYNTAX ERROR. CONTACT PROGRAMMER.

7. LOGIC EXPRESSION REFERENCES A CONDITION (A-Z) WHICH WAS NOT ENTERED.
8. OPERATOR NOT ENCLOSED WITH PERIODS. REENTER LOGIC.

Program logic:

1. On the first call to LOGEXP, a call to INIT is made to "hash-code" the elements of SYMBOL into CHARS. CODES is used to save the original indices.

2. A prompt message is typed and a call to KEYBRD is made to get the input string which is then packed into LOGIC.

3. After initialization of pointers and counters, a call is made to SCAN to bracket the nonblank section of STRING.

4. At this point the actual algorithm begins. Transition matrix parsing is used with the following transition matrix (IMAT) :

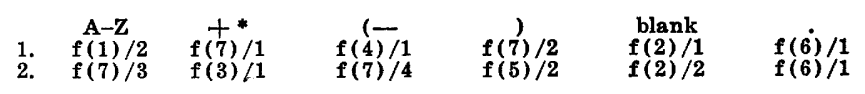
where $f(i) / j$ means "do the $i$ 'th job and set the next row value to j." The jobs are:

f(1) - Insert character code into Reverse-Polish string and test to determine if there has been a condition entered for it.

$f(2)$ - Go scan next character.

f (3) - Pop stack into POLISH until value of topmost element is less than character code. Then do $f(4)$.

f (4) - Push down character code into stack.

f (5) - Pop stack into POLISH until the value for (is reached. Remove value for (.

$f(6)$-Period character sensed, find next matching period and determine logical operator.

$f(7)$-Type the error message pointed to by the row value, then request reentry of logic.

Each character of STRING is scanned using the subroutine FIND to obtain its code ICODE. ICODE is an index to ICOLS which then determines the proper column of IMAT. This element IFTN is then broken down into a function pointer JOB and a next row value STATE. Control is then passed to the function indicated by JOB. After the function has been completed, the next character of STRING is scanned if an error was not detected. If an error was detected, the appropriate message is typed.

$$
\text { GRAS P SOURCA PROGRAM }
$$

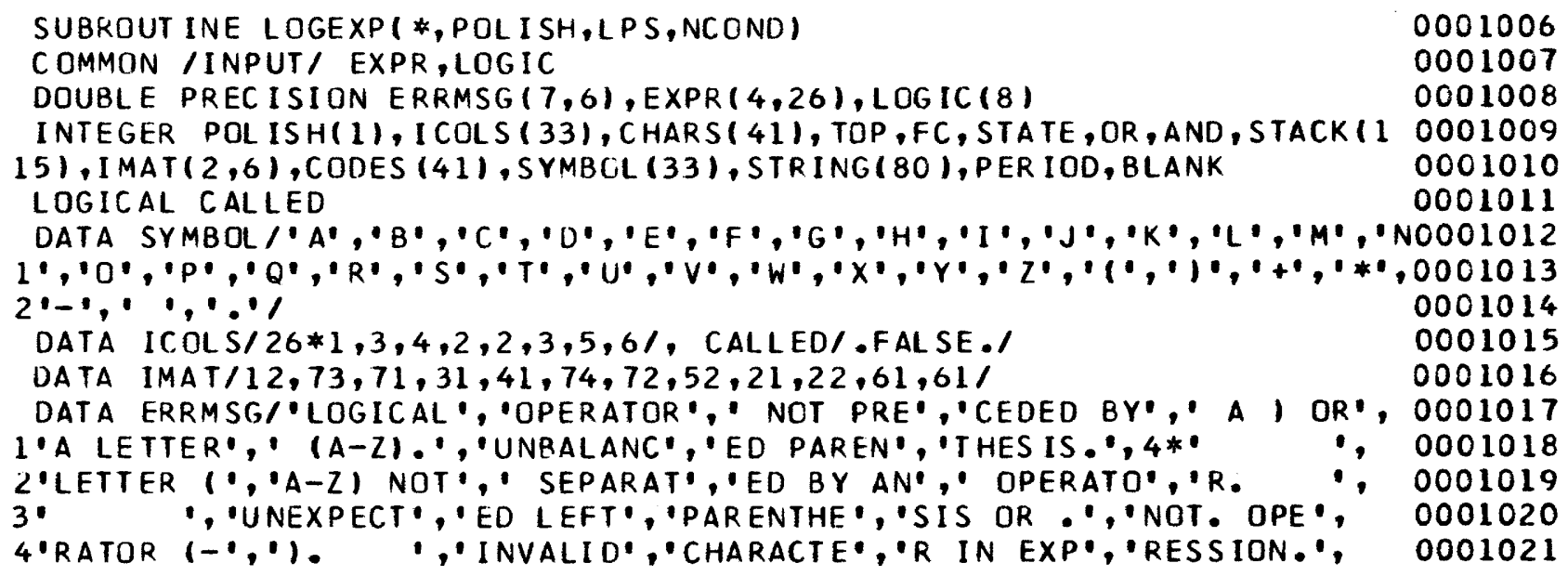




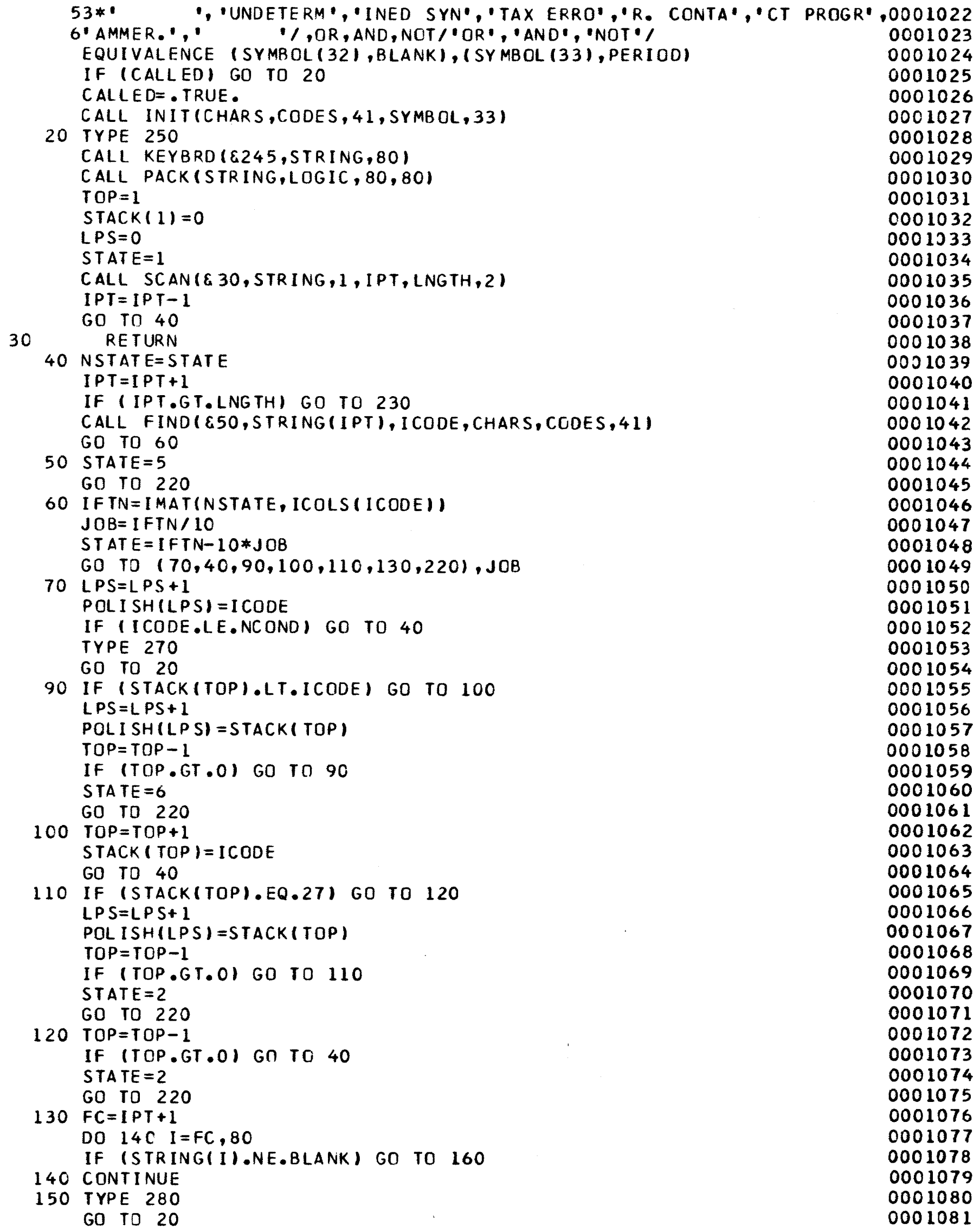


$160 \mathrm{FC}=\mathrm{I}$

0001082

DO 170 IP T $=F C, 80$

0001083

IF (STRING(IPT).EQ.PERIOD) GO TO 180

170 CONTINUE

GO TO 150

180 NCHAR $=3$

I $\mathrm{CODE}=0$

190 NCHAR $=$ NCHAR -1

$N C H=F C+N C H A R$

IOP = CHARS $(21)$

CALL PACK (STR ING(FC), IOP, NCH-FC+1,4)

IF (IOP.EQ. AND) ICODE $=30$

IF (IOP.EQ.NOT) ICODE =31

IF (IOP.EQ.OR) I CODE $=29$

IF (ICODE.NE. O) GO TO 200

IF (NCHAR.GT.1) GO TO 190

0001084

0001085

0001086

0001087

0001088

0001089

0001090

0001091

0001092

0001093

0001094

0001095

0001096

0001097

STATE $=6$

GO TO 220

200 IF (ICODE.LT.31) GO TO 210

0001098

0001099

0001100

IF (NSTATE.EQ.1) GO TO 1 CO

0001101

STATE $=4$

GO TO 220

210 IF (NSTATE.EQ.2) GO TO 90

0001102

0001103

0001104

STA TE $=1$

220 TYPE 300, (ERRMSG( I, STATE) , I $=1,7$ )

60 TO 20

230 IF (TOP.EQ.1) GO TO 30

IF (STACK(TOP).GT.28) GO TO 240

STATE $=2$

GO TO 220

240 LPS $=$ LPS +1

POL ISH (LPS) $=S T A C K(T O P)$

$T O P=T O P-1$

GO TO 230

0001105

00011.06

0001107

0001108

0001109

0001110

0001111

0001112

0001113

0001114

0001115

0001116

0001117

250 FORMAT (" ENTER LOGIC: ",\$)

270 FORMAT $1 \cdot$ LOGIC EXPRESS ION REFERENCES A CONDITION (A-Z) , WHICH WOOO 1118 IAS NDT ENTERED.',

0001119

280 FORMAT 1 " OPERATOR NOT ENCLOSED WITH PERIODS. RE-ENTER LOGIC."

$30 C$ FORMAT (' LOGICAL ERROR:'/1X,7A8)

0001120

0001121 END

0001122 


\section{SUBROUTINE NAME: MEAN}

Purpose: MEAN provides for the computation of range, mean, sum, root mean square, and sum of squares for as many as five specified items in a specified file.

Calling sequence: CALL MEAN (J,ISWTCH)

Arguments:

J-Pointer used to retrieve argument values from the common area /FTNCOM/.

ISWTCH-Switch indicating which of three parts (initialization, body, postprocessing) of the code is to be executed. Subroutine called: UNCODE

Common data referenced:

ITYPE in blank common

TAGS, IREC, ARGS, NARGS in /FTNCOM/
Called by: FDRIVE

Error checking and reporting: None

Program logic: The value of ISWTCH determines which of three sections of the code is executed.

If $\mathrm{ISWTCH}=1$, sums and range values are initialized. If ISWTCH $=2$, the type for each argument value is determinted and its value is added to the appropriate sums. Range values are updated if required. If $\mathrm{ISWTCH}=3$, the final computations are performed and the results typed out to the user.

The mean is determined using $\bar{X}=\Sigma X / N$ and the root mean square is determined using $R M S=\Sigma X^{2} / N$, where $N$ is the number of nonblank values of $X$.

\section{GRASP SOURCE PROGRA M}

SUBROUTINE MEAN(J, ISWTCH)

COMMON NAMES, ITYPE, IPTS, IDIM

COMMON /FTNCOM/ TAGS, IREC, ARGS, NARGS, IFTN, NFTN

DIMENSION ARGS $(6,5)$, NARGS(5), IFTN(5), ITYPE (500), IREC (500),

1IPTS(500), NSUM(5), SUMX(5), SUMXS(5), VMAX(5), VMIN(5)

DOUBLE PRECISION NAMES $(500), \operatorname{TAGS}(5,5)$

INTEGER ARGS

EQUIVALENCE (IVAL, VAL)

DATA IBLNK/" /

IF(ISWTCH-2) $5,15,25$

$5 K=$ NARGS $(J)$

DO $10 \quad I=1, K$

$\operatorname{SUMX}(I)=0$.

$\operatorname{VMAX}(I)=-1 \cdot E 30$

$\operatorname{NSUM}(I)=0$

$\operatorname{VMIN}(I)=1 \cdot E 30$

10 SUMXS $(I)=0$.

GO TO 55

$15 K=$ NARGS $(J)$

DO $20 \quad I=1, K$

IVAL $=$ IREC $(A R G S(I+1, J))$

IF (I VAL.EQ.IBLNK) GO TO 20

$N \operatorname{NUM}(I)=N \operatorname{NUM}(I)+1$

VALUE $=$ IVAL

I F (ITYPE (ARGS $(I+1, J)), E Q .5)$ VALUE $=U N C O D E(V A L, I Q)$

IF (I TYPE(ARGS( I+1,J),$E Q .2)$ VALUE =VAL

IF (VALUE.LT.VMIN(I)) VMINI I )=VALUE

IF (VALUE,GT.VMAX(I) VMAX(I) =VALUE

SUMX(I) = SUMX(I) +VALUE

SUMXS(I) = SUMXS(I)+VALUE*VALUE

20 CONT INUE

GO TO 55

$25 K=N A R G S(J)$

DO $50 \quad I=1, K$

IF (NSUM(I).EQ.0) GO TO 30

TYPE 60, TAGS(I,J), NSUM(I)

AMEAN = SUMX(I)/NSUM(I)

RMS = SUMXS (I)/NSUM(I)

IF $(I$ TYPE $(A R G S(I+1, J)) . E Q .2)$ GO TO 40

IF (ITYPE (ARGS $(I+1, J)) . E Q .5)$ GO TO 40
0001123

0001124

0001125

0001126

0001127

0001128

0001129

0001130

0001131

0001132

0001133

0001134

0001135

0001136

0001137

0001138

0001139

0001140

0001141

0001142

0001143

0001144

0001145

0001146

0001147

0001148

0001149

0001150

0001151

0001152

0001153

0001154

0001155

0001156

0001157

0001158

0001159

0001160

0001161

0001162 
$M I N=V M I N(I)$

$M A X=V M A X(I)$

TYPE 8C, MIN, MAX, AMEAN, RMS, SUMX(I), SUMXS(I)

GO TO 50

30 TYPE 70, TAGS(I,J)

GO TO 50

40 TYPE 80 , VMIN(I), VMAX (I), AMEAN, RMS, SUMX (I), SUMXS(I)

50 CONTINUE

55 RETURN

60 FORMAT ( $/$ "MEAN STATISTICS FOR , A8, 'WITH, 16, , ITEM(S). $\left.^{\circ}\right)$

70 FORMAT (/, NO VALUES PRESENT FOR , A8)

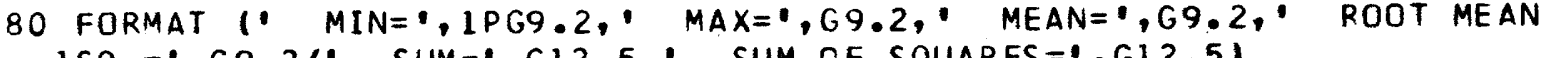

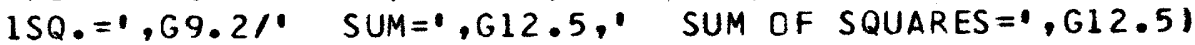

END

0001163

0001164

0001165

0001166

0001167

0001168

0001169

0001170

0001171

0001172

0001173

0001174

0001175

0001176 


\section{SUBROUTINE NAME: NAME}

Purpose: NAME provides the user with the mechanism for examining the structure and content of the current data base. The user is permitted to select categories of interest. Item names, types, and descriptions for all entries in selected categories are printed. The user is aliso permitted to see the values which are assumed (in the current data base) by character- and multiple-choice-type items.

Calling sequence: CALL NAME (\&n)

Argument:

$\mathrm{n}$-Statement number (in caller) to which a branch is made if the second nonstandard return is taken from DEFLST

(EOF sensed by KEYBRD), or EOF is sensed in BDEF.

Subroutines called: DEFLST, PAUSE, FINGDP, LENGTH, BDEF

Common data referenced: None
Called by: DRIVER

Error checking and reporting: None

Program logic:

1. DEFLST is called to select those categories of interest (LIST).

2. For each category selected, a call is made to FINDGP to obtain the names, types, and descriptions for all items within that category. They are then printed under the category name.

3. Programmed pauses after each category or 30 lines of output are provided via calls to PAUSE.

4. A call to LENGTH is made to determine the number of nonblank words in the description.

5. Unit 20 (used by DEFLST and FINDGP) is rewound prior to returning to DRIVER.

$$
\text { G R A P SOURAE PROARA M }
$$

\section{SUBROUT INE NAME(*)}

INTEGER CAT $(8,17)$, DESC $(12,45)$, TYPE (45), LIST $(17)$

0001177

DOUBLE PRECISION NAMES( 45$)$

CALL DEFLST $(\varepsilon 50, \varepsilon 60$, CAT, NUMC, MC, LIST )

TYPE 70

CALL PAUSE( $\& 50)$

0001178

0001179

0001180

DO $30 \mathrm{~K}=1$, NUMC

0001181

$K N U M=L I S T(K)$

CALL FINDGP ( $\& 50, K N U M, N U M, M A X L, N G, D E S C)$

READ (20) (NAMES $(J), \operatorname{TYPE}(J),(\operatorname{DESC}(I, J), I=1, \operatorname{MAXL}), J=1, N U M)$

0001182

0001183

0001184

CALL LENGTH (CAT $(1, K N U M), M C, M C L)$

TYPE 90, (CAT (I,KNUM), I=1,MCL)

TYPE 91

LINE $=0$

10 LINE $=$ LINE+1

IF (LINE.GT.NUM) GO TO 30

IF (MOD(LINE, 30$)$.NE.0) GO TO 20

CALL PAUSE( $\& 50)$

TYPE 90, (CAT(I, KNUM), I =1, MCL)

TYPE 100

TYPE 91

CALL LENGTH(DESC 1, , INE), MAXL, MXL)

TYPE 110, NAMES (LINE), TYPE (L INE), (DESC(I,LINE), I =1,MXL) GO TO 10

30 CALL PAUSE $(\varepsilon 50)$

50 REWIND 20

CALL RDEF $(\varepsilon 60)$

0001185

0001186

0001187

0001188

0001189

0001190

0001191

0001192

0001193

0001194

0001195

0001196

0001197

0001198

0001199

0001200

0001201

0001202

0001203

RETURN

60 RETURN 1

0001204

0001205

70 FORMAT (" IN EACH CATEGORY, THE ITEM NAMES, TYPE CODES, ", AND DESOOO1206 1CRIPT IONS WILL BE / LISTED. TYPE CODES: $1 / 9 X, 11=$ WHOLE NUMBERS'/90001207 $2 X,{ }^{\circ}=$ NUMBERS WITH FRACTIONAL PARTS $/ 9 X, ' A=$ ALPHANUMERIC STRINGSOOOI208 $3^{\prime} / 9 X, ' B=$ MULTIPLE CHOICE TYPES $19 X,{ }^{\prime} \mathrm{Q}=$ QUALIFIED NUMERIC VALUES 0001209

$4 \%$ AT EACH PAUSE STRIKE CR KEY TO CONTINUE (STARTING NOW).1)

9C FORMAT (' CATEGORY: ',9A5)

91 FORMATI NAME TYPE DESCRIPTIUN \% - -

1 - - - - - - -

0001211

0001212

100 FORMAT $(1+,, T 50,1$ C CN' T)'
110 FORMAT $(1 \times, A 7,1 X, A 1,2 X, 12 A 5)$

END 


\section{SUBROUTINE NAME: OBEY}

Purpose: OBEY associates input or output file names with FORTRAN unit numbers and provides a degree of filename checking and protection.

Calling sequence: CALL OBEY (\&m,MSG,N)

Arguments :

$\mathrm{m}$-Statement (in caller) to which a branch will be made if a protected (output) or unknown (input) file name is referenced.

MSG-Contains (in packed-character form) either of the following:

"EQUATE 11 name," indicating input,

"EQUATE 12 name," indicating output.

$\mathrm{N}$-The number of words in MSG.

Subroutines called: KEYBRD, IFILE, OFILE

Common data referenced:

IN, IOUT in /IOUNIT/

FNAMES, NUMI, WHICH in /FILNAM/

Called by: RETRVE, OPREP, FTNC

Error checking and reporting:

1. Input file names are checked for recognition.

2. Output file names are checked to prevent writing on a "protected" file.
3. The total number of output files is checked against the maximum 20.

Error messages for each of the above three checks are provided.

Program logic:

1. If the message length $N$ is not 4 or if the first 4 characters in MSG are not EQUA, return is immediate.

2. MASTER is set to the current data-base name in /FILNAM/ and MSG is moved to IMSG.

3. If the third word of IMSG is not " 2 ," input is assumed, and the file name (last word of IMSG) is checked against the names of files created during this session. If no match is found, the user is informed and given the opportunity to exit and enter a new command. Finally, IFILE is called to associate unit 23 with the file name provided.

4. If the third word of IMSG is " 2 ," output is assumed, and the file name FNAME (last word in IMSG) is checked against the list of protected file names in /FILNAM/. If a match is found, the nonstandard return is taken. Otherwise, FNAME is added to the list FILES, and unit 24 is associated with the file FNAME via a call to OFILE.

$$
\text { GRASPSOURAE PROARAM }
$$

SUBROUT INE OBEY (*,MSG,N)

0001217

COMMON /IOUNIT/ IN, IOUT

0001218

COMMON /FILNAM/ FNAMES, NUMI, WHICH, PAD

INTEGER MASTER, FNAME, FILES $(20)$, MSG (1), IMSG (4), FNAMES(20), WHICH

0001219

1 , PAD (4)

EQUIVALENCE (IMSG (4),FNAME)

DATA $12, N U M F$, IEQ/ $2^{\prime}, 0$, 'EQUA'/, IYES/'Y'/

IF (N.NE.4) GO TO 100

IF(MSG( 1$)$.NE. IEQ) GO TO 100

MASTER = FNAMES (WHICH)

0001220

0001221

0001222

0001223

0001224

0001225

DO $2 I=1,4$

0001226

$2 \operatorname{IMSG}(I)=M S G(I)$

IF(IMSG (3).EQ.I2) GO in 10

I $N=23$

IF (FNAME.EQ.MASTER) GO TO 6

IF (NUMF.GT.O) GO TO 4

0001227

0001228

0001229

0001230

0001231

0001232

3 TYPE 5 CO

CALL KEYBRD $(\& 100,1,1)$

0001233

0001234

IF (I. FO. IYES) GO TO 6

0001235

8 RETURN 1

4 DO $5 \quad I=1$, NUMF

IF (FILES(I) . EQ.FNAME) GO TO 6

0001236

0001237

5 CONT INUE

0001238

0001239

GO TO 3

6 CALL IFILE(IN,FNAME)

0001240

0001241

GO TO 100

3001242

0001243

0001244

$K=4 *(J-1)$

DO $11 I=1$, NUMI

I F(FNAMES $(K+I)$. EQ. FNAME) GO TO 14

0001245

0001246

11 CONTINUE

0001247

GO TO 12 
14 TYPE 501 , FNAME

0001249 GO TO 8

12 IFINUMF.EQ.OI GO TO 20 DO $13 I=1$, NUMF

IF(FILES(I).EQ.FNAME) GO TO 21

0001250

0001251

0001252

0001253

13 CONTINUE

20 NUMF $=$ NUMF +1

IFINUMF.LE.20) GO TO 22

NUMF $=20$

TYPE 23

0001254

0001255

0001256

0001257

GO TO 8

0001258

0001259

0001260

FILES $($ NUMF $)=$ FNAME

21 IOUT $=24$

CALL OFILE( IOUT, FNAME)

100 RETURN

23 FORMATI" NO MORE THAN 20 FILES MAY BE CREATED IN ONE RUN.')

0001261

0001262

0001263

0001264

0001265

0001266

1 - DO YOU STILL WANT IT? (Y OR N): ',\$)

501 FORMAT(IX,A6, MAY NOT BE USED AS AN OUTPUT FILE NAME')

0001267

END 


\section{SUBROUTINE NAME: OFILE}

Purpose: This subroutine is used to associate dynamically the name of a new data set with a FORTRAN output unit number (that is, logical device number). When this subroutine is called, the file is opened, and write statements referencing the unit number given in the argument list are directed to the named file. The file may be closed by use of a rewind statement.

Calling sequence: CALL OFILE (I,NAME)

Arguments :

I-An integer variable or constant specifying a logical device number.
NAME-Either a literal (hollerith) constant or variable containing a file name consisting of five or fewer characters.

Subroutines called: None

Common data referenced: None

Called by: COLPNT, OBEY

Error checking and reporting: None

Program logic: This routine is a DEC 1070, TOPS -10 system resident routine. It provides the capabilities referred to in the section "Purpose" above. If the GRASP system is to be implemented on some other main frame, a comparable routine must be written or acquired. Therefore, a listing has not been provided. 


\section{SUBROUTINE NAME: OPREP}

Purpose: This routine is used to prompt for and accept the name of a file and a page size.

Calling sequence: CALL OPREP(\&n,\&m,NPAGE)

Arguments :

$\mathrm{n}$-Statement number (in calling routine) to which a branch will be made if an EOF is sensed by KEYBRD.

$\mathrm{m}$-Statement number (in calling routine) to which a branch will be made if the nonstandard return from OBEY is taken.

NPAGE-Page size (in lines) as entered by user. Subroutines called: KEYBRD, OBEY, ICONV, PACK Common data referenced: NAMES, WHICH in /FILNAM/
Called by: DUMPIT, LIST

Error checking and reporting: An error flag set by ICONV is tested. If set, the user is requested to reenter the value.

Program logic:

1. A file name is prompted for and accepted (via KEYBRD). This name is then packed into FNAME and compared with blank.

2. If blank, FNAME is set to the default file name obtained in /FILNAM/.

3. FNAME is then passed to OBEY via EQUATE.

4. A page size is then prompted for and accepted in character form. The numeric value is obtained by a reference to ICONV. If zero, then NPAGE is set to 10 million.

SUBROUTINE OPREP(*,*,NPAGE)

INTEGER DBLNK, DFAULT, FNAME, EQUATE ( 4), TANK ( 5 ), FNAMES( 21$),$ WHICH

1 , $P A D(4)$

LOGICAL BAD

EQUIVALENCE (EQUATE(4), FNAME)

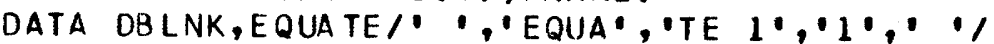

0001272

0001273

TYPE 20

0001274

DFAUL T $=$ FNAMES $(W H I C H)$

CALL KEYBRD ( \&15, TANK, 5)

CALL PACK(T ANK, FNAME, 5, 5)

I F (FNAME . EQ . DBLNK) FNAME =DFAULT

0001275

0001276

0001277

0001278

0001279

CALL OBEY (E 18, EQUATE,4)

10 TYPE 30

CALL KEYBRD $(\varepsilon 15$, TANK, 5$)$

0001280

0001281

0001282

NPAGE = I CONV (TANK, 5, I,BAD )

IF (BAD) GO TO 10

IF (NPAGE.EQ.0) NPAGE $=10000000$

0001283

0001284

0001285

RETURN

0001286

0001287

15 RETURN 1

18 RETURN 2

20 FORMAT ("ENTER NAME OF FILE: "\$)

30 FORMAT ("ENTER NUMBER OF LINES/PAGE: ,\$1

0001288

0001289

0001290

END 


\section{SUBROUTINE NAME: PACK}

Purpose: All user input to the GRASP system is in unpacked form (in other words, one single left-justified character per word). PACK is used to convert from this unpacked form to packed form. This is necessary because character data in files accessed by GRASP is in packed form to conserve space.

Calling sequence: CALL PACK (SOURCE,DESTN,N,SIZE)

Arguments :

SOURCE-The array containing the unpacked character string.

DESTN-The array which is to contain the packed character string.
$\mathrm{N}$-The number of characters to pack.

SIZE-The size (in characters) of the area to receive the packed data.

Subroutines called: None

Common data referenced: None

Called by: DRIVER, COLPNT, CONDTN, DECOMP, FILES, FTNC, LOGEXP, OPREP, PARSE, PNTER, RELEXP, RETRVE, VLIST

Error checking and reporting: None

Program logic: The ENCODE statement is used to move the characters from the unpacked string (SOURCE) to the packed string (DESTN). 


\section{SUBROUTINE NAME: PARSE}

Purpose: PARSE converts arithmetic expressions to an encoded Reverse-Polish form. Extensive syntax checking, conversion, and preliminary addressing are performed to facilitate later evaluation by EVAL. The arithmetic expressions may contain the usual arithmetic operators $(+,-, *, /)$, numeric constants, item names, and the following functions:

ABS ( )-absolute value;

SQRT ( )-square root;

LOG ( )- $\log$ base 10 ;

SQR ( )-square;

TEN ( )-power of 10 .

Parentheses may be used for grouping to control the order of evaluation.

Calling sequence: CALL PARSE(EXPR,L,TYPE,POLISH, I,ERR)

Arguments:

EXPR-Arithmetic expression to be parsed in unpacked character form.

L-The length of EXPR.

TYPE, POLISH-Arrays which will contain the encoded Reverse-Polish form. See section on subroutine EVAL for additional encoding information.

I-Length of TYPE and POLISH.

ERR-Logical flag set if an error is detected.

Subroutines called: INIT, FIND, BFIND, INCONV, PACK

Common data referenced: NAMES, IPNTS, IDIM in blank common.

Called by: PREVAL

Error checking and reporting: The expression is checked for normal FORTRAN-like syntax (such as balanced parentheses, binary operators bracketed by valid names or expressions, and correct spelling of function names). The message "ERROR IN EXPRESSION" is typed if an error is detected. If an operand or function name is not recognized, that message is typed.

Program logic: The logical variable CALLED is tested. If it has not been set by a previous call, it is set to .TRUE. and INIT is called to "hash code" the elements of SYMBOL into CHARS and CODES. Next, the variables ERR, ROW, TOP, I, and C are initialized. The remainder of the computation involves scanning EXPR, an element at a time. As in LOGEXP, a transition-matrix technique is used to parse the expression, converting it to reverse-Polish form. The transition matrix (TM) is given below:

$\mathrm{A}-\mathrm{Z}-\mathrm{Z}-\mathrm{C}^{*}($ ) blank $0-9$

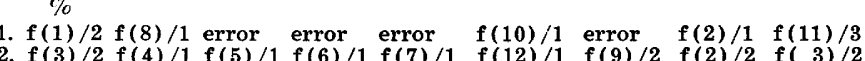

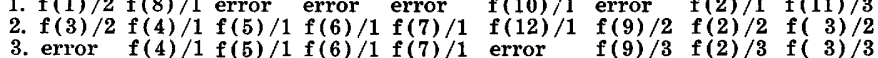

where the $f(i)$ are separate tasks as follows:

$f(1)$-Start a name.

f(2) - Go scan next character.

f (3)-Append current character to name.

f(4-7) - Binary arithmetic operator sensed: Set CODE to indicated operator; pop stack until CODE is less than the topmost stack element; push CODE down on stack.

f(8)-Unary minus sensed: set CODE and push down on stack.

f(9)-Right parenthesis sensed: pop stack until topmost element is code for left parenthesis (PAREN); decrease size of stack by one.

$f(10)$-Left parenthesis sensed; push down parenthesis code PAREN.

$f(11)$-Digit or period sensed: start a constant. NAME is used to contain the constant in character form.

$\mathrm{f}(12)$-Left parenthesis sensed in row 2 : hence, the contents of NAME are assumed to be a function name. Check for validity and print an error message if invalid; otherwise, set CODE and push down on stack.

The proper element of TM is selected by the variables ROW and COLUMN. The COLUMN value is determined by a lookup (via FIND) of the current character and the ROW value is set by the last element of TM referenced. Once the proper element of TM is selected, the next ROW value is set and a branch is made to the current task.

This process is repeated until all elements of EXPR have been processed. See the section on subroutine EVAL for details of the encoding of TYPE and POLISH.

$$
\text { GRASP SOURCE PROARAM }
$$

SUBROUT INE PARSE(EXPR, L, TYPE, POL ISH, I, ERR)

INTEGER TM, TOP, ROW, COLUMN, ELEMNT, SWITCH,TYPE, C, COLS, SYMBOL, CHARS, COOOI3O5

IODES, CHAR, E XPR

LOGICAL POP, NUM, ERR, CALLED

$122,23,113,32,33 /$ 0001307

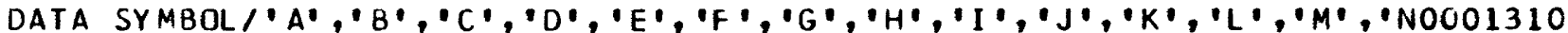

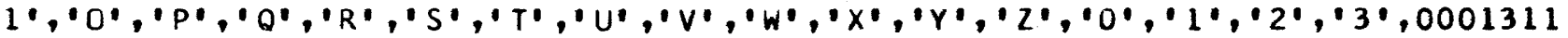

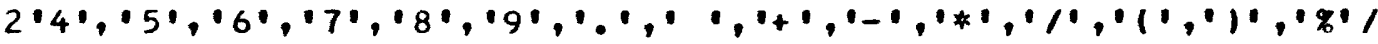

0001312

DATA COLS/26*1,11*9,8,3,2,5,4,6,7,1/

DATA IBLNK, CALLED,DBLNK/, "FALSE.,

DATA PAREN, PLUS, DIFF, PROD, DIV, UNARY $/ 0,-1,,-2, \ldots-3,,-4,,-5, I$ 
DATA IFNCTS/"ABS', SQRT" 'LOG', 'SQR', 'TEN'/

0001316

IF (CALLED) GO TO 20

CALLED = .TRUE.

CALL INITICHARS, CODES, 47, SYMBOL, 45)

0001317

0001318

20

$E R R=$. FAL SE.

$R O W=1$

$T O P=0$

$I=0$

0001319

0001320

0001321

0001322

0001323

$\mathrm{C}=0$

$30 \mathrm{C}=\mathrm{C}+\mathrm{I}$

IF $(C \cdot L E \cdot L)$ GO TO 50

0001324

0001325

IF (ROW.EQ.1) GO TO 350

0001326

IF (POP) GO TO 250

IF (NUM) GO TO 40

SWI TCH $=1$

GO TO 300

$40 \mathrm{SWITCH}=2$

GO TO 320

0001327

0001328

0001329

0001330

0001331

0001332

0001333

0001334

0001335

CALL FIND $\& 350$, CHAR, COLUMN, CHARS, CODES, 47)

COLUMN $=$ COLS (COLUMN)

ELEMNT $=T M(R O W$, COLUMN $)$

$J O B=E L E M N T / 10$

ROW $=E L E M N T-10 * \mathrm{JOB}$

GO TO $160,30,70,130,140,150,160,170,180,230,240,2701$, JOB

0001336

0001337

0001338

0001339

0001340 GO TO 350

60 NAME $(1)=$ CHAR

NCHAR $=1$

$P O P=. F A L S E$.

$N U M=$. FAL SE.

GO TO 30

70 NCHAR $=$ NCHAR +1

NAME $(N C H A R)=C H A R$

GO TO 30

80 IF (POP) GO TO 100

$P O P=$. TRUE.

IF (NUM) GO TO 90

SWITCH=3

GO TO 300

0001341

0001342

0001343

0001344

0001345

0001346

0001347

0001348

0001349

0001350

0001351

0001352

0001353

0001354

0001355

0001356

GO TO 320

100 IF (TOP.EQ.0) GO TO 120

IF (CODE.LT.STACK(TOP)) GO TO 120

0001357

0001358

0001359

SWITCH=5

VALUE $=S T A C K(T O P)$

I NDE $X=V A L U E$

0001360

GO TO 330

110 TOP $=$ TOP -1

GO TO 100

0001361

0001362

0001363

0001364

0001365

0001366

STACK $(T O P)=C O D E$

GO TO 30

$130 \mathrm{CODE}=\mathrm{DIFF}$

0001367

0001368

GO TO 80

$140 \mathrm{CODE}=\mathrm{PLUS}$

GO TO 80

$150 \mathrm{CODE}=\mathrm{DIV}$

GO TO 80

$160 \quad \mathrm{CODE}=P R O D$

0001369

0001370

0001371

0001372

0001373

0001374 


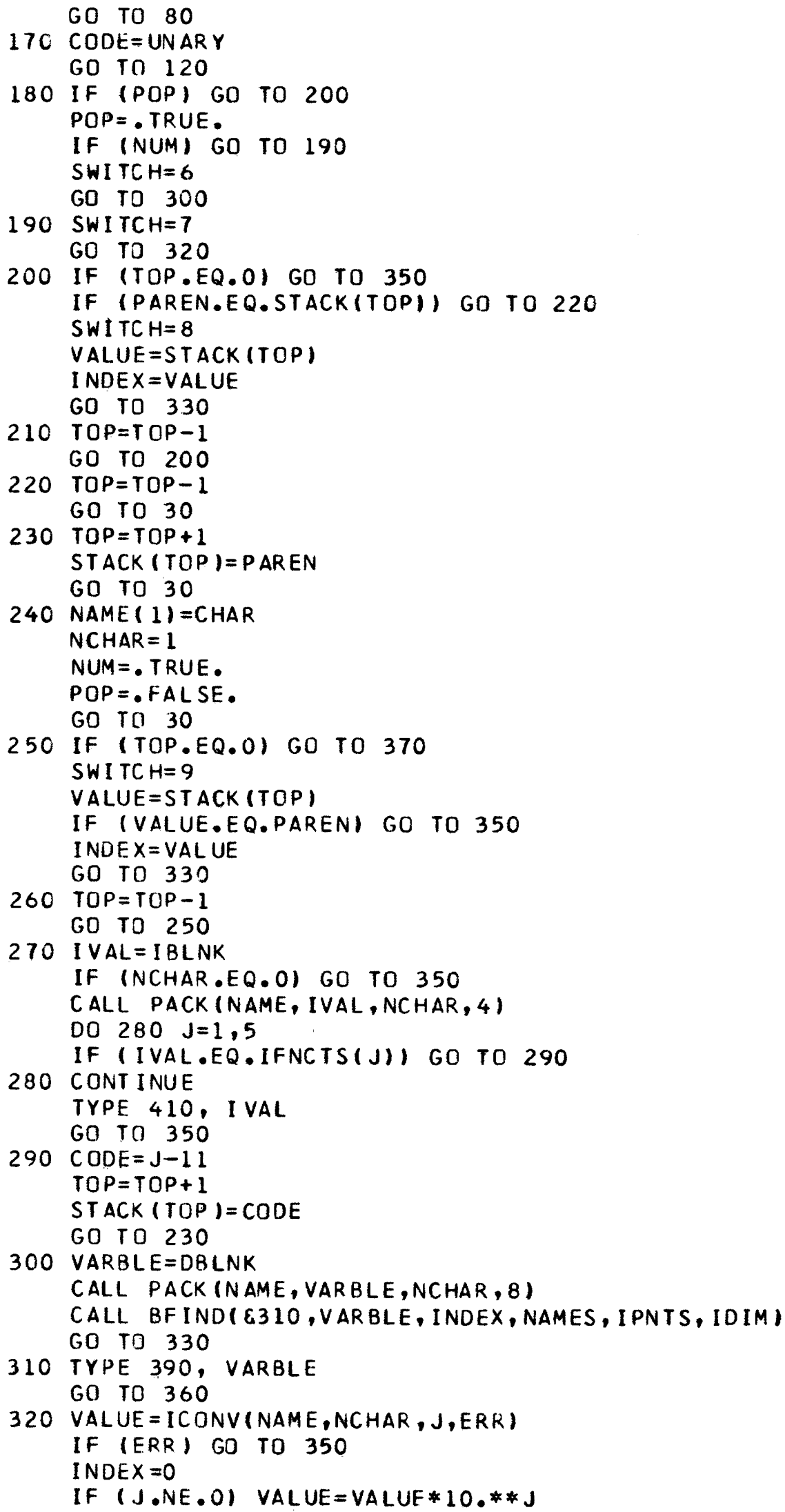

0001375

0001376

0001377

0001378

0001379

0001380

0001381

0001382

0001383

0001384

0001385

0001386

0001387

0001388

0001389

0001390

0001391

0001392

0001393

0001394

0001395

0001396

0001397

0001398

0001399

0001400

0001401

0001402

0001403

0001404

0001405

0001406

0001407

0001408

0001409

0001410

0001411

0001412

0001413

0001414

0001415

0001416

0001417

0001418

0001419

0001420

0001421

0001422

0001423

0001424

0001425

0001426

0001427

0001428

0001429

0001430

0001431

0001432 
$330 \quad I=I+I$

0001433

IF (I.LE. 15) GO TO 340

0001434

TYPE 420

GO TO 350

340 POL I SH(I I = VALUE

TYPE $(I)=$ INDEX

GO TO $(250,250,100,100,110,200,200,210,26 C)$, SWITCH

0001435

0001436

0001437

0001438

0001439

0001440

0001441

0001442

0001443

0001444

0001445

0001446

0001447 


\section{SUBROUTINE NAME: PAUSE}

Purpose: This routine is used to provide a system-generated pause in output. If a nonblank character is entered by the user, the nonstandard return is taken.

Calling sequence: CALL PAUSE (\&n)

Argument:

$\mathrm{n}$-Statement (in caller) to which a branch will be made if a nonblank character is returned by KEYBRD, or if the nonstandard return is taken from KEYBRD.

Subroutine called: KEYBRD

Common data referenced: None

Called by: BDEF, COLPNT, DUMPIT, NAME, ROWPNT

Error checking and reporting: None

Program logic: PAUSE accepts a single (left-justified) character from KEYBRD. If an EOF is sensed or the character is nonblank, take the nonstandard return.

\section{GRASP SOURAEAROGRAM}

SUBRJUTINE PAUSE(*)

0301448

DATA IBLNK/" /, IBELL/"0340CC000000/

0001449

TYPE 1 , I BELL

CALL KEYBRD $(E 10, I, 1)$

0001450

IF (I.EQ. IBLNK) RETUR

0001451

0001452

10 RE TURN 1

1 FORMAT $(1 X, A 1)$

0001453

END 


\section{FUNCTION NAME: PNTER}

Purpose: PNTER is used to look up user-entered characterstring or multiple-choice-type values in the value part of "conditions" statements. Lookup is performed in the appropriate dictionary, and the value returned is a pointer to the particular dictionary item. If the value is not found, an error flag is set and zero is returned.

Calling sequence: IPT = PNTER (VALUE, IDIM, NAME, ITYPE,ERR)

Arguments :

VALUE-Unpacked character-string value to be looked up. IDIM-Length of the string in VALUE.

NAME-Item number for which the character string represents a value.

ITYPE-Item type of item pointed to by NAME.

ERR-Error flag which is set if the value is not found in the dicitionary pointed to by NAME.

Subroutines called: ACCESS, BINTYP, PACK

Common data referenced: None

Called by: RELEXP
Error checking and reporting: If the character-string value is not found, a message is typed, the error flag is set, and zero is returned as the value of PNTER.

Program logic: If the length of the string is given as zero, a value of blank is returned immediately. Otherwise, the string is packed into STRING. The value of ITYPE then determines whether the character-type dictionaries should be accessed (via ACCESS) or the multiple-choice-type dictionaries should be accessed (via BINTYP). If a charactertype dictionary is indicated, a call to ACCESS is made, where the fifth parameter has a value of 3 . This returns $K$ as the pointer to the first dictionary item. ACCESS is then called, using the value 4 as the fifth parameter (which returns the $K$ 'th entry and updates $K$ to point to the next entry), until all entries have been returned or until a match is found. If a match is found, the entry number is returned as a value. Otherwise, zero is returned as a value, and the nonstandard return is taken. If a multiple-choice-type dictionary is indicated, a call to BINTYP returns the possible values in LABEL. The string (equivalenced to BLABEL) is then compared with the items of LABEL.

INTEGER FUNCT IONPNTER (VALUE, I DIM, NAME, ITYPE, ERR)

0001456

DOUBLE PRECISION LABEL (25), BLABEL

INTEGER VAL UE( 1$),$ TANK( 25), BITEM(15,25), STRING(12)

0001457

LOGICAL ERR

EQUIVALENCE (STRING (1), BLABEL)

0001458

DATA IBLNK/, '/

0001459

$E R R=$. FALSE.

$N=I B L N K$

IF (IDIM.EQ.0) GO TO 110

$00 C 1460$

0001461

0001462

DO $10 \quad I=1,12$

10 STRING (I ) = I BLNK

CALl PACK IVALUE, STRING, IDIM, 601

0001463

0001464

0001465

0001466

0001467

DO $20 \quad I=1,12$

IF (STRING(13-I).NE.IBLNK) GO TO 30

20 CONT INUE

GO TO 110

0001468

0001469

0001470

0001471

30 LENGTH=13-I

IF (ITYPE-3) $35,35,80$

35 CALL ACCESSINAME, K, TANK, NUM, 3 )

0001472 $N=0$

40

IF(K.EQ.0) GO TO 60

$\mathrm{N}=\mathrm{N}+1$

CALL ACCESS (NAME, K, TANK, NWORDS, 4)

IF (NWORDS.LT.LENGTH) GO TO 40

DO $50 \mathrm{I}=1$, LENG TH

IF (TANK (I) .NE.STRING(I)) GO TO 40

0001473

0001474

0001475

0001476

0001477

0001478

0001479

0001480

0001481

50 CONTINUE

GO TO 110

0001482

0001483

0001484

60 ERR =.TRUE.

TYPE 130, (VALUE(I), I=1, IDIM)

0001485

GO TO 100

80 CALL BINTYP (NAME, LABEL, BITEM, L, M)

0001486

DO $90 \mathrm{~N}=1, \mathrm{M}$

0001487

0001488

IF (BLABEL,EQ.LABEL(N)) GO TO 110

0001489 
90 CONTINUE

TYPE 140, BLABEL

0001490

$E R R=$. TRUE.

0001491

$100 \mathrm{~N}=0$

110 PNTER $=N$

0001492

RETURN

0001493

0001494

130 FORMAT

140 FORMAT (" BINARY TYPE VARIABLE DOES NOT ASSUME VALUE ',A8)

0001495

END

0001496

0001497

0001498 
SUBROUTINE NAME: PREVAL

Purpose: PREVAL acts as an interface between the calling routine (VLIST) and the arithmetic-expression parsing routine PARSE. This interface allows a reduction in the number of dimensions for the variables in /EXPRNS/ which contain the Reverse-Polish form of the arithmetic expressions entered by the usen.

Calling sequence: CALL PREVAL(\&n,IEXPR,L,KNT)

Arguments:

$\mathrm{n}$-Statement (in calling routine) to which a branch is made if the routine PARSE sets an error flag.

IEXPR-Contains (in unpacked character form) the expression to be parsed.

$\mathrm{L}$-The length of IEXPR.
KNT-Arithmetic expression counter.

Subroutine called: PARSE

Common data referenced: POLISH, ITYPE, LPS in /EXPRNS/

Called by: VLIST

Error checking and reporting: Error flag returned from PARSE is tested.

Program logic:

1. The expression counter KNT is incremented.

2. Call PARSE, passing the input arguments IEXPR, L, and the KNT'th columns of ITYPE, POLISH along with the KNT'th element of LPS, and an error flag.

3. Take the nonstandard return if the error flag ERR has been set. 


\section{SUBROUTINE NAME: QUIT}

Purpose: QUIT performs "wrap-up" processing prior to exiting from the GRASP system. This involves a typed statement regarding the disposition of files created during the current session.

Calling sequence: CALL QUIT(OFILES,NFILES)

Arguments :

OFILES-List of output files created during this session.

NFILES-The number of items in OFILES.

Subroutines called: KEYBRD, RLIST

Common data referenced: None

Called by: DRIVER
Error checking and reporting: The user's response to prompts is checked for validity.

Program logic:

1. The list of created file names is typed, and the user is asked if he would like to save any of them.

2. If so, he is asked to enter a list of numbers corresponding to those files he wishes to save.

3. The system then instructs him how to delete the files he does not wish to save. This routine is provided primarily for bookkeeping. The file-maintenance functions can be performed at the program level on those systems having this capability.

$$
\text { GRASP SOURAE PROGRAM }
$$

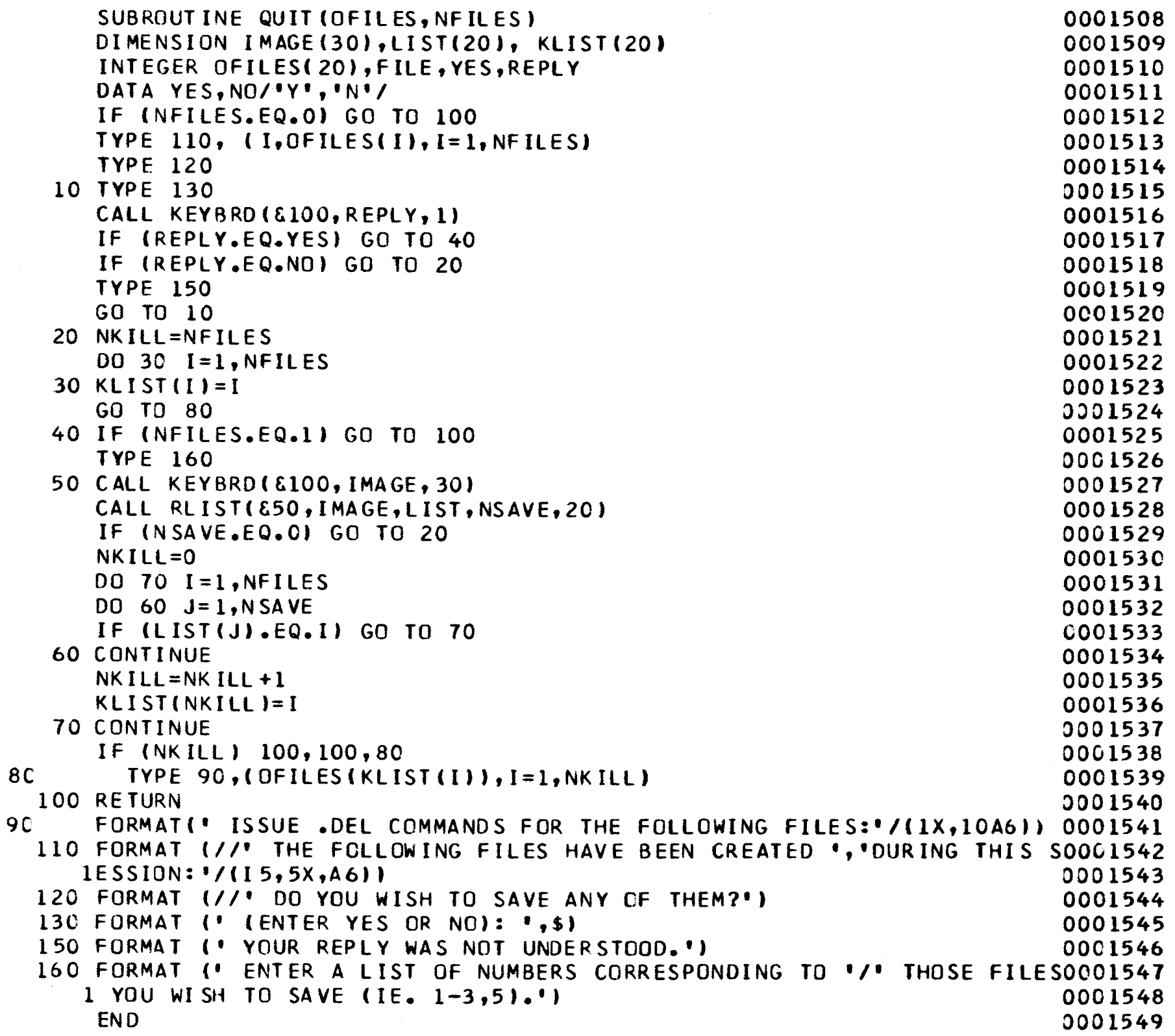




\section{SUBROUTINE NAME: RELEXP}

Purpose: This subroutine is used to decode the "condition" appearing in IMAGE into the components NAMEPT, RCODE, and IVAL. If it is unsuccessful, an error message is typed and an error flag is set. The "condition" is in unpacked character form and is assumed to be a name followed by a relation followed by a value. Name must be an item name in the current data base (as established by the file command). Relation must be one of the following: $\mathrm{EQ}$, equal; LT, less than; GT, greater than; LE, less than or equal; GE, greater than or equal; $\mathrm{NE}$, not equal; $\mathrm{BE}$, between. Value must be a number, number pair, character string, set of qualifiers, permissible multiple-choice acronym, or blank. The following table gives valid constructions for "conditions":

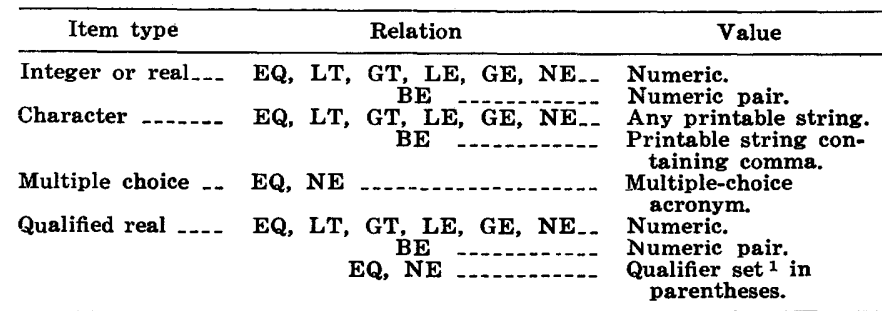

1 Qualifier set is one or more of the following characters, each of which occur, at most, once; G, H, L, N, T, or blank.

Calling sequence: CALL RELEXP(\&n,IMAGE,NAMEPT, RCODE,IVAL,ERR)

Arguments:

$\mathrm{n}$-Statement number (in calling routine) to which a branch will be made if an all-blank condition is detected.

IMAGE-Contains "condition" in unpacked-character form.

NAMEPT-Returned pointer to item name.

RCODE-Returned encoding of relation having the following possible values:

1-7 corresponding to the relations

EQ, LT, GT, LE, GE, NE, BE.

11 or 16 corresponding to the relations $\mathrm{EQ}$ or $\mathrm{NE}$, applied to a set of qualifiers.

IVAL-Returned as one of the following:

1. Integer or real value.

2. Pointer to a particular entry in the character dictionary associated with the item pointed to by NAMEPT.

3. Bit encoding, giving the position of a particular multiplechoice acronym in the file containing possible acronym values for the item pointed to by NAMEPT.

4. Pointer to the number pair in the common block BTWN which will be used by this instance of the BE relation.

5. Bit encoding of a qualifier set.

ERR-Returned error flag that is set if an error is detected. Subroutines called: SCAN, BFIND, ICONV, PNTER, PACK Common data referenced:
NAMES, ITYPE, PNTERS, IDIM in blank common IVALS, NBE in / BTWN/

Called by: CONDTN

Error checking and reporting:

1. All testing is performed to insure conformity to the table of valid constructs appearing in the preceding "purpose" section.

2. An error flag that may be set by the routines ICONV or PNTER is tested.

3. A nonstandard return from BFIND indicates an invalid name.

An error message is printed reporting any of the following errors:

a. Unable to find relation (that is, EQ, LT, GT, LE, GE, $\mathrm{NE}, \mathrm{BE})$.

b. Incorrect qualifier set.

c. Qualifier codes are referenced in forms other than EQ or NE.

d. Invalid name as first syntactic unit of condition.

e. No comma separating a value pair used with the BE relation.

Program logic:

1. A call to SCAN is made to bracket the name as the first syntactic element. If the image is all blank, the nonstandard return is taken.

2. The name is packed into NAME via ENCODE, and BFIND is used to do the lookup. If the name is not found, a message is typed, and the error flag is set.

3. The next call to SCAN brackets the relation. It is packed into REL and tested against the list of valid relations. Note that RCODE is used as the index. If invalid, a message is typed, and the error flag is set.

4. The value part of the condition is then bracketed via the next call to SCAN. If the value field is blank, IVAL is set to blank.

5. Otherwise, the type of name is determined using ITYPE in blank common.

6. The logical variable BE (indicating the "between" relation) is determined. If set, the second value is determined and stored in the BTWN common area, and IVAL is set to point to the BTWN location. The second value determination is logically similar to the first which is described in step 8.

7. If BE was not set, the value element is tested as a qualifier set. If it is one, the appropriate tests are made, and IVAL is bit encoded to show which codes are present. RCODE is, also, incremented by 10 as a flag indicating comparison of qualifier cores.

8. If the value element was not a qualifier set, and the relation was not BE, IVAL is set via a call to ICONV, if type was numeric. Note that for real values, VAL (equivalenced to IVALL) is set. IVAL is then set by IVALL, which shares storage with VAL. For character and multiple-choice types, IVAL is set using the external function PNTER.

$$
\text { GRASP SOURCEAROGRAM }
$$

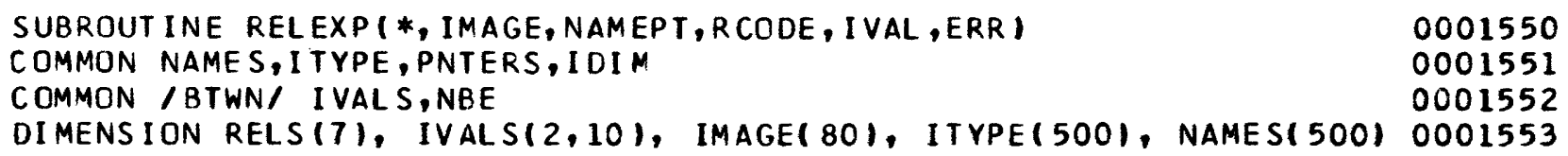


DOUBLE PRECI SION NAME, NAMES, DBLNK

0001554

INTEGER FCNAME, FCOP, FCCON, RCODE, PNTER, BLANK, PNTERS(500), E, REL, RELSO0O1555

1 , COMMA, RPAREN, I QUAL (6)

LOGICAL ERR, BE

EQU IV ALENCE (VAL, IVALL), (IQUAL, BLANK)

DATA COMMA, RPAREN, LPAREN, DBLNK, I QUAL $/, \cdots, \cdots, \cdots$,

1 ' ', 'G', 'H', 'L', 'N', T'/,

1 RELS/'EQ', 'LT', 'GT', 'LE', GE', 'NE', BE'।

$E R R=. F A L S E$.

$I=1$

CALL SCAN $1 \varepsilon 295$, IMAGE, I, FCNAME,LCNAME, 11

NAME $=$ DBLNK

CALL PACK (IMAGE (FCNAME), NAME, LCNAME-FCNAME+ 1,8)

CALL BFINDIE110,NAME, NAMEPT, NAMES, PNTERS, IOIM)

$I=$ LCNAME +1

CALL SCAN (E20, IMAGE, I,FCOP,J,1)

IFIJ.NE. FCOP+1) GO TO 20

REL $=B$ LANK

CALL PACK(IMAGE (FCOP), REL, 2,4)

DO 10 RCODE $=1,7$

IF(RELS(RCODE).EQ.REL) GO TO 30

10 CONTINUE

20 TYPE 320

GO TO 144

$30 \quad I=J+1$

CALL SCAN ( \& 40, I MAGE, I, FCCON, LCCON, 2$)$

GO TO 140

40 I $V A L=B L A N K$

GO TO 210

295 RETURN 1

$140 \mathrm{~J}=$ I TYPE (NAMEPT)

$B E=R C O D E . E Q .7$

$I F(B E)$ GO TO 220

IF (IMAGE(FCCON) . NE . LPAREN) GO TO 150

IF (J.NE.5) GO TO 150

IF(IMAGE (LCCON).EQ.RPAREN) GO TO 142

1405 TYPE 141

GO TO 144

142 IF (RCODE.EQ.1) GO TO 145

I $F(R C O D E \bullet E Q .6)$ GO TO 145

TYPE 143

$144 E R R=$. TRUE .

GO TO 210

$145 \mathrm{RCODE}=\mathrm{RCODE}+10$

I $V A L=0$

$F C C O N=F C C O N+1$

$L C C O N=L C C O N-1$

DO $147 \mathrm{~K}=$ FCCON, LCCON

$J=I M A G E(K)$

DO $146 \quad I=1,6$

146 CONT INUE

IF (IQUAL (I).EQ.J) GO TO 147

GO TO 1405

147 I VAL $=1 V A L+2 * *(I-1)$

GO TO 210

110 TYPE 310 , NAME

GO TO 144

150 GO TO $(160,170,190,19 \mathrm{C}, 170), \mathrm{J}$

160 I VAL $=I$ CONV $(I M A G E(F C C O N), L C C O N-F C C O N+1, E, E R R)$

go To 200

0001556

0001557

0001558

0001559

0001560

0001561

0001562

0001563

0001564

0001565

0001566

0001567

0001568

0001569

0001570

0001571

0001572

0001573

0001574

0001575

0001576

0001577

0001578

0001579

$000158 \mathrm{C}$

0001581

0001582

0001583

0001584

0001585

0001586

0001587

0001588

0001589

0001590

0001591

0001592

0001593

0001594

0001595

0001596

0001597

0001598

0001599

0001600

0001601

0001602

0001603

0001604

0001605

0001606

0001607

0001608

0001609

0001610

0001611

0001612

0001613 
$170 K=$ ICONV (IMAGE (FCCON), LCCON-FCCON+1,E,ERR)

0001614

IF (K.NE.BLANK) GO TO 180

I $V A L=K$

GO TO 200

180 VAL $=K * 10 . * * E$

IVAL $=$ IVALL

GO TO 200

$19 \mathrm{C}$ IVAL $=$ PNTER (IMAGE $(F C C O N), L C C O N-F C C O N+1$, NAMEPT, J,ERR )

0001615

0001616

0001617

0001618

0001619

0001620

200 IF (ERR) GO TO 210

IF (.NOT.BE) GO TO 210

$N B E=N B E+1$

$I \operatorname{VALS}(1, N B E)=I V A L$

0001621

0001622

0001623

0001624

$I V A L=N B E$

210 RETURN

220 DO $230 \quad I=F C C O N, L C C O N$

IF (IMAGE(I ).EQ.COMMA) GO TO 240

230 CONT INUE

TYPE 330

GO TO 144

240 GO TO $(250,260,280,280,260), J$

250 I VAL $=$ IC ONV(IMAGE $(I+1), L C C O N-I, E, E R R)$

GO TO 290

$260 K=I C O N V(I M A G E(I+1), L C C O N-I, E, E R R)$

IF (K.NE.BLANK) GO TO 270

IVAL $=K$

GO TO 290

270 VAL $=K * 10, * * E$

I $V A L=I V A L L$

GO TO 290

280 I $V A L=P N T E R(I M A G E(I+1), L C C O N-I, N A M E P T, J, E R R)$

0001625

0001626

0001627

0001628

0001629

0001630

0001631

0001632

0001633

0001634

0001635

0001636

0001637

0001638

0001639

0001640

0001641

0001642

0001643

290 IF (ERR) GO TO 210

$I$ VAL $S(2, N B E+1)=I V A L$

LCCON $=1-1$

GO TO 150

141 FORMATI' QUALIFIER CODES MUST BE ONE OR MORE OF "L, $N, T, G, H^{*}$,

1 - AND ENCLOSED IN PARENTHESIS. I

143 FORMAT (" ONLY EQINE CAN BE USED WITH QUALIFIER CODES. $"$

310 FORMAT 1 INVAL ID NAME = ,A8 I

320 FORMATI" UNABLE TO FIND RELATION (LT,GT,LE,GE,EQ,NE,BE)')

330 FORMAT (' NO COMMA SEPARATING CONSTANTS FOLLOWING BE OPERATOR $)$ END

0001644

0001645

0001646

0001647

0001648

0001649

0001650

0001651

0001652

0001653

0001654 


\section{SUBROUTINE NAME: RETRVE}

Purpose: RETRVE is used to retrieve records from a selected file and write them on some other selected file. User-specified encoded retrieval criteria are passed to RETRVE via its argument list.

Calling sequence: CALL RETRVE(\&n,\&m,IFILES,OFILES, NFILES,POLISH,LPS,VARS,CODES,VALS,NCOND)

Arguments :

$\mathrm{n}$-Statement number (in calling routine) to which a branch is made if previously undetected (by LOGEXP) errors are encountered.

$\mathrm{m}$-Statement number (in calling routine) to which a branch is made if KEYBRD senses an EOF.

IFILES, OFILES-Arrays of input and output file names, respectively.

NFILES-Number of elements in either IFILES or OFILES (IFILES and OFILES are of equal size).

POLISH-Array containing the Reverse-Polish form of the logic expression to be used for data retrieval.

LPS-The number of elements in POLISH.

VARS, CODES, VALS-Arrays that give an encoding of the conditional expressions entered by the user.

NCOND-Number of elements in VARS, CODES, and VALS.

Subroutines called: KEYBRD, OBEY, GETPUT, COMP, UNCODE, PACK

Common data referenced:

FNAMES, SELECT in / FILNAM/

ITYPE in blank common

INPUT, OUTPUT in /IOUNIT/

Called by: DRIVER

Error checking and reporting:

1. Check to assure entry of retrieval criteria (that is, LPS $>0$ )

2. Check to assure absence of undetected errors in the retrieval criteria.
Messages are typed corresponding to the two error situations above.

Program logic:

1. LPS is checked to insure that retrieval criteria have been entered.

2. The elements of VALS are moved to IVAL to allow the equivalencing necessary for mixed modes (in particular, integer and real) possible in retrieval criteria.

3. Input- and output-file names are prompted and accepted, then associated with FORTRAN unit numbers via calls to KEYBRD and OBEY. The new file names are added to IFILES and OFILES.

4. The input file is then read, one record at a time (via GETPUT), until the nonstandard (EOF) return is taken. After each call to GETPUT, the record (IREC) is tested against the retrieval criteria indicated in POLISH, VARS, CODES, and VALS via the logical valued push-down stack technique described as follows: Any element of POLISH less than 27 points to one of the conditional expressions encoded in VARS, CODES, VALS. That expression is evaluated via a reference to the logical function COMP, and the result is placed in the push-down stack. If POLISH (I) $>26$, it points to one of the logical operators "and," "or," "not" (denoted by *,,+- ). If the operator is -, the "not" operation is performed on the topmost stack element. If the operator is * or + , the operation is performed on the topmost two stack elements, the size of the stack is decremented, and the resultant (logical) value replaces the new topmost stack element. After the last element of POLISH has been processed, the size of the stack should be 1 , and the value of this element indicates whether or not the record meets the retrieval criteria. If so, it is added to the output file by a call to GETPUT. Counts of records read and records retrieved are kept and typed at the end of retrieval processing.

\title{
GRASP SOURAE PROGRAM
}

\author{
SUBROUT INE RETRVEI *, *, IFILES, OF ILES, NFILES, POL I SH, LPS, VARS, CODES, 0001655 \\ IVALS, NCONDI \\ COMMON NAMES, ITYPE, IPTS, IDIM \\ 0001656 \\ COMMON /IOUNIT/ INPUT, OUTPUT \\ COMMON /FILNAM/ FNAMES, SELECT, PAD \\ 0001657 \\ 0001658 \\ DIMENSION VAL (26) \\ DOUBLE PRECISION NAMES $(500)$ \\ INTEGER I VAL (26), CODES ( 1$)$, VARS $(1)$, WHICH, DREC (500), OUTPUT, TOP, POL \\ 1ISH( 1 ), ITYPE (500), ONE, TWO, VAL S (1), EQUA TE ( 4), IPT S(500), SELECT \\ INTEGER FILEID, DBLANK, IFILES (1), OFILES (1), DFAUL T, FNAMES ( 21 ) \\ LOGICAL COMP, VALUE, STACK( 20), EVAL, PAD(4) \\ EQUIVALENCE (IREC, REC), (IVAL, VAL), (STACK, EVAL), (EQUATE (4), FILEID)

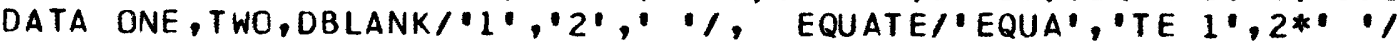 \\ IF (LPS.GT.0) GO TO 10 \\ TYPE 180 \\ GO TO 170 \\ 10 DO $20 \quad I=1, N C O N D$ \\ 0001659 \\ 0001660 \\ 0001661 \\ 0001662 \\ 0001663 \\ 0001664 \\ 0001665 \\ 0001666 \\ 0001667 \\ 0001668 \\ 0001669 \\ 0001670 \\ 0001671 \\ $20 I \operatorname{VAL}($ I $)=\operatorname{VAL} S(I)$ \\ 0001672 \\ DFAUL $T=F N A M E S(S E L E C T)$ \\ 0001673 \\ NRECS $=0$ \\ 0001674 \\ NFOUND $=0$ \\ 0001675
}


NFILES $=$ NF IL ES+1

0001676

EQUAT E $31=0 N E$

0001677

TYPE 190

CALL KEYBRD( 1775, OREC, 5$)$

CALL PACK IOREC, FILEID,5,5)

IF (FILEID.EQ.DBLANK) FILEID=DFAULT

I FILES (NFILES ) = FILEID

0001678

0001679

0001680

CALL OREY $(\varepsilon 170$, EQUATE,4)

EQUATE $(3)=$ TWO

TYPE 210

CALL KEYBRD ( 1175, DREC, 5$)$

CALL PACK (DREC, FILEID, 5,5)

OFILES $(N F I L E S)=F I L E I D$

CALL OBEY(\&170, EQUATE,4)

30 CALL GETPUT $(\varepsilon 140$, DREC, 1$)$

NREC $S=N R E C S+1$

$T O P=0$

DO $110 \mathrm{~J}=1$, LPS

I NDEX $=P O L$ I SH(J)

IF (INDEX.GT.26) GO TO 70

$T O P=T O P+1$

WHI $C H=V A R S($ I NDE $X)$

$I=I T Y P E(W H I C H)$

I REC $=$ OREC (WHICH)

GO TO $(40,50,40,60,62)$, I

40 STACK $(T O P)=\operatorname{COMP}($ IREC

- I VAL (INDEX),01,02, CODES(INDEX), 1 )

GO TO 110

50 STACK $(T O P)=\operatorname{COMP}(I D 1, I D 2, R E C$

, VAL (INDEX), CODES (INDEX), 2 )

GO TO 110

6C STACK $(T O P)=$ COMP $(I R E C$

GO TJ 110

0001681

0001682

0001683

0001684

0001685

0001686

0001687

0001688

0001689

0001690

0001691

0001692

0001693

0001694

0001695

0001696

0001697

0001698

0001699

0001700

0001701

0001702

0001703

0001704

0001705

0001706

62 IF (IREC.NE. DBLANK) GO TO 63

- IV AL ( INDEX), D1, D2, CODES (INDEX), 3)

IF (CODES (INDEX).LT.11) GO TO 50

$S T A C K(T O P)=$.FAL SE.

GO TO 110

$63 R E C=U N C$ ODE (REC, IQ)

IF (CODES (INDEX)-11) $50,64,66$

$64 \operatorname{STACK}(\operatorname{TOP})=\operatorname{MOD}($ IVAL (INDEX) $/ 2 * *(I Q-1), 2), E Q .1$ GO TO 110

$66 \operatorname{STACK}(T O P)=\operatorname{MOD}(\operatorname{IVAL}($ INDEX) $/ 2 * *(I Q-1), 2) \cdot E Q \cdot 0$ GO TO 110

70 VALUE $=$ STACK $($ TOP $)$

IF (INDEX-30) $80,90,100$

80 TOP $=$ TOP -1

$S T A C K(T O P)=S T A C K(T O P), O R \cdot V A L U E$

GO TO 110

90 TOP $=$ TOP-1

STACK $(T O P)=S T A C K(T O P)$. AND. VAL UE

GO TO 110

0001707

0001708

0001709

$000171 \mathrm{C}$

0001711

0001712

0001713

0001714

0001715

0001716

0001717

0001718

0001719

0001720

0001721

0001722

0001723

0001724

0001725

100 STACK $(T O P)=$.NOT. $S T A C K(T O P)$

110 CONT INUE

IF (TOP.EQ.1) GO TO 120

TYPE 220

REWIND INPUT

RE TURN 1

120 IF (EVAL) GO TO 130

GO TO 30

130 CALL GETPUT ( \&140,DREC, 2)

NFOUN $D=N F$ OU ND +1

GO TO 30

0001726

0001727

0001728

0001729

0001730

0001731

0001732

0001733

0001734

0001735 


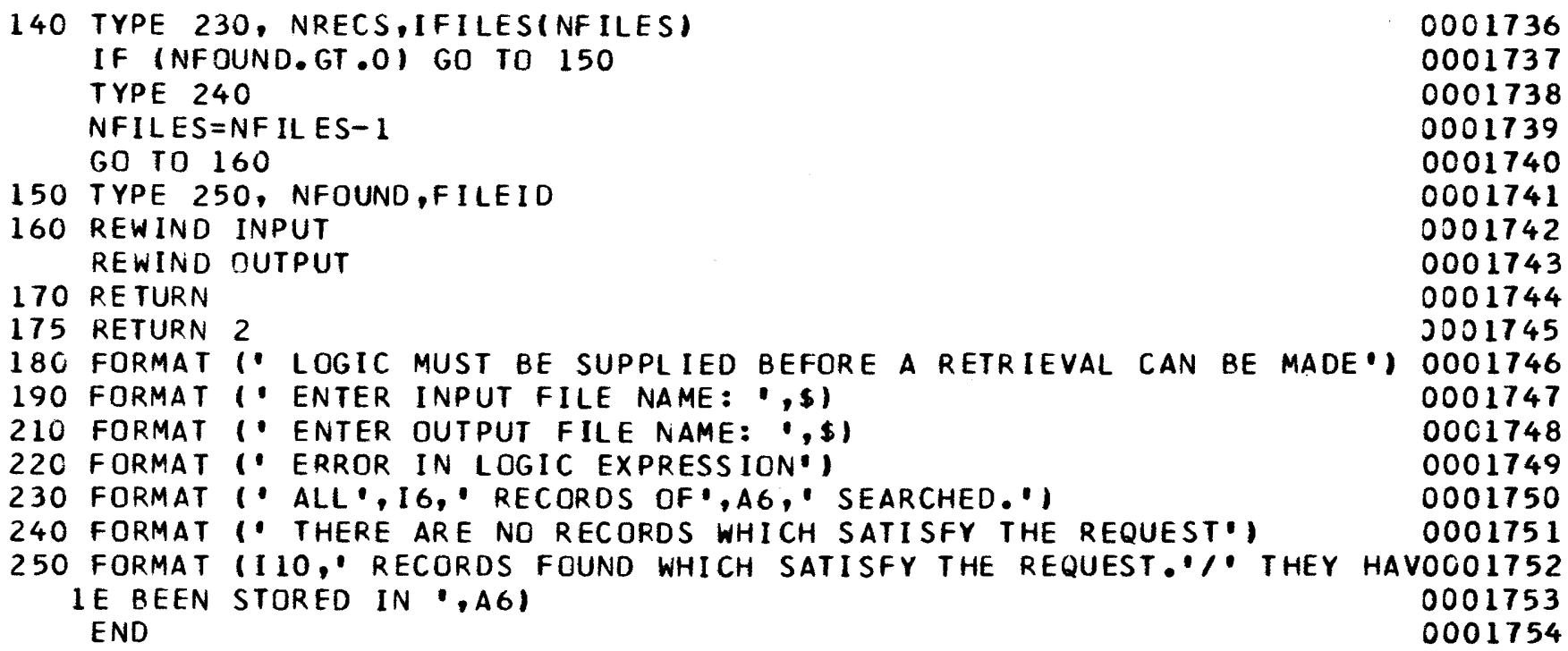




\section{SUBROUTINE NAME: RLIST}

Purpose: RLIST is used to convert an unpacked character string representing a list of user-entered numbers into a corresponding numeric list.

Calling sequence: CALL RLIST(\&n,IMAGE,LIST,NUMC, MOST)

Arguments :

$\mathrm{n}$-Statement number (in caller) to which a branch will be made if an uncorrectable error in the entered character string is detected.

IMAGE-The unpacked character-string form of the list of numbers.

LIST-The list of numbers which are returned in numeric form.

NUMC-The number of items in LIST.

MOST-The maximum number of items that LIST may contain.

Subroutines called: None

Common data referenced: None

Called by: DEFLST, QUIT

Error checking and reporting: If an illegal character (not $0-9$, dash, or comma) is detected, an error message is typed and the nonstandard return is taken. If the list isn't composed of numbers or number ranges separated by commas, an error message is typed, and the nonstandard return is taken.

Program logic: Each character of the unpacked string is processed via the following transition matrix:

\begin{tabular}{|c|c|c|}
\hline $0-9$ & & - \\
\hline $\begin{array}{ll}\text { 1. } & f(1) / 2 \\
\text { 2. } & \mathrm{f}(2) / 2 \\
\text { 3. } & \mathrm{f}(1) / 4 \\
\text { 4. } & \mathrm{f}(2) / 4\end{array}$ & $\begin{array}{l}\text { error } \\
f(3) / 1 \\
\text { error } \\
f(4) / 1\end{array}$ & $\begin{array}{l}\text { error } \\
f(3) / 3 \\
\text { error } \\
\text { error }\end{array}$ \\
\hline
\end{tabular}

$f(i)$ are defined as:

$\mathrm{f}(1)$-Start a number value.

$f(2)$-Build number value by adding digit on right.

$f(3)$ - Number built, add it to list.

$f(4)$-Fill LIST with values up to and including current value.

Rows 1 and 2 are used to process a single list element or the first of a number-range pair.

Rows 3 and 4 are used to process the second of a number-range pair. Blanks are completely ignored.

The columns of the transition matrix are associated with the indicated characters, and the rows correspond to individual states.

\section{SUBROUT INE RL. IST(*, IMAGE, LIST, NUMC, MCST)}

INTEGER LIST (1), IMAGE (30), CHAR (12), COL $(12), \operatorname{IMAT}(4,3)$

DATA IMAT/12,22,14,24,0,31, C,41,0,33,0,0/, IBLNK/' $/$

DATA CHAR/, $0^{\prime}, 11^{\prime}, 2^{\prime}, 3^{\prime}, 4^{\prime}, 5^{\prime}, 6^{\prime}, 7^{\prime}, 8^{\prime}, 9^{\prime}, 0^{\prime}, 0^{\prime}, 1$

DATA COL/10*1,2,3/

NUMC $=\mathrm{C}$

LAST $=1$

I $P=0$

I ROW $=1$

10 I $P=I P+1$

IF (IP.GT.30) GO TO 120

ICHAR = IMAGE (IP)

IF (ICHAR.EQ.IBLNK) GO TO 10

DO $20 \quad I=1,12$

IF (ICHAR.EQ.CHAR ( I ) ) GO TO 40

20 CONTINUE

TYPE 150, ICHAR

30 RETURN 1

35 TYPE 145 , IVAL

GD TO 30

40 IFS = IMAT (IROW, COL (I) )

IF (IFS.NE. O) GO TO 60

50 TYPE 160

GO TO 30

60 I ROW $=$ MOD $($ IFS, 10$)$

I $F S=I F S / 10$

GO TO $(70,80,90,100)$, IFS

70 I VAL $=I-1$

GO TO 10

80 I $V A L=10 * I V A L+I-1$

GO TO 10
0001755

0001756

0001757

0001758

0001759

0001760

0001761

0001762

0001763

0001764

0001765

0001766

0001767

0001768

0001769

0001770

0001771

0001772

0001773

0001774

0001775

0001776

0001777

0001778

0001779

0001780

0001781

0001782

0001783

0001784

0001785 
$90 \quad N U M C=N U M C+1$

IF (NUMC.GT.MOST) GO TO 110

IF(IVAL.GT.MOST) GO TO 35

LIST (NUMC) = IVAL

GO TO $(10,140)$, LAST

100 LIST $($ NUMC +1$)=L$ IST $($ NUMC $)+1$

NUMC $=$ NUMC +1

IF (NUMC.GT.MOST) GO TO 110

0001786

0001787

0001788

$00 C 1789$

0001790

0001791

0001792

IF (IVAL.GT.MOST) GO TO 35

IF (LIST(NUMC).LT. IVAL) GO TO 100

0001793

0001794

GO TO $(10,140)$, LAST

110 TYPE 170 , MOST

NUMC $=$ MOST

GO TO 140

120 IF (NUMC.NE.0) GO TO 130

IF (IROW.EQ.1) GO TO 140

0001795

0001796

0001797

0001798

0001799

0001800

NUMC $=1$

LIST $(1)=$ IVAL

GO TO 140

130 IF (MOD(IROW, 2).NE.0) GO TO 50

0001801

0001802

0001803

0001804

0001805

LAST $=2$

$I R O W=I R O W / 2$

0001806

GO TO $(90,100)$, IROW

0001807

0001808

140 RE TURN

145 FORMAT(I5,' DOES NOT CORRESPONO TO A CATEGORY. RE-ENTER NUMBERS') OO01810

150 FORMAT (1X,Al," IS AN ILLEGAL CHARACTER. RE-ENTER NUMBERS.") 0001811

160 FORMAT (' EACH NUMBER OR NUMBER RANGE (IE. 4-7) EXCEPT ', 'THE LASTO001812

1 MUST BE FOLLOWED BY A COMMA. $\%$ RE-ENTER NUMBERS.' 1

170 fORMAT (' TOO MANY NUMBERS GIVEN. ONLY THE FIRST',I3," WILL BE USE0001814 $10 \cdot 1)$

END 


\section{SUBROUTINE NAME: ROWPNT}

Purpose: ROWPNT prints selected items or expressions, one to a line, from a selected file.

Calling sequence: CALL ROWPNT (\&n,NPAGE)

Arguments :

n-Statement (in caller) to which VLIST will branch when an EOF is encountered by KEYBRD.

NPAGE-Number of lines per page of printed output.

Subroutines called: VLIST, ACCESS, GETPUT, PAUSE, EVAL, UNCODE, BINTYP, BLIST

Common data referenced:

POLISH, ICODE, LPS in /EXPRNS/

ITYPE in blank common
Called by: LIST

Error checking and reporting: None

Program logic:

1. The list of items to be printed is obtained via a call to VLIST.

2. A call to ACCESS is made to initialize the lookup of dictionary-type items.

3. Each record of the selected file is obtained via GETPUT and a line counter is incremented and tested. If it exceeds the page size, a pause is generated via PAUSE.

4. After each record is obtained, the selected items are evaluated (if necessary) and printed.

\section{$G R A S P S O U R C E$ P $P$ P O GRAM}

SUBROUT INE ROWPNT (*,NPAGE)

0001817

COMMON NAMES, ITYPE, IPT S, IPAD

0001818

COMMON IE XPRNS/ POLISH, ICODE, LPS

0001819

DOUBLE PRECISION NAMES, LABEL, NAMES I, VNAMES( 20$)$

I NTEGER BLANK, TANK, I PTS $(500)$, I QUAL $(6)$, POL ISH $(15,8)$,

0001820

1 ICODE $(15,8), L P S(8)$

DIMENSION I TYPE (500), BITEM( 15,25), ITEMS (20), IREC (500),

0001821

0001822

1 REC (500), NAMES(500), TANK(25), LABEL (25), LIST (25)

0001823

LOGICAL ERR

EQUIVALENCE (REC, IREC), (IVAL, VAL), (L IST, TANK), (BLANK, IQUAL)

0001824

0001825

DATA IQUAL/' ', 'G', 'H', 'L', 'N', T'/

KOUNT $=0$

CALL VLIST ( 8270, VNAMES, ITEMS, NUM)

IF (NUM.EQ.O) GO TO 260

TYPE 280

CALL ACCESSIII, IVAL, TANK, J, I)

120 CALL GETPUT $(\& 260$, IREC, 1$)$

KOUNT $=$ KOUNT +NUM +1

IF (KOUNT.LE.NPAGE) GO TO 130

KOUNT $=0$

CALL PAUSE ( 8260$)$

0001826

0001827

0001828

0001829

0001830

0001831

0001832

0001833

0001834

0001835

0001836

0001837

130 DO $240 \mathrm{JJ}=1$, NUM

I I = I T EMS ( JJ)

IF(I I.GT.O) GO TO 135

0001838

0001839

II $I=-I I$

NAMES I = VNAMES $(\mathbf{J} \mathbf{J})$

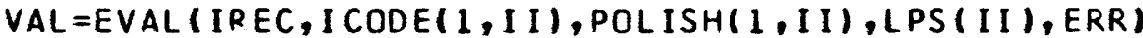

IF (ERR) GO TO 240

GO TO 150

135 I VAL = I REC ( I I )

IF (IVAL.EQ.BLANK) GO TO 240

0001840

0001841

0001842

0001843

0001844

0001845

0001846

0001847

$K$ I ND = I TYPE ( I I )

NAMES I = VNAMES $(\mathrm{J} J)$

GO TO $(140,150,160,220,170)$, KIND

0001848

0001849

0001850

140 TYPE 300 , NAMESI, I VAL

0001851

GO TO 240

150 TYPE 310 , NAMES I, VAL

0001852

GO TO 240

0001853

0001854

160 CALL ACCESS (II, I VAL, TANK, J, 2)

0001855

TYPE 320, NAMES I, (TANK $(I), I=1, J)$

0001856

GO TO 240

0001857 
$170 \quad V A L=1 J N C O D E(V A L, I Q)$

TYPE 310 , NAMES I, VAL, I QUAL (IQ)

GO TO 240

220 CALL BINTYP (I I L LABEL, B ITEM, K, M)

KOUNT $=$ KOUNT + 1

TYPE 340, NAMESI

CALL BL IST(LIST, NUMS, IVAL)

DO $230 \quad I=1$, NUMS

KOUNT $=$ KOUNT +1

$\mathrm{J}=\mathrm{L}$ IS T ( I )

230 TYPE 330, LABEL $(J),(B \operatorname{ITEM}(L, J), L=1, K)$

240 CONTINUE.

TYPE 290

GO TO 120

$26 C$ RETURN

270 RETURN 1

280 FORMAT $(/ / /)$

290 FORMAT $(1 \mathrm{X}, 3(8 \mathrm{H} * * * * * * * *))$

$30 C$ FORMAT $(1 X, A B, 1 H=, 19)$

310 FORMAT $(1 X, A 8,1 H=, 1 P G 12,5, A 1)$

320 FORMAT $(1 X, A 8,1 H=, 12 A 5 / 15 X, 12 A 5)$

330 FORMAT $(5 X, A 8,15 A 4)$

340 FORMAT $(1 X, A 8,1 H=)$

END

0001858

0001859

0001860

0001861

0001862

0001863

0001864

0001865

0001866

0001867

0001868

0001869

0001870

0001871

0001872

0001873

0001874

0001375

0001876

0001877

0001878

0001879

0001880

0001881 


\section{SUBROUTINE NAME: SCAN}

Purpose: This subroutine is used to set character-position pointers for the syntactic elements of a condition (name, relation, value (s)) or a logical expression.

Calling sequence: CALL SCAN (\&n,IMAGE,IS,I1,I2,IT)

Arguments :

$\mathrm{n}$-Statement number (in calling routine) to which a branch will be made if IMAGE is all blanks.

IMAGE-String of unpacked left-justified characters.

IS-Starting position of the scan.

I1-Pointer to first character of syntactic element.

I2-Pointer to last character of syntactic element.

IT-Embedded blank switch.
Subroutines called: None

Common data referenced: None

Called by: RELEXP, LOGEXP

Error checking and reporting: None

Program logic:

1. The position of the first nonblank character is determined.

2. If all characters after the IS'th are blank, the nonstandard return is taken.

3. If no embedded blanks are permitted $(I T=1)$, the position of the last nonblank character to the right of the position found in step 1 is determined, and control passes to the caller.

4. Otherwise (if, $I T=2$ ), the position of the first nonblank character to the left of position 80 is determined and control returns to the caller.

\section{GRASP SOURCE PROGRAM}

SUBROUT INE SCAN(*, IMAGE, IS, I 1, I 2, I T)

INTEGER IMAGE (1)

0001882

DATA IBLNK/ ' /

0001883

DO $1 \mathrm{I}=I S, 80$

0001884

IF (IMAGE (I).NE. IBLNK) GO TO 2

0001885

CONTINUE

RETURN 1

0001886

0001887

0001888

2 I $1=I$

$J=I 1+1$

GO TO $(3,10)$, I T

0001889

0001890

3 DO 4 I $2=J, 80$

IF(IMAGE( I 2$) \cdot E Q$. IBLNK) GO TO 5

0001891

0001892

4 CONTINUE

0001893

I $2=81$

0001894

0001895

5 I $2=12-1$

6 RETURN

0001896

10 DO $11 \mathrm{I}=\mathrm{J}, 80$

0001897

I $2=80-I+J$

0001898

IF (IMAGE (I2).NE. IBLNK) GO TO 6

0001899

0001900

11 CONT INUE

0001901

GO TO 6

0001902

END 
SUBROUTINE NAME: START

Purpose: START determines availability of data bases and their associated files.

Calling sequence: CALL START

Arguments: None

Subroutine called: IFILE

Common data referenced:

All variables in /FILNAM/ except NUMF
Called by: DRIVER

Error checking and reporting: None

Program logic:

1. The name GFILE is associated with FORTRAN input unit 20.

2. A welcoming message is typed and records of GFILE are read to fill the /FILNAM/ common area.

3. As each record is read, parts of it are output to the terminal.

\section{G R A S P SOURAE PROARA M}

SUBROUT INE START

COMMON /FILNAM/ MASTER, MASK, DEFTN, DFILE, BFILE, NUMF, NUM I, IDIMS DOUBLE PRECISION CONTNT (4)

INTEGER MASTER (4),MASK (4), DEFTN( 4), DFILE (4), BFILE(4), IDIMS( 4 )

CALL IFILE( $20,0^{\circ}$ GFILE' $)$

NUMF $=1$

TYPE 1

10 READ $(20,11$,END $=20)$ MASTER(NUMF), CONTNT, MASK (NUMF),

1 DEFTN(NUMF), DF ILE (NUMF), BFI LE(NUMF), I DIMS(NUMF)

TYPE 12 , MASTERINUMFI, CONTNT

NUMF $=$ NUMF +1

GO TO 10

20 NUMF $=$ NUMF -1

REWIND 20

TYPE 2

RETURN

1 FORMATI/ WELCOME TO THE USGS GRASP RETRIEVAL SYSTEM. $" /$

1 - AT THE CURRENT TIME THE FOLLOWING DATA BASES ARE AVAILABLE: ')

2 FORMAT $/ \%$ BEFORE ANY OF THESE DATA BASES MAY BE ACCESSED, 1

1 - THE "FILE" COMMAND SHOULD BE USED TO IDENTIFY THE DATA',

2 ' BASE OF INTEREST $\cdot 1$

11 FORMAT $(A 5,1 X, 4 A 10,4(1 X, A 5), 14)$

12 FORMAT $\left(/ 1 X_{1}, A 6,1-?, 4 A 10\right)$

END

0001904

0001905

0001906

0001907

0001908

0001909

0001910

0001911

3001912

0001913

0001914

0001915

0001916

0001917

0001918

0001919

0001920

0001921

0001922

0001923

0001924

0001925

0001926

0001927 


\section{FUNGTION NAME: UNCODE}

Purpose: UNCODE breaks down each qualified real value into a real value and a qualifier code.

Calling sequence: VALUE $=\mathrm{UNCODE}(\mathrm{VAL}, \mathrm{ID})$

Arguments:

VAL_Packed value and qualifier.

ID-Encoding of qualifier value.

Subroutines called: None
Common data referenced: None

Called by: COLPNT, DUMPIT, FIT, MEAN, RETRVE, ROWPNT, EVAL

Error checking and reporting: None

Program logic: The type REAL argument VAL may be visualized as composed of both whole and fractional parts. ID is set to the 3 low-order bits of the whole part. The whole part is then shifted right 3 bits, and the result is added to the fractional part to form the value returned by the function.

\section{G R A P SOURA E PROGRAM}

FUNCT ION UNCODE (VAL, ID)

RSIGN = SIGN(1.0, VAL)

0001929

$V A L=A B S(V A L)$

0001930

I PART $=V A L$

REST $=$ VAL $-I P A R T$

0001931

I $D=$ MOD (IP ART, 8$)$

0001932

UNCODE $=R S I G N *((I P A R T / 8)+R E S T)$

0001933

RE TURN

0001934

END 


\section{SUBROUTINE NAME: VLIST}

Purpose: VLIST prompts for and accepts (via KEYBRD) a set of item names or arithmetic expressions that will be printed by the caller. The user is provided the ability to reuse the list that was last entered.

Calling sequence: CALL VLIST (\&m,VNAMES,LIST,N)

Arguments:

$m-$ Statement number (in caller) to which a branch will be made if an EOF is sensed by KEYBRD.

VNAMES-List of item names to be printed.

LIST-Item numbers corresponding to VNAMES.

$\mathrm{N}-\mathrm{Number}$ of elements in VNAMES and LIST.

Subroutines called: KEYBRD, SCAN, BFIND, PREVAL, PACK

Common data referenced:

NAMES, PNTS, IDIM in blank common

Called by: BDEF, COLPNT, ROWPNT

Error checking and reporting: None

Program logic:

1. The user is asked if he wishes to enter a new list of item names. If not, the values of the arguments as set by a previous call are returned. Otherwise, a new list is processed as below.

2. The routine requests the user to enter a set of item names or expressions. Each entry is processed as specified below until a blank entry is detected. Control is then returned to the caller.

3. An entry is accepted via KEYBRD, and leading and/or trailing blanks are eliminated via SCAN.

4. If the entry length is greater than seven characters, an expression is assumed. If the entry is not found to be an item name (via BFIND), an expression is assumed.

5. If the entry is determined to be an item name, that name is stored in VNAMES, and the corresponding item number is stored in LIST.

6. If the entry is an expression, a call to PREVAL is made to parse it into Reverse-Polish form for later evaluation. KNT points to the Reverse-Polish form (stored in /EXPNS/ by PREVAL), and the negative of KNT is returned in LIST.

7. The values of the arguments are saved for future calls if required.

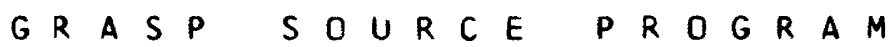

SUBROUTINE VLISTI*, VNAMES,LIST,NI

0001937

COMMON NAMES, TYPE, PNTS, IDIM

DOUBLE PREC ISION NAMES (500), NAME, BLANK, VNAMES ( 1$)$, VSAVE $(20)$

0001938

INTEGER PNTS(500), TYPE (500), LIST(1), EXPR (80), HALVES(2), EXPHDG (20) 0001940

1 , LSAVE (20)

EQUIVALENCE (HALVES( 1$)$, NAME)

DATA IEQUAL, BLANK $/=!, ! \quad \because, N S A V E, N O / 0, N^{\circ} /$

0001941

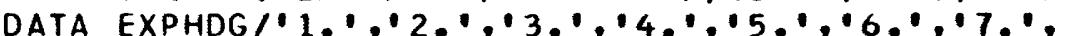

0001942

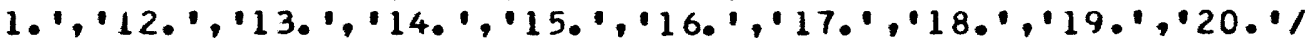

IF (NSAVE.EQ.0) GO TO 5

TYPE 4

CALL KEYBRD $(\varepsilon 110,1,1)$

IFII.NE.NO) GO TO 5

$N=N S A V E$

DO $6 \quad I=1$, NSAVE

LIST (I) =LSAVE(I)

6 VNAMES( I ) =VSAVE (I:

GO TO 130

$5 \mathrm{~N}=0$

$K N T=0$

TYPE 120

$10 \mathrm{~N}=\mathrm{N}+1$

TYPE 140, EXPHDG (N)

CALL KEYBRO $(\& 110$, EXPR, 801

CALL SCAN(\&115, EXPR,1,L1,L,2)

10001944

0001945

0001946

0001947

0001948

0001949

0001950

0001951

0001952

0001953

0001954

0001955

0001956

0001957

0001958

0001959

0001960

IF(L-LI.GT.6) GO TO 60

0001961

$L 2=L 1+6$

NAME $=$ BLANK

0001962

0001963

CALL PACK (EXPR $(L 1), N A M E, L 2-L 1+1,8)$

0001964

CALL BFIND( 660, NAME, I, NAMES, PNTS, I DIM)

0001965

0001966

30 VNAME $S(N)=N A M E$

LIST $(N)=I$

0001967

IF (N.EQ.20) RETURN

0001968

GO TO 10 
60 IF (KNT .EQ.8) RETURN

0001971

NAME $=B L A N K$

DO $70 K=1,10$

0001972

IF (EXPR $(K+L 1-1)$.EQ. IEQUAL) GO TO 80

0001973

70 CONTINUE

$K=1$

$\operatorname{HALVES}(2)=E \times P H D G(N)$

0001974

0001975

0001976

GO TO 90

$80 \mathrm{~J}=$ MINO $(K-1,7)+L 1-1$

CALL PACK(EXPR $(L 1)$, NAME,J $-L 1+1,8)$

$K=K+1$

90 CALL PREVAL $(\varepsilon 100$, EXPR $(K+L 1-1), L, K N T)$

$I=-K N T$

GO TO 30

$100 \mathrm{~N}=\mathrm{N}-1$

GO TO 10

110 RE TURN 1

$115 \mathrm{~N}=\mathrm{N}-1$

NSAVE $=\mathrm{N}$

DO $116 \quad I=1$, NSA VE

LSAVE (I) $=$ LIST I I)

116 VSAVE (I) = VNAMES (I)

130 RE TURN

4 FORMATI' DO YOU WISH TO ENTER A NEW LIST OF NAMES OR',

1 - EXPRESSI ONS? (YES OR NO):,$\$$ )

120 FORMAT 1 'ENTER THE NAMES OF ITEMS OR THE EXPRESSIONS ',

I'WHICH YOU WANT PRINTED.')

000197.7

0001978

0001979

0001980

0001981

0001982

0001983

0001984

0001985

0001986

0001987

0001988

0001989

0001990

0001991

0001992

0001993

0001994

0001995

0001996

140 FORMAT $(1 X, A 4, \$)$

0001997

END

0001998

0001999 
